A Self-Determination Theory Perspective on Mentoring Relationships at Work

Suzanne Janssen 


\section{A SELF-DETERMINATION THEORY PERSPECTIVE ON MENTORING RELATIONSHIPS AT WORK}


Thesis, University of Twente, 2015

(C) Suzanne Janssen

ISBN: 978-90-365-3980-7

Cover design by Suzanne Janssen en Pieter Cornelissen

Picture by Tom Frost, Climbers on Kangtega, 1986. Licensed under CC BY 3.0 via Wikimedia Commons

Printed by Gildeprint - Enschede, The Netherlands 


\title{
A SELF-DETERMINATION THEORY PERSPECTIVE ON MENTORING RELATIONSHIPS AT WORK
}

\author{
PROEFSCHRIFT \\ ter verkrijging van \\ de graad doctor aan de Universiteit Twente, \\ op gezag van de rector magnificus, \\ prof. dr. H. Brinksma, \\ volgens besluit van het College voor Promoties \\ in het openbaar te verdedigen \\ op vrijdag 30 oktober 2015 om 14.45 uur
}

\author{
door \\ Suzanne Janssen \\ geboren op 8 mei 1984 \\ te Brummen
}


Dit proefschrift is goedgekeurd door de promotor prof. dr. M.D.T. de Jong en de assistent-promotor dr. M. van Vuuren. 
Samenstelling promotiecommissie

Promotor:

Prof. dr. M.D.T. de Jong

Assistent-promotor:

Dr. M. van Vuuren

Leden:

Prof. dr. S.N. Khapova

Prof. dr. E.R. Seydel

Prof. dr. R.E. de Vries

Prof. dr. J.A. Walburg

Prof. dr. C.P.M. Wilderom 



\section{Contents}

Chapter 1 An introduction on mentoring relationships 9 at work and Self-Determination Theory

Chapter 2 Informal mentoring at work:

A review and suggestions for future research

Chapter 3 Identifying support functions in developmental

Chapter 4 Motives to mentor: Self-focused, protégé-focused, relationship-focused, organization-focused, and unfocused motives

Chapter 5 Relational contracts for fulfilling supervisory 101 mentoring relationships: A dyadic study of PhD candidates and their supervisors

Chapter 6 Work group members' perceptions of mentoring relationships: A qualitative exploration

Chapter 7 General discussion

References

Samenvatting (summary in Dutch) 



\section{CHAPTER 1}

An introduction on mentoring relationships at work and Self-Determination Theory 
"People often think that the goal of mentoring is to help others to climb the corporate ladder. I think, when you're a good mentor, you help people to get the most out of them. Ambition is something that we always relate to a step higher in the organization, but if you really talk to people, this only applies to 25 or 30 percent. And to me, mentoring is about helping people to find out what they really want, and to accomplish that."

-Anonymous mentor

\subsection{Introduction}

All employees have been in the role of novice several times in their lives. For instance when they left school and entered their first job, when they switched between jobs, or when they accepted tasks within their job that were completely new to them. During such career challenges, most people feel excited, full of enthusiasm, but also a little insecure. Am I able to make it in this job? How is the organization's culture? Do I have the right skills for this project? Especially in such challenging times, people may look for support from others: family members, friends, and colleagues. These developers provide support during difficult times, give them feedback on how they handle situations in your job, and discuss their future career plans with them. Such developmental relationships are crucial in every career, as they affect how people function, how employees perceive themselves, and how they are seen by their colleagues. This dissertation focuses on a specific type of developmental relationships: the mentor-protégé relationship. This is a relationship "between a person who is perceived to have greater relevant knowledge, wisdom, or experience (the mentor) and a person who is perceived to have less (the protégé)" (Bozeman \& Feeney, 2007, p. 731) for the primary purpose of developing the protégé's career.

This chapter first gives an introduction on the topic of workplace mentoring. After that, self-determination theory (SDT) (Deci \& Ryan, 1985) is introduced as a potentially relevant underlying mechanism of mentoring relationships. The chapter ends with the outline of this dissertation and a reflection on how this dissertation aims to contribute to shortcomings and underdeveloped areas in the current mentoring literature. 


\subsection{Workplace Mentoring}

Generally, mentoring relationships emerge in either formal or informal forms. The fundamental difference between those two types of relationships can be summarized in four aspects. First, formal relationships are managed by a third party to meet the organization's needs (program-based), while informal mentoring relationships are spontaneously initiated by employees themselves and are driven by their specific needs, personal preferences, and a certain chemistry or mutual attraction (Blake-Beard, O'Neill, \& McGowan, 2007; Kram, 1985; Ragins \& Cotton, 1999). As a result, issues of access and organizational justice (i.e., who gets mentoring support and why) are at the heart of informal mentoring relationships (Scandura, 1997). Second, informal mentoring relationships are often less visible than formal mentoring relationships, because these informal relationships are most often not articulated and may not even be recognized by their members. Some informal mentors may not even be aware of their mentoring role, as most people do not speak in terms of mentor or protégé when they talk about their informal relationships (Chao, 2009). Third, the scope of both types of relationships differs. The scope of informal mentoring relationships is unbounded and the focus is on both professional (e.g., "How can I climb the corporate ladder?") and personal (e.g., "How do I become more sure of myself?") development. Formal mentoring relationships often have a clear focus on professional development, and goals and expectations that contribute to this professional development are articulated. Last, formal mentoring relationships are bounded in their duration, while informal mentoring relationships are not. Most formal mentoring relationships last for nine months to a year, and the developmental goals for the protégé should be accomplished in that time (Wanberg, Kammeyer-Mueller, \& Marchese, 2006). In contrast, informal mentoring relationships do not have a specified duration. Most informal mentoring relationships last for multiple years.

The research reported in this dissertation focuses on informal mentoring relationships: a developmental relationship which is acknowledged by at least one of the members as a mentoring relationship and which exists outside a formal mentoring program. As development is a continuous and ongoing process, rather than something programmatic and episodic, it is believed that informal mentoring relationships are more relevant and impactful for 
individuals' professional development than relationships in formal mentoring programs. The few studies which compare the outcomes of formal and informal mentoring relationships, show indeed that protégés in informal mentoring relationships report more favorable outcomes than protégés in formal mentoring relationships (e.g., Chao, Walz, \& Gardner, 1992; Ragins \& Cotton, 1999; Scandura \& Williams, 2001).

In her seminal work, Kram (1985) was the first to show that mentors may provide two types of support functions to their protégés. First, they provide career support functions: sponsorship, exposure and visibility, coaching, protection, and offering challenging assignments. These functions help protégés to establish a role in the organization and to advance their career. Second, mentors provide psychosocial support functions: role modeling, acceptance and confirmation, counseling, and friendship. These functions help protégés to develop a sense of professional identity and competence. The provision of these mentoring functions is associated with several objective and subjective career outcomes for protégés. For example, mentoring is associated with faster promotion rates, higher compensation, career satisfaction, and higher job satisfaction (Allen, Eby, Poteet, Lentz, \& Lima, 2004). Apart from the protégés, also mentors benefit from this relationship. Fulfilling a mentoring role is associated with subjective career outcomes, like higher job satisfaction and increased organizational commitment (Ghosh \& Reio, 2013).

Informal mentoring relationships are typically seen as developing in stages (Kram, 1983). The first stage (initiation) is a period of six to twelve months in which members for the first time engage in the relationship and in which positive expectations encourage both members to nurture the relationship. In this stage, the mentor offers the protégé mainly career functions (such as sponsorship and coaching). The second stage (cultivation) is characterized by a rapid increase of both career and psychosocial functions offered by the mentor. Both the mentor and protégé gain positive experiences through their interactions and the positive behaviors in this stage encourage a continuing and significant relationship. In the third stage (separation), usually after about two to five years, there is a decline in career and psychosocial support functions provided by the mentor. In this stage, the protégé experiences new independence and the mentoring relationship becomes a less central part in life. Finally, after several years of separation, interactions between the mentor 
and protégé evolve in a new form in which the mentor provides only occasionally functions. This stage is called the redefinition phase. The relationship may continue as friendship or the relationship may end by then and be replaced by another developmental relationship.

A major criticism in mentoring literature is the lack of theory development. Single case studies based on limited samples are typically reported and this type of research contributes little to the insight into underlying developmental mechanisms of mentoring (e.g., Bozeman \& Feeney, 2007; Russell \& Adams, 1997). As a result, there is a black box of mentoring processes in mentoring literature. In this dissertation, SDT is applied as an approach for unveiling the underlying mechanisms of informal mentoring relationships and to get more insight into the role of their need-fulfillment processes.

\subsection{Self-Determination Theory}

SDT is a macro-theory on human motivation. Central to SDT is the examination of how the fulfillment of individuals' needs for autonomy, competence, and relatedness relates to psychological health, well-being, motivation, and relationship functioning (Deci \& Ryan, 2000). SDT considers people as actively engaged organisms who interact with their environment and strive towards intra- and interpersonal growth. According to SDT, the environment plays a crucial role in people's need-fulfillment processes: when individuals are not supported by their social environment in their need-fulfillment (i.e., by their relational partners), their motivation, functioning, and well-being will not be optimal. Different from other motivational theories, SDT focuses not only on the level of motivation (i.e., how much motivation), but also on the orientation of that motivation (i.e., what type of motivation). For example, employees can be highly motivated to do a task because they find it interesting, or because they get an extra bonus for it.

SDT is a theoretical framework, combining several theories (Vansteenkiste, Niemiec, \& Soenens, 2010), which are all built upon the same basic assumptions about human motivation and the role of the social context in motivational processes. These assumptions can be summarized in three principles (Deci \& Ryan, 2008; Van den Broeck, Vansteenkiste, \& De Witte, 2008): First, SDT is concerned with basic need satisfaction, and it examines how the environment of 
an individual plays an important motivational role by fulfilling individual's basic needs. Second, SDT is concerned with why people are motivated to perform a certain behavior, by examining autonomous and controlled motivation. Last, SDT is concerned with the types of goals or values that people can pursue and how these impact motivation and well-being. SDT distinguishes intrinsic and extrinsic goal pursuit. These three principles will now be discussed in further detail.

\subsubsection{Basic need satisfaction}

SDT distinguishes three universal basic psychological needs: autonomy, competence, and relatedness. These psychological needs are "nutriments that are essential for ongoing psychological growth, integrity, and well-being" (Deci \& Ryan, 2000, p. 229). Autonomy refers to the experience of acting with a sense of choice, volition, and self-determination. Individuals experience autonomy when they can make own decisions in accordance with their goals. Note that a SDT perspective on autonomy differs from "independence." Acting autonomously does not rule out a sense of relatedness, but means a sense of self-directedness in one's actions (Stone, Deci, \& Ryan, 2009). Competence means feeling capable of achieving desired outcomes and feeling effective in one's efforts. Individuals experience competence when they feel that they can accomplish their goals and feel a sense of confidence in their behaviors. Relatedness refers to feeling connected to others, experiencing a sense of belongingness, and feeling understood by others. Individuals experience relatedness when they have satisfying, supportive social relationships.

According to SDT, opportunities to satisfy these three basic needs facilitate people's self-motivation and effective functioning. Several studies have been conducted that demonstrate the importance of the fulfillment of these basic needs. For example, Sheldon, Ryan, and Reis (1996) showed in a diary study how individuals' perceived fulfillment of competence and autonomy relates to daily well-being. They found that individuals who experienced greater fulfillment of both autonomy and competence tended to have better days on average (as indicated by their tendency to experience more positive affect and vitality and less negative affect and physical symptoms, such as headaches and stomach discomfort). Moreover, on days when individuals experienced more need fulfillment, they also experienced greater well-being. The role of needfulfillment is also shown in studies conducted in work contexts. For example, 
employees' need-fulfillment of autonomy, competence, and relatedness promote their work satisfaction, psychological health, self-esteem task motivation, and psychological adjustment on the job (Deci et al., 2001; Ilardi, Leone, Kasser, \& Ryan, 1993).

\subsubsection{Autonomous versus controlled motivation}

The second core concept of SDT is that it distinguishes different types of extrinsic motivation. Classic motivation theories often differentiate motivation into intrinsic (or autonomous) motivation and extrinsic (or controlled) motivation as separable constructs (Ryan \& Deci, 2000a). SDT shows that extrinsic motivation can vary in the degree to which it is experienced as autonomous versus controlled. So, where early studies regarded extrinsic motivation as a unitary construct, SDT distinguishes various types of extrinsic motivation. A central process in SDT is the process of internalization, which involves endorsing the value of extrinsically motivated behaviors (Ryan \& Deci, $2000 \mathrm{~b}$ ). The basic hypothesis of SDT is that greater internalization impacts individuals' well-being (Vansteenkiste et al., 2010). Several studies on SDT showed the validity of the internalization continuum (e.g., Deci, Eghrari, Patrick, \& Leone, 1997; Hayamizu, 1997; Williams \& Deci, 1996). Next to amotivation (where there is no motivation at all to perform the behavior) and intrinsic regulation (when the behavior is experienced as having been freely chosen and therefore fully autonomous), the continuum distinguishes four types of extrinsic motivation.

First, there is external regulation. Behavior is externally regulated as it is performed in order to satisfy an external demand or reward contingency (Deci \& Ryan, 1985). The motive is then outside the person. For example, when employees follow a training program because their supervisor told them to do so, the behavior is externally regulated. When the motive has begun to be internalized, but regulation of the behavior is dependent on the evaluation against external standards, the behavior is introjected regulated. Introjection often appears as ego involvements: People often engage in activities that are socially acceptable, in order to avoid feelings of guilt, or to gain others' respect (Ryan, 1982). An example of this is when an employee follows a training program because all of his or her colleagues are doing this. The next step on the continuum of autonomy is identified regulated behavior (Deci \& Ryan, 2000). In 
this case, the behavior in itself might not be enjoyable (i.e., intrinsically motivating), but it is seen as serving an important purpose and is typically experienced as somewhat internal. When an employee follows a training program because he or she would like to climb the corporate ladder and the training is needed for that, attending the training is a form of identified regulated behavior. When extrinsic motivation is most complete internalized, the behavior is integrated regulated (Deci \& Ryan, 2000). The person fully accepts and integrates the values guiding the behavior with other needs and values that define his or her self-concept. For example, when the employee regards self-development as an important personal value, following a training program is an example of a behavior that is integrated with this personal value.

Studies on this internalization continuum show that more autonomous regulations are associated with better performance, social functioning, and overall well-being (Deci \& Ryan, 2000). As such, these studies underline the importance of the process of internalization for individuals' functioning. Several studies examined which factors facilitate the internalization process. Again, the fulfillment of basic needs plays a crucial role here. Both competence and autonomy need to be fulfilled to facilitate individuals' intrinsic motivation, so social contexts that provide opportunities to satisfy these needs are believed to promote the internalization process (Deci \& Ryan, 2000). Moreover, the role of relatedness as a third basic need became apparent, as people are more likely to adopt social norms and values from people to whom they feel close. In social contexts where only the needs for competence and relatedness are fulfilled, it is more likely that partial internalization will occur (Markland \& Tobin, 2010).

\subsubsection{Intrinsic and extrinsic goal pursuit}

A last basic concept in SDT involves the types of goals or values that people can pursue with their behaviors. According to SDT, people can have different types of life goals, such as personal growth, community and physical health (intrinsic goals), or financial success, fame, and appearance (extrinsic goals). SDT examines how these two different forms of goals impact individuals' motivation and well-being. Again, the fulfillment of individuals' basic needs plays an important role here. Ryan, Sheldon, Kasser, and Deci (1996) proposed that intrinsic and extrinsic goals have a different impact on peoples' motivation and well-being. They argue that intrinsic goals are likely to satisfy the basic needs 
for autonomy, competence, and relatedness and are thus positively associated with well-being. Extrinsic goals, however, are less likely to satisfy these basic needs and are thus associated with lower levels of well-being. The study of Sheldon, Ryan, Deci, and Kasser (2004) shows that both what goals people value (extrinsic vs. intrinsic goals) and why people value these goals (extrinsic vs. intrinsic motivation) make significant independent contributions to psychological well-being. In other words, people will experience greater wellbeing when they seek goals implicating growth and connection (intrinsic goals), rather than goals implicating money and reputation (extrinsic goals) and goals that are interesting and personally meaningful (intrinsic motivation), rather than goals they feel compelled or pressured to pursue (extrinsic motivation).

\subsection{Self-Determination Theory and Interpersonal Relationships}

SDT's principles have been examined in various social contexts, such as education (e.g., De Naeghel, Van Keer, Vansteenkiste, \& Rosseel, 2012), psychotherapy and counseling (e.g., Ryan, Lynch, Vansteenkiste, \& Deci, 2011), health care (e.g., Ryan, Patrick, Deci, \& Williams, 2008), and organizations and work (Gagné et al., 2015). A smaller group of studies applied SDT to the field of close relationships. In this field, the application of the basic assumptions of SDT have resulted in two research lines (La Guardia \& Patrick, 2008). Studies in the first research line examine how basic psychological needs are supported or undermined by relational partners. Studies in the second research line examine how motivational orientations toward relationships influence the course of a relationship. Below, some typical studies for both the research lines are described.

First, several studies examined how basic psychological needs are supported or undermined by relational partners and how this relates to individual well-being and relational functioning (La Guardia, Ryan, Couchman, \& Deci, 2000). For example, Patrick, Knee, Canavello, and Lonsbary (2007) examined the role of need fulfillment in relationship functioning and both individual (i.e., selfesteem, positive affect, vitality) and relationship (i.e., satisfaction and commitment) well-being in three studies. Each study shows how overall need fulfillment of the basic needs and need fulfillment of each individual need were associated with relationship functioning and well-being. Relatedness was found 
to be the strongest unique predictor of relationship outcomes. Moreover, the authors found that need fulfillment was associated with greater individual wellbeing, and better relationship quality. In another study, La Guardia, Ryan, Couchman, and Deci (2000) also found that individuals' basic psychological need satisfaction makes unique contributions to well-being.

Second, SDT has been applied to the field of interpersonal relationships to examine motivational orientations and reasons to engage in relationships, perform relational activities, and maintain relationships. For example, Gaine and La Guardia (2009) developed the Motivations for Relational Activities (MRA) scale, to examine the extent to which people feel autonomous and controlled in a variety of specific relational activities. They showed that the motivations towards specific relational activities (e.g., individuals' motivations to disclose their feelings, thoughts, and concerns to their partner) independently and significantly contributed to the prediction of relationship well-being, in terms of greater commitment, satisfaction, intimacy, and vitality levels. In their study on romantic relationships, Knee, Patrick, Vietor, Nanayakkara, and Neighbors (2002) videotaped couples in semistructured interviews in which they discussed differences in how they both view their relationship. The goal of their study was to examine how individuals' autonomy orientation is related to interaction behaviors in their relationships. SDT describes three types of causality orientation: the autonomy orientation (characterized by an interest in and valuing of what is occurring), the control orientation (characterized by a focus on rewards, gains, and approval), and the impersonal or amotivated orientation (characterized by anxiety concerning competence). The study of Knee et al. (2002) shows that, when facing challenges in their relationships, individuals' autonomy orientation was associated with more relationship-maintaining coping strategies (e.g., discussing feelings with someone), while individuals' controlled orientation was associated with more denial (e.g., pretending nothing has happened).

These studies show the usefulness of SDT in explaining relationship functioning and well-being. Recently, Haggard, Dougherty, Turban, and Wilbanks (2011) suggested to apply SDT to mentoring research, to examine both protégé and mentor motives for engaging in a mentoring relationship. Researchers could for example examine under which circumstances employees are motivated to perform mentoring behaviors. Given the outline of how the core assumptions of 
SDT can be relevant in the context of interpersonal relationships, it is argued that the usefulness of SDT for mentoring research may be broader than only examining the quality or type of motivation to engage in mentoring relationships. Especially in the context of mentoring relationships, it may be useful to examine how mentors' need-supportive behaviors are experienced by protégés, and how these behaviors help protégés to develop. Accordingly, in line with relational mentoring (Ragins, 2012), a need-based approach was adapted and it is argued that the fulfillment of autonomy, competence, and relatedness may be a crucial process in mentoring relationships.

\subsection{Dissertation Outline}

This dissertation is divided in three parts. First, a literature review of current mentoring literature is presented. This literature review forms the foundation for the four empirical studies, which are presented in the second part of this dissertation. The final part consists of a discussion of the results and theoretical implications of the research reported in this dissertation.

\section{Literature Review}

This dissertation aims to contribute to several research areas that tend to be overlooked by mentoring scholars. Chapter 2 provides a review of informal mentoring literature, in which these overlooked areas are discussed. Based on two basic premises of relationships, several areas in current mentoring research are discussed that could be further cultivated by future research. The first premise is that relationships never exist in a vacuum. However, traditionally, mentoring literature has often overlooked the context of mentoring, and scholars focused on single mentoring relationships. Participants are then asked to indicate their primary mentoring relationship. Higgins and Kram (2001) called for a reconceptualization to developmental networks and in recent years, this phenomenon received increasing attention from mentoring scholars. Developmental networks have been defined as "the set of people a protégé names as taking an active interest in and action to advance the protégé's career by providing developmental assistance" (Higgins \& Kram, 2001 , p. 268). These networks of relationships include but are not limited to one's primary mentor. Inspired by developmental network research, it is argued that mentoring literature could pay more attention to the broader context of mentoring (Chandler, Kram, \& Yip, 2011; Jones \& Corner, 2012). 
The second premise is that individuals not only engage in human relationships for instrumental purposes. They also have relational motives such as human strivings for connection and the need to belong as drivers to engage in human relationships (Baumeister \& Leary, 1995). However, as shown by relational mentoring theory (Ragins, 2012) mentoring (Blau, 1964; Emerson, 1976) scholars to date have mostly applied a transactional and instrumental approach towards mentoring. Relational mentoring theory also questions the one-sided focus on protégés in mentoring studies. As is shown by Allen, Eby, O'Brien, and Lentz (2008), protégés are the primary focus of inquiry in mentoring studies. Although there is increasing knowledge on for example mentors' career benefits (Ghosh \& Reio, 2013) and negative experiences (Eby, Durley, Evans, \& Ragins, 2008b), many questions concerning mentors' perspectives remain still underexplored. Moreover, mentoring relationships are mostly still conceptualized and measured as if there are two detached actors, instead of focusing on the relationship between those actors. In other words, only few studies have conceptualized, measured, and analyzed mentoring relationships in terms of dyads. (Baumeister \& Leary, 1995). Inspired by these insights from relational mentoring theory, it is argued that mentoring literature could pay more attention to relational or affiliative motivations of both members. (Ragins, 2012)

\section{Empirical Studies}

The empirical studies all contribute to the overlooked areas in mentoring literature. Table 1.1 shows an overview of the empirical studies and how they contribute to the research areas identified in the literature review. In chapter 3 , a qualitative study is reported which describes the manner in which constellations of developmental relationships meet protégés' needs for autonomy, competence, and relatedness. In this study, SDT is applied to categorize developmental support functions. Based on interviews with protégés, this chapter shows how protégés identified the importance of their developer's need-supportive functions to their success, including creating freedom, encouraging self-initiation (autonomy), emulating effective behaviors, confirming and praising (competence), and intimacy and self-disclosure (relatedness). This way, this study provides a theory-based classification of developers' support functions and contributes to a better understanding of the content of developmental networks. 
Chapter 4 describes a study that applied SDT to examine the motives mentors have for providing developmental support to their various protégés. Based on interviews with informal mentors, five broad categories of mentor motives are identified: self-focused (based on individual reasons), protégé-focused (directed at the protégé), relationship-focused motives (directed at the relationship between the mentor and the protégé), organization-focused motives (benefiting the organization), and unfocused motives (mentoring as the result of unconscious information processing). In the category of selffocused motives, five subcategories of motives are identified, corresponding with the categories of the motivation continuum of organismic integration theory (ranging from extrinsic motivation to intrinsic motivations). Next to that, this study also shows how relational motivations play a role in mentors' willingness to mentor others. It shows how affiliative motivations-the need to form and maintain close relationships with others-(McAdams \& Constantian, 1983) and communal orientation-the focus on the well-being of others(Clark \& Mills, 1993) play a role in employees' willingness to mentor. This way, this study contributes to our understanding of mentors' motives and sheds light on relational motivations to engage in several simultaneous mentoring relationships.

Chapter 5 describes a study in which couples of alumni PhD-students and their former supervisors are interviewed about their mentoring relationship. Based on individual interviews, this study shows how mentors and protégés come to agreements on how to fulfill protégés' basic psychological needs for autonomy, competence, and relatedness. Analyses show the challenges that mentors and protégés experience in these need-fulfillment processes, including finding a balance between fulfilling protégé's needs for making own decisions and the success of the project (autonomy), making their expectations regarding the other's competencies clear (competence), and finding a right balance between showing their professional and personal identity (relatedness). This way, this study contributes to our understanding of how members' experiences and evaluations of the mentoring relationship with regard to protégé's basic needfulfillment (mis)align.

In chapter 6, a shift is made to the context of mentoring relationships as this chapter describes the perceptions that outsiders (i.e., work group members) have of informal mentoring relationships in their direct work context. Based on 
interviews with work group members, it shows how work group members associate both positive and negative consequences with mentoring relationships for protégés, mentors, and organizations. However, when work group members describe consequences for themselves, they describe mainly negative consequences. Participants' negative feelings of exclusion, jealousy, and unfairness support the value of an organizational justice perspective on mentoring relationships when they are examined in their broader contexts.

\section{Discussion}

Finally, chapter 7 reflects on the findings and conclusions of each individual study. In this chapter, a reflection on the critical review of mentoring literature is also made, and it elaborates on further research on mentoring and SDT.

Table 1.1. Overview of the empirical chapters

\begin{tabular}{|c|c|c|c|c|c|}
\hline & & Chapter 3 & Chapter 4 & Chapter 5 & Chapter 6 \\
\hline Focus of inquiry & & $\begin{array}{l}\text { Protégés } \\
(n=18)\end{array}$ & $\begin{array}{l}\text { Mentors } \\
(n=20)\end{array}$ & $\begin{array}{l}\text { Dyads } \\
(n=20)\end{array}$ & $\begin{array}{l}\text { Outsiders } \\
(n=21)\end{array}$ \\
\hline \multirow[t]{5}{*}{ Research area } & $\begin{array}{l}\text { Developmental network } \\
\text { perspective }\end{array}$ & $\mathrm{X}$ & $\mathrm{X}$ & & \\
\hline & Organizational context & & & & $\mathrm{X}$ \\
\hline & $\begin{array}{l}\text { Relational motivations } \\
\text { and functions }\end{array}$ & $\mathrm{X}$ & $\mathrm{X}$ & $\mathrm{X}$ & \\
\hline & Mentors' perspective & & $\mathrm{X}$ & & \\
\hline & Dyadic processes & & & $\mathrm{X}$ & \\
\hline \multirow[t]{3}{*}{$\begin{array}{l}\text { Theoretical } \\
\text { foundation }\end{array}$} & $\begin{array}{l}\text { SDT: Basic need- } \\
\text { fulfillment processes }\end{array}$ & $\mathrm{X}$ & & $\mathrm{X}$ & \\
\hline & $\begin{array}{l}\text { SDT: Autonomous vs. } \\
\text { controlled motives }\end{array}$ & & $\mathrm{X}$ & & \\
\hline & $\begin{array}{l}\text { Organizational justice } \\
\text { perspective }\end{array}$ & & & & $\mathrm{X}$ \\
\hline
\end{tabular}




\section{CHAPTER 2}

\section{Informal mentoring at work: A review and suggestions for future research}

Janssen, S., Van Vuuren, M., \& De Jong, M. D. T. Informal mentoring at work: A review and suggestions for future research. International Journal of Management Reviews (in press). 
"He gave me a sense of security. It's nice to have someone around, to fall back on when you are trying to find your way through a dark forest and think: 'Oh my, do I ever arrive there, in the end, where the woods stop?"'

-Anonymous protégé

\subsection{Introduction}

How engagement in developmental relationships contributes to the growth and development of individuals, is a question that has received much attention from vocational scholars. Typically, scholars have focused on the mentor-protégé dyad: "a relationship between an older, more experienced mentor and a younger, less experienced protégé for the purpose of helping and developing the protégé's career" (Ragins \& Kram, 2007b, p. 5). Over the past 30 years, a large body of literature has emerged on a wide array of mentoring topics, including mentoring functions provided (Dickson et al., 2013; Kram, 1985; Noe, 1988; Ragins \& McFarlin, 1990; Scandura \& Ragins, 1993), career benefits associated with mentoring (Allen et al., 2004; Noe, Greenberger, \& Wang, 2002; Ragins \& Cotton, 1999), characteristics of successful mentoring programs (Allen, Eby, \& Lentz, 2006a; Horvath, Wasko, \& Bradley, 2008; Underhill, 2006), and negative experiences and behaviors (Burk \& Eby, 2010; Eby \& McManus, 2004; Feldman, 1999).

That the field of mentoring research flourished this way can partly be explained by its focused attention to specific elements of the mentoring concept. Mentoring literature is particularly strong in explaining how individual characteristics shape mentoring and predict mentoring outcomes (Chandler et al., 2011; Eby \& Allen, 2008; Jones \& Corner, 2012). However, it has also been criticized (e.g., Russell \& Adams, 1997) because of its empirically-driven research, with little attention to theory building. By its strong focus on the outcomes of mentoring (Allen et al., 2008), other important aspects of mentoring have been overlooked. Mentoring research shows an "...impatience with troublesome conceptual and analytical problems" (Bozeman \& Feeney, 2007, p. 720), and tends to neglect more fundamental questions.

We believe two general premises of human relationships could contribute to a fuller understanding of such fundamental aspects of mentoring. First, one has 
to acknowledge the impact of relationships' environments on the ways in which people engage in and construct these relationships (Berscheid, 1999; Blau, 1964). Relationships do not exist in a vacuum. Individuals are embedded in different social networks that influence how each bond with others is formed and developed over time (e.g., Felmee, 2001). Inspired by developmental network research, we argue that mentoring literature could pay more attention to the broader context of mentoring (e.g., Chandler et al., 2011; Jones \& Corner, 2012), including temporal influences. A second premise is that individuals not only engage in human relationships for instrumental purposes, that is, for positive outcomes for themselves. They also have relational or affiliative motives to form relationships. For example, Clark and Mills (1993) show that although sometimes people may follow social exchange norms and rules (e.g. giving benefits with the expectation of receiving comparable benefits in return), people can also follow communal norms (e.g. giving benefits in support of the partner's welfare without expecting benefits in return). However, as shown by relational mentoring theory (Ragins, 2012; Ragins \& Verbos, 2007) mentoring literature has adopted a functional approach, resulting in the study of instrumental motivations to engage in mentoring relationships. Inspired by these insights from relational mentoring theory, we argue that mentoring literature could pay more attention to relational or affiliative motivations of both members.

This review has two goals. Our first goal is to critically evaluate past mentoring research and explore aspects of our two premises of relationships that are relevant for theory development. This leads to four areas in the mentoring literature that could be further advanced: (1) the context of mentoring, (2) temporal influences on mentoring, (3) underlying developmental mechanisms of mentoring, and (4) relational motivations of mentors and protégés (see Table 2.1). In discussing these four areas, we identify promising research efforts that are critical for our understanding of mentoring and we discuss how these efforts should be strengthened to cover the four areas more fully. Our second goal is to discuss the extent to which ongoing developments in research are able to contribute to a fuller understanding of these four areas of mentoring research. In our sections on future directions, we aim to show how insights from adjacent research areas (e.g., relationship science and leadership) could further cultivate our knowledge of mentoring. 


\subsubsection{Boundary Conditions}

Three boundary conditions should be taken into account when reading this review. First, this review focuses on informal mentoring relationships. These relationships differ from formal mentoring relationships on four dimensions (Baugh \& Fagenson-Eland, 2007). First, informal mentoring relationships are initiated by the members themselves and are most likely driven by the needs of both mentor and protégé, while formal mentoring relationships are matched by a third party to meet the organization's needs (Blake-Beard et al., 2007; Ragins \& Cotton, 1999). Second, informal mentoring relationships are seen as more intense than formal mentoring relationships, because the scope of informal relationships is unbounded and the focus is not only on professional development but also on personal development. According to Ragins and Cotton (1999), protégés with informal mentors receive more career development and psychosocial functions than protégés with formal mentors. However, this result was not confirmed in a later study by Allen and Eby (2004). Third, informal mentoring is not always recognized or articulated by both members and as a result, is less visible than formal mentoring. Last, mentoring programs are constrained in their duration, while informal mentoring relationships are not.

A second boundary condition is that we did not focus on the influences of particular individual characteristics on mentoring. Individual attributes of participants in a mentoring relationship have been a major focus of researchers' attention (Chandler et al., 2011). From these studies, we learned that in every mentoring relationship the specific constellation of race, cultural background, gender, and personality of the participants may influence the dynamics within that context. Acknowledging that all interactions are contextual accomplishments, these particular characteristics will not be the major focus of this review. Rather than the variance within dyads, we review the overarching themes that emerged in academic discussions about mentoring.

Third, a word on the conceptualization of 'relationships' is warranted. In contrast to the broad consensus that relationships are essential for humans, the range of perspectives on the nature of relationships and traditions of studying relationships is bewildering. This range can be pictured as an example of the basic ontological distinction between realist entity approaches and 
constructionist process approaches of the world (Chia, 1995; Van de Ven \& Poole, 2005). Taking an entity view means treating the world as a stable material substance, in which fixed things can be studied through causal models with independent and dependent variables. A process approach stresses the flux of life as a starting point, preferring the use of verbs rather than nouns for describing the ever-evolving emerging of organizing. Within organization and management studies the tension between these approaches and their respective critiques are addressed regularly for important areas, including change (Hernes \& Weik, 2007; Tsoukas \& Chia, 2002; Weik, 2011), internationalization (Welch \& Paavilainen-Mäntymäki, 2014), leadership (Cunliffe \& Eriksen, 2011; Uhl-Bien, 2006), learning (Cunliffe, 2008), and strategy (Sminia, 2009). In mentoring studies this division is almost completely absent in favor of the entity approach (see Jones \& Corner, 2012, for an exception). We refrain from reiterating the value of a more process-oriented approach throughout the review, and conform ourselves to the work that is actually done. In the conclusion section, we will suggest ways in which the process approach could enrich mentoring studies in the future.

\subsubsection{Method for this Review}

We adopted a broad approach when searching papers for review. We used 'mentor*' as our primary broad search string and identified sources within the following databases: PSYCINFO, Scopus, and Web of Science. We retained papers by their relevance as indicated by title or abstract, or by examination of the paper. In order to identify papers potentially missed, manual searches of key journals in the field of workplace mentoring (Academy of Management Journal, Academy of Management Review, Career Development International, Group \& Organization Management, Journal of Applied Psychology, Journal of Management, Journal of Organizational Behavior, Journal of Vocational Behavior, and Personnel Psychology) were conducted. We also conducted manual searches of reference lists to identify additional relevant papers and handbooks (e.g. Handbook of Mentoring at Work: Research, Theory and Practice (Ragins and Kram, 2007a) and The Blackwell Handbook of Mentoring: A Multiple Perspectives Approach (Allen \& Eby, 2007a)). Although many studies do not specify the exact type of mentoring studied (Allen et al., 2008), when possible, we specified if the reviewed studies examined formal or informal mentoring. Articles discussing other forms of mentoring than workplace mentoring (such as student-faculty 
mentoring) were excluded from our review. We included articles published through 2014. Table 2.1 shows an overview of key studies included and how these studies relate to the four research areas of this review. We will now discuss each of the four areas in detail.

\subsection{The Context of Mentoring}

The process of mentoring can take place in several forms, varying from formal developmental interactions such as coaching sessions, to long-term and intense relationships. While current mentoring research is increasingly concerned with developmental networks (e.g., Higgins \& Thomas, 2001; Van Emmerik, 2004), traditionally, mentoring has been studied mostly on a dyad level. In these studies, mentoring is seen as a phenomenon that is bounded to one specific relationship: the mentoring dyad.

Studying an isolated mentoring dyad can unveil important dynamics of core concepts like the impact of diversity, gender, culture, and power distance (Ramaswami, Huang, \& Dreher, 2014). For ecological validity, however, the study of mentoring needs embeddedness in larger social contexts (Chandler et al., 2011). Isolating the two members of a mentoring relationship entails three important limitations. First, such focus overlooks possible influences of other people on the protégé's development. For most people, it would be rare to find someone who can meet all of their developmental needs. Early studies already showed that individuals look for support alongside their primary mentorprotégé relationship. Kram and Isabella (1985) showed that various types of colleagues provide developmental support. Their biographical interview study of significant peer relationships identifies the information peer (sharing information with the protégé), the collegial peer (providing career strategizing, job-related feedback, and friendship), and the special peer (providing confirmation, emotional support, personal feedback, and friendship). Based on the answers on two open-ended questions of a larger survey, Allen and Finkelstein (2003) found that family members, supervisors, colleagues, subordinates, and friends provide comparable developmental support as mentors do. However, for a long time, mentoring studies ignored the influence of others on the protégé's career development. 
Second, the interplay between other work relationships and the mentoring relationship is generally overlooked (cf. Kram \& Ragins, 2007). Mentors and protégés are not only influenced by other mentors and protégés, but also by other work and nonwork relationships. Interactions with these individuals may affect the interactions and mentoring processes between mentor and protégé. For example, when a mentor has positive relationships with coworkers, the protégé may perceive his or her own relationships with these coworkers as more favorable than when the mentor has negative relationships with them.

Third, we have little insight in the interplay between mentoring relationships and their organizational context. Studies examining the influence of the organizational context focus on the effects of organizational mentoring programs (Chandler et al., 2011), rather than on how organizational features (e.g. structures, processes, culture) influence the ways in which individuals are engaged in informal mentoring relationships. We have very little insight into how mentoring relationships, in turn, influence their organizational context.

\subsubsection{Developmental Network Research}

Acknowledging that isolating one mentor and one protégé holds important limitations, Higgins and Kram (2001) applied a social network perspective to mentoring and reconceptualized mentoring into a multiple-relationships phenomenon. Their developmental network perspective addresses the question of how being engaged in multiple, simultaneous developmental relationships affects one's career development. Developmental networks consist of developers from various social spheres, who can provide varying amounts and types of career and/or psychosocial support (Dobrow, Chandler, Murphy, \& Kram, 2011). Developmental networks may include mentors, but most likely also consist of other developers, who provide less prominent career and/or psychosocial support. Most developmental network studies explore how structural characteristics of developmental networks (e.g. tie strength, diversity, size) contribute to one's development, or how protégé characteristics influence the shape of one's developmental network (e.g., Cotton, Shen, \& Livne-Tarandach, 2011; Cummings \& Higgins, 2006).

Several studies showed that the size of a developmental network may contribute to protégés' career outcomes. The size of one's advice network is positively 
Table 2.1. Underdeveloped areas and current developments in informal mentoring literature

\begin{tabular}{|c|c|c|c|}
\hline $\begin{array}{l}\text { Underdeveloped } \\
\text { areas in } \\
\text { literature }\end{array}$ & $\begin{array}{l}\text { Key questions to } \\
\text { address }\end{array}$ & Current developments & Future research directions \\
\hline \multicolumn{4}{|c|}{$\begin{array}{l}\text { Premise 1: Mentors and protégés are embedded in different social networks that influence how each bond with others is } \\
\text { formed and developed over time }\end{array}$} \\
\hline $\begin{array}{l}\text { The context of } \\
\text { mentoring }\end{array}$ & $\begin{array}{l}\text { What is the influence } \\
\text { of other people on } \\
\text { protégés' } \\
\text { development? } \\
\text { - How do mentoring } \\
\text { relationships and } \\
\text { other work } \\
\text { relationships } \\
\text { influence each other? } \\
\text { - How do mentoring } \\
\text { relationships and } \\
\text { their organizational } \\
\text { context influence } \\
\text { each other? }\end{array}$ & $\begin{array}{l}\text { Developmental network } \\
\text { research } \\
\quad \text { Cotton et al. (2011); } \\
\text { Cummings \& Higgins (2006); } \\
\text { Higgins (2000); Higgins } \\
\text { (2001); Higgins et al. (2010); } \\
\text { Higgins and Kram (2001); } \\
\text { Higgins and Thomas (2001); } \\
\text { Kirchmeyer (2005); Van } \\
\text { Emmerik (2004) }\end{array}$ & $\begin{array}{l}\text { Seeing mentoring in its broader } \\
\text { context } \\
\text { - Interplay between } \\
\text { - } \quad \text { Multiplexity in developmental } \\
\text { networks } \\
\text { - Content of dyads in } \\
\text { developmental networks } \\
\text { - Interplay with the } \\
\text { organizational context }\end{array}$ \\
\hline $\begin{array}{l}\text { Temporal } \\
\text { influences on } \\
\text { mentoring }\end{array}$ & $\begin{array}{l}\text { How do mentoring } \\
\text { relationships evolve } \\
\text { over time? } \\
\text { How do long-term } \\
\text { interpersonal } \\
\text { processes between } \\
\text { mentors and protégés } \\
\text { evolve? } \\
\text { How does a } \\
\text { mentoring history } \\
\text { influence one's } \\
\text { current mentoring } \\
\text { relationships? }\end{array}$ & $\begin{array}{l}\text { Longitudinal approach to } \\
\text { mentoring } \\
\quad \text { Blickle et al. (2009); } \\
\text { Bouquillon et al. (2005); } \\
\text { Dobrow and Higgins (2005); } \\
\text { Donaldson et al. (2000); } \\
\text { Payne and Huffman (2005); } \\
\text { Singh et al. (2009); Wang et } \\
\text { al. (2009) }\end{array}$ & $\begin{array}{l}\text { A life cycle approach of mentoring } \\
\text { relationships } \\
\text { - Influence of specific events on } \\
\text { the course of mentorships } \\
\text { - Mentoring schema theory } \\
\text { (Ragins \& Verbos, 2007) }\end{array}$ \\
\hline \multicolumn{4}{|c|}{ Premise 2: Mentors and protégés have both instrumental and relational motives to form mentoring relationships } \\
\hline $\begin{array}{l}\text { Underlying } \\
\text { developmental } \\
\text { mechanisms of } \\
\text { mentoring }\end{array}$ & $\begin{array}{l}\text { What is the exact } \\
\text { relationship between } \\
\text { mentoring processes } \\
\text { and positive } \\
\text { outcomes? } \\
\text { - What is the black box } \\
\text { of mentoring } \\
\text { processes and } \\
\text { interactions? }\end{array}$ & $\begin{array}{l}\text { Mediating factors as } \\
\text { explanation } \\
\text { Baranik et al. (2010); Pan } \\
\text { et al. (2011) }\end{array}$ & $\begin{array}{l}\text { Uncovering developmental } \\
\text { mechanisms } \\
\text { - Self-determination theory (Deci } \\
\text { \& Ryan, 2012) } \\
\text { - Relational leadership theory } \\
\text { (Uhl-Bien, 2006) }\end{array}$ \\
\hline $\begin{array}{l}\text { Relational } \\
\text { motivations of } \\
\text { both mentors and } \\
\text { protégés }\end{array}$ & $\begin{array}{l}\text { - How are mentors' } \\
\text { and protégés' } \\
\text { relational } \\
\text { motivations of } \\
\text { influence on their } \\
\text { mentoring } \\
\text { relationships? } \\
\text { - What are mentors' } \\
\text { needs and benefits? } \\
\text { - What is the influence } \\
\text { of dyadic processes } \\
\text { on mentoring? }\end{array}$ & $\begin{array}{l}\text { Relational mentoring theory } \\
\text { Fletcher and Ragins } \\
\text { (2007); Ragins and Verbos } \\
\text { (2007); Ragins (2011) }\end{array}$ & $\begin{array}{l}\text { Towards a balanced view on } \\
\text { mentoring } \\
\text { - The need to belong as a } \\
\text { motivational factor } \\
\text { - Mentors' needs } \\
\text { - Mutuality processes in } \\
\text { mentoring relationships }\end{array}$ \\
\hline
\end{tabular}


related to career success (Van Emmerik, 2004), the number of developers and the amount of support are positively related to work satisfaction (Higgins, 2000), and the number of developmental relationships predicts achieved rank among American academics (Kirchmeyer, 2005). The amount of support provided by a constellation of developers may also have positive effects on protégés' outcomes. A longitudinal study by Higgins, Dobrow, and Roloff (2010) showed that the amount of psychosocial support positively relates to protégés' optimism (e.g. flexibility and adaptability in stressful situations), and that increasing the amount of career and psychosocial support results in more optimism later in their career. Other research shows that network diversity (i.e., number of social spheres from which developers come) influences career benefits for protégés (Higgins, 2001). The diversity of instrumental relationships contributes to the number of job offers during job searches, and diverse psychosocial relationships foster protégés' confidence in overcoming career obstacles.

The developmental network approach clearly shifts the focus of mentoring research towards the question of how being engaged in multiple, simultaneous relationships influences one's career development. Still, other contextual questions in mentoring literature remain unaddressed. First, current research into developmental networks is typically aimed at picturing the network as a whole, rather than picturing the individual dyads that make up this network. As a result, the interplay between several developmental relationships is hardly captured in current developmental network studies. This way, there is limited insight into how different developmental relationships influence one another. Second, we could extend our understanding of how one's participation in several simultaneous developmental relationships influences behaviors, communications, and support functions in these relationships. Both protégé and mentor engage in multiple (non)work relationships, but we lack insight in spillover effects between those relationships. Third, because of the focus on the network rather than on its distinct dyads, behaviors and support functions in these various specific developmental relationships-next to the mentoring dyad-are still underexplored. Last, only few studies have explored the interplay between organizational context and mentoring. Insights in the mutual influence of organizational characteristics and mentoring processes are scarce. 


\subsubsection{Future Directions: Seeing Mentoring in its Broader Context}

\section{The interplay between developmental relationships}

Current mentoring research hardly investigates the interplay between several developmental relationships in a network. The developmental network approach is useful in addressing the question how various developmental relationships influence career progression, but no research yet explored the way developmental relationships influence each other. Kram and Ragins (2007) address this possibility in their conceptualization of relational caches, which they define as "a transportable sets of relational skills and competencies" ( $p$. 671). They argue that competencies derived from one relationship may affect the processes and outcomes of other relationships. Related fields also show how experiences in one relationship can influence the course of another relationship. For example, in the trust literature (Burt \& Knez, 1996; Ferrin, Dirks, \& Shah, 2006), there is an increasing understanding of how trust between two members of a relationship is influenced by relationships with third parties. In developmental network research, it would also be valuable to study effects of third-parties on attitudes and behaviors of protégés and mentors. For example, when a mentor has more than one protégé, how does the diffusion of the mentor's attention affect protégés' evaluations (Bozeman \& Feeney, 2008)? As Hall and Chandler (2007) state, it is likely that an individual's current work life is composed of several mini learning cycles and therefore, individuals act like newcomers several times during their careers. Following this idea of career paths, it might be the case that an individual is protégé in one mentoring relationship, but mentor in another, simultaneous relationship. Future research using sociometric surveys could examine how attitudes and behaviors in one relationship are influenced by other relationships, and explore mediating factors that affect these processes.

\section{Multiplexity in developmental networks}

Previous studies on developmental relationships generally suppose that both members of the relationship have only one role in their relationship (Dobrow et al., 2011). With few exceptions (e.g., Cotton et al., 2011), developmental network research has not examined the possibility of simultaneously fulfilling different roles in one relationship. These different roles are called 
"multiplexity", which is "the overlap of roles, exchanges, or affiliations in a social relationship" (Verbrugge, 1979, p. 1286).

Cotton et al. (2011) focused on the multiplexity of support functions provided by developers. They found that some developers demonstrate multiplexity by providing multiple career subfunctions or multiple psychosocial subfunctions in one relationship. Further, protégés described hybrid multiplexity relationships, in which one single developer provides both career and psychosocial support. To extend this research line, it would be helpful to examine the effects of other multiplexity forms. Nowadays, work and nonwork are seen as connected and having important mutual influence, making the occurrence of spillover effects between those domains likely. A protégé's colleague (work developer) can also be his or her friend (nonwork developer). To date, no studies examined the consequences of multiplexity between work and nonwork roles in a developmental network context. It would be useful to explore how simultaneous roles may, for example, influence the multiplexity of communication topics, or the range of support functions provided in a developmental relationship.

\section{The content of dyads in developmental networks}

Next, developmental network research has given scant attention to network content (Cotton et al., 2011). We have insufficient insight in how support functions, phases, and behaviors of protégés and developers are similar or different for various developmental relationships. Ragins and Cotton (1999) already showed that formal mentoring relationships may differ from informal mentorships in terms of the amount of support that protégés receive. Recent evidence suggests that Kram's (1985) original mentoring functions to other developmental relationships may be less generalizable than previously thought (Cotton et al., 2011; Murphy \& Kram, 2010). These studies add several subfunctions to Kram's (1985) classic set. Cotton et al. (2011) qualitatively examined support functions provided to Major League Baseball players and added subfunctions such as "freedom and opportunity for skill development", and "inspiration and motivation." Murphy and Kram (2010) examined how work and nonwork developers contribute to one's career success and added "encouragement and emotional support," and "work-life interface failure" as functions. These studies show the importance of a careful exploration of support functions. It seems reasonable as well that particular characteristics of 
the dyad in terms of gender and race influence the content of the relational interactions (Durbin \& Tomlinson, 2014). Future research should extend this research by qualitatively exploring how functions, behaviors, and relationship phases differ for various types of developmental relationships (varying in, for example, relationship strength and frequency of contact).

\section{The interplay with the organizational context}

Although the relationship between individual characteristics and mentoring has been widely studied, the relationship between organizational characteristics and mentoring has not. We propose a mutuality perspective to examine the interplay between mentoring relationships and their broader organizational context. First, scholars may examine how the organizational context influences mentoring relationships. Chandler et al. (2011) distinguish several levels of analysis. One of these levels is the organizational microsystem, in which researchers focus on how the organizational context shapes mentoring processes. So far, only few empirical investigations focused on this level, testing, for example, the influence of an organization's culture and beliefs, hierarchy, and reward systems on mentoring (e.g., Ghosh, 2014; Hu, Baranik, \& $\mathrm{Wu}, 2014$; Rohatinsky, 2014). Future studies could examine how variations in gender at organizational levels influence mentoring processes: Do protégés in a context of corporate masculinity report other needs and support functions than protégés in feminine contexts (McKeen \& Bujaki, 2007)? Scholars may also examine how the position of mentor and protégé in an organization's structure affects their attitudes towards mentoring and mentoring behaviors: How do mentoring relationships in self-managing teams, for example, differ from those in organizations with clear senior-junior relationships?

Second, no study has yet examined how developmental relationships, in turn, influence their organizational context. We have very little insight in ways mentors and protégés show their mentorship to other organizational members: Do they express their bond in public, and through which actions and rituals? There are only few studies on how mentoring is sensed by colleagues in work contexts and how their reactions influence both members. As Scandura (1997) explained, issues of fairness and justice may be important to examine in any mentoring context, since nonprotégés may experience negative favoritism. Future research could closely examine the relationship between mentoring and 
procedural, distributive, and interpersonal justice among protégés and nonprotégés.

\subsection{Temporal Influences on Mentoring}

A complete theory includes the specific context in which a phenomenon occurs, as well as the temporal factors which affect the theorized phenomenon under study (George \& Jones, 2000; Whetten, 1989). Applying a cross-sectional design (Allen et al., 2008), many mentoring studies isolate single mentoring moments and leave out such temporal factors. This hinders our understanding of mentoring in three ways.

First, there is insufficient understanding of how mentoring relationships evolve over time. Kram (1983) identified four stages of mentoring based on openended interviews with fifteen young managers and their informal mentors, which was largely supported in a quantitative study by Chao (1997). In the first phase (initiation), the mentor offers the protégé mainly career support. In the second phase (cultivation), the range of career and psychosocial support offered by the mentor increases rapidly to a maximum, although this finding was not supported by Chao (1997). The third phase (separation) is characterized by a decline in career and psychosocial support provided by the mentor, caused by the career development of one or both individuals. Finally, interactions between mentor and protégé evolve in a new form in which the mentor provides occasional support or the relationship ends (redefinition). There are other models with three (Missirian, 1982) and six stages (Phillips, 1977). In a comparative study, Pollock (1995) tested hypotheses for these three models. Missirian's (1982) three-stage model was supported, there was some support for Kram's (1983) model, and only little support for Phillips' (1977) six-stage model. In all, only few studies describe stages of mentoring relationships, and their findings are not fully consistent. Furthermore, it is uncertain whether these models are still valid in modern work contexts. ICT has affected the course of mentoring relationships and the support functions provided in the various stages. It is nowadays possible to have contact with a

possible mentor, even before a first face-to-face meeting. The initiation phase of mentoring relationships may start in virtual ways. The redefinition phase could differ from the previous models, as virtual communication allows people to interact with each other even when they are physically separated. Further 
research should also examine how career mobility has affected the depth and quality of mentoring relationships, and, accordingly, the support functions provided in the different phases.

Second, we have an incomplete understanding of how long-term interpersonal processes between mentors and protégés evolve. Most studies conceptualize how individual characteristics such as gender (Young, Cady, \& Foxon, 2006), race, or personality (Hu, Thomas, \& Lance, 2008) influence formal and informal mentoring. Still, we have only limited insight in how typical relational factors (like trust, disclosure, interdependence, or relationship commitment) unfold in mentoring relationships. How do members' perceptions of these processes influence the course of mentoring relationships?

Last, influences of a mentoring history on current mentoring relationships have hardly been investigated. Ragins and Scandura (1999) drew attention to spillover effects in consecutive informal mentorships, when explaining individuals' willingness to mentor. They concluded that individuals with both experiences as mentor and as protégé, expected greater benefits and fewer costs of being a mentor than individuals with only experience as a mentor. A mentor's positive experience as protégé predicts expected outcomes when becoming a mentor. Such important findings hint at the significance of previous mentoring experiences, but to date no study unpacked how these previous experiences influence mentoring relationship dynamics.

\subsubsection{Developmental Changes over Time}

Recently, more studies apply a longitudinal approach to mentoring (Allen et al., 2008). Most of these examine if mentoring leads to long-term outcomes such as organizational commitment (Donaldson, Ensher, \& Grant-Vallone, 2000; Payne \& Huffman, 2005), career success (Blickle, Witzki, \& Schneider, 2009), or organizational knowledge sharing (Bryant, 2005). Some studies also examine how individual characteristics relate to receiving mentoring (Blickle, Schneider, Meurs, \& Perrewé, 2010; Singh, Ragins, \& Tharenou, 2009) or one's willingness to mentor in the future (Wang, Noe, Wang, \& Greenberger, 2009).

While insights in how one's professional development changes over time are important, they ignore how mentoring relationships and the interpersonal processes in mentoring relationships change over time. For example, Dobrow 
and Higgins (2005) showed that developmental network density relates negatively to professional identity clarity, but this type of study typically sidesteps how identity clarity is accomplished in mentoring relationships. Bouquillon, Sosik, and Lee (2005) found no significant differences across the various mentoring stages for protégés' trust and identification in their study on both formal and informal mentoring. They did not examine the process of how trust is built (i.e., which actions are perceived as signs of trust, and how this influences members' behaviors). It would be useful to understand how such interpersonal processes unfold and vary over time, and how this influences members' attitudes, behaviors, and outcomes. There are some studies that show temporal aspects of stage models, like Mezias and Scandura (2005), who illustrate different mentoring roles relevant for expats over time. For strategic implications, like designing formal mentoring programs, however, more research is needed on the unfolding of mentoring relationships.

\subsubsection{Future Directions: A Life Cycle Approach of Mentoring Relationships}

\section{Influence of specific events on the course of mentorships}

We propose two research lines to capture the life cycle of mentoring relationships, including both macro and micro changes. First, we need to zoom out on mentoring relationships, to map macro changes. This will provide a balanced view of how mentoring relationships change over time. It would be fruitful to identify how specific events in mentoring interactions relate to positive or negative change. We propose two research approaches. Turning point analysis investigates the changing nature of relationships by examining events that contribute to specific changes. Turning points are events that create positive or negative changes in a relationship, and are associated with relational satisfaction, commitment, and metacommunication (Baxter \& Bullis, 1986). Examining turning points may lead to a better understanding of which events relate to change in mentoring relationships. An appropriate method here is the Retrospective Interview Technique. Participants are asked to identify turning points in their mentoring relationship, which are graphically plotted on a time line. They also report on dependent variables such as their commitment level or relationship satisfaction on those specific points in time, 
so the researcher can analyze how particular turning points change interpersonal processes such as trust, commitment, and closeness.

The Critical Incident Technique (CIT) is an open method that focuses on positive and negative incidents, which allow participants to mention any event that comes to mind. Originally, the CIT was developed as a technique to observe human behavior and to decide on the competencies needed of professionals (Flanagan, 1954). Participants are asked to recall and describe experiences in detail about which they have outright positive or negative feelings. Participants are asked to describe what exactly happened, who were involved, and what the effect of the specific incident was, on, for example, relationship satisfaction, commitment, or relationship quality. Specific incidents, both positive and negative, give insight in the content of mentor-protégé relationships and in the way mentoring relationships evolve.

Second, we need to zoom in on specific stages of the mentoring relationship. For example, we have limited insight in the endings of mentoring relationships. Previous studies showed that there are physical and psychological (e.g. jealousy, outgrew) reasons to terminate a mentoring relationship (e.g., Ragins \& Scandura, 1997). However, we lack insight into specific incidents causing a mentoring relationship to end, and behaviors for ending mentorships. It is also unclear why some social interactions at work will lead to mentoring relationships, while others will not. Once a mentoring relationship results from these social interactions, it keeps changing. When members violate norms, both mentor and protégé will reestablish a new form of mentoring relationship. However, we know little about such relational dynamics and how these influence the evolution of mentoring relationships.

\section{Mentoring schema theory}

Mentoring schema theory (Ragins \& Verbos, 2007) could be helpful in exploring the influence of members' personal history. Based on relational schemas (Baldwin, 1992; Planalp, 1985, 1987), researchers could examine how mentoring schemas influence members' behaviors in their contact with partners (Chandler et al., 2011). Mentoring schemas are "cognitive maps derived from past experiences and relationships that guide mentors' and protégés' perceptions, expectations, and behaviors in mentoring relationships" (Ragins \& Verbos, 2007, p. 101). These schemas include mental representations 
about general roles of mentors and protégés (i.e., "mentors are experts") as well as specific mental representations reflecting mentor and protégé roles in their specific relationship (i.e., "my mentor takes the lead during conversations"). It would be interesting to study how these cognitive maps relate to the evaluation of behaviors of both partners. For example, how are actions of mentors in a current mentorship affected by their own experiences as protégé? Perspectivetaking could play a role here. Perspective-taking needs a process in which meaning analysis takes place: "an implicit or explicit shift in the manner in which a situation is experienced" (Arriaga \& Rusbult, 1998, p. 929). Previous studies on perspective-taking (e.g., Batson, Early, \& Salvarani, 1997) showed that imagining how you would feel in a situation creates empathy, but also personal distress, which evokes egoistic motivation. However, imagining how the other feels produces empathy, which evokes altruistic motivation. It could be that mentors with experiences as both mentor and protégé, will be better able to imagine how the other feels, evoking altruistic motivation. Future research may examine how both perspectives lead to different motivations and behaviors of both members, and how these influence members' satisfaction.

\subsection{Underlying Developmental Mechanisms of Mentoring}

One of the most studied topics in mentoring literature is the outcomes of mentoring (Allen et al., 2008). Both formal and informal mentoring are associated with several behavioral, attitudinal, and career benefits for protégés and mentors (Allen et al., 2004; Eby, Allen, Evans, Ng, \& DuBois, 2008a; Ghosh \& Reio, 2013). However, there is criticism on studies investigating beneficial outcomes of mentoring. First, most studies use cross-sectional designs. Although these studies give insight in which key variables are related to one another, they are not suitable to prove cause-and-effect relationships. It is unclear whether positive outcomes related to mentoring are indeed a result of mentoring activities. Another explanation would be that protégés already hold such positive characteristics and work attitudes, which may be why they are selected by informal mentors in the first place (Allen et al., 2008; Ragins \& Cotton, 1993). Moreover, mentoring research has been criticized for consisting of one-shot empirical data, rather than theory-based studies. Mentoring literature lacks "an integrated research model or framework" (Burke \& McKeen, 1997, p. 44), resulting in empirical listings that show that mentoring could be useful, without providing theoretical explanations for these results: 
"findings are abundant but explanations are not" (Bozeman \& Feeney, 2007, p. 720). There is still a black box of mentoring processes and interactions. Only with a clear understanding of underlying mechanisms, we can address the question of why mentoring processes are effective. Without such models, this question is still one of the most pressing agenda items in mentoring research (Bearman, Blake-Beard, Hunt, \& Crosby, 2007). Mentoring research would benefit from studies that contribute to our understanding of the exact relationship between mentoring and positive outcomes.

\subsubsection{Mediating Factors as Explanation for Developmental Change}

In recent years, some attempts have been made to come up with explanations for the working of mentoring. These studies include mediating factors that could explain the underlying mechanism of mentoring and positive outcomes. Baranik, Roling, and Eby (2010) drew on social exchange theory and showed that perceived organizational support partly explains the relationship between supervisory mentoring and protégés' work attitudes. Perceived organizational support is a social exchange relationship between employees and their organization, and refers to employees' perceptions about the degree to which the organization cares about their well-being and values their contribution. Baranik et al. (2010) argue that mentors serve as agents of the organization, who, by providing support functions, influence protégés' perceived organizational support, which in turn predicts work attitudes such as job satisfaction and commitment. Perceived organizational support thus serves as an explanatory mechanism for understanding why certain mentoring functions predict protégé job satisfaction and commitment.

Pan, Sun, and Chow (2011) drew on personal learning perspective to explain why supervisory mentoring influences protégés' job performance and career satisfaction. They proposed that both personal learning and self-efficacy are important concepts for mentoring. They showed that supervisory mentoring leads to personal learning, which in turn predicts job performance and career satisfaction. Employees' self-efficacy has a dual moderating effect on the impact of mentoring on protégés' career outcomes.

Both studies extend our understanding of underlying mechanisms. Still, there is much work to do in uncovering such mechanisms. Next to social exchange theory and a personal learning perspective, insights from related fields could be 
useful in examining mentoring processes and mechanisms. We discuss two possible approaches to examine (1) how need-fulfillment processes in mentoring relationships are related to mentoring effectiveness, and (2) how relational dynamics in mentoring interactions constitute mentoring relationships.

\subsubsection{Future Directions: Uncovering Developmental Mechanisms}

\section{Self-determination theory}

Self-determination theory (SDT) is a theory of human motivation (Deci \& Ryan, $1985,2012)$. SDT considers people as actively engaged, growth-oriented organisms who interact with their environment and strive towards intra- and interpersonal growth. SDT has been applied in various research contexts, such as education (Vansteenkiste, Simons, Lens, Sheldon, \& Deci, 2004), health care (Ryan et al., 2008), and organizations and work (Deci, Connell, \& Ryan, 1989). The key idea of SDT is that humans have three basic needs: autonomy, competence, and relatedness. Autonomy refers to having the experience of acting with a sense of self-choice and self-determination. Note that autonomy in SDT has a different meaning than in traditional mentoring literature. Acting autonomously does not mean acting independently, but it means a sense of selfdirectedness in one's actions (Stone et al., 2009). Competence means feeling capable, and acting with a sense of confidence and effectiveness. Relatedness refers to being engaged in satisfying, encouraging relationships. According to SDT, the fulfillment of these three needs together promotes people's selfmotivation, effective functioning, and relationship satisfaction. Similar to what SDT calls innate growth tendencies of people (Deci \& Ryan, 2000), processes of development and growth are central in mentoring relationships. Accordingly, we argue that the fulfillment of autonomy, competence, and relatedness plays a crucial role in mentoring relationships, even more than it does in other work relationships (e.g., LMX).

SDT can be applied in several ways. For example, researchers could examine under which circumstances employees are motivated to perform mentoring behaviors. Second, SDT examines how the fulfillment of autonomy, competence, and relatedness relates to psychological health and well-being. In line with relational mentoring (Ragins, 2012), scholars could adopt a need-based 
approach in their studies and examine how the fulfillment of both mentors' and protégés' needs is related to relationship functioning. In a first examination of needs fulfillment in mentoring, Janssen, Van Vuuren, and De Jong (2013) examined qualitatively how protégés' needs for autonomy, competence, and relatedness are fulfilled by their developers. This study showed the importance of need-supportive developmental functions, including encouraging selfinitiation (autonomy), confirming and praising competent behaviors (competence), and intimacy and self-disclosure (relatedness). Although we assume that mentoring relationships may be especially important for meeting the need for competence, SDT research shows that the presence of support for all three needs is important. Future studies could further examine how need fulfillment processes are related to relationship functioning. Informal mentoring relationships are most likely need-driven (Ragins \& Cotton, 1999), more than other (formal) work relationships; it is therefore crucial to gain insight in the fulfillment of basic needs and the alignment between mentors and protégés in their expectations regarding needs-fulfillment. Future studies may also examine how mentors' basic needs are fulfilled by their mentoring relationships. Deci, La Guardia, Moller, Scheiner, and Ryan (2006) showed that both receiving and giving autonomy support relate to need satisfaction. Mentors who give autonomy support to their protégés may thus also experience need satisfaction. The application of SDT in mentoring research is still in its infancy (e.g., Janssen, van Vuuren, \& de Jong, 2014; Sun, Pan, \& Chow, 2014), but offers promising directions for research on mentoring mechanisms.

\section{Relational leadership theory}

A second potentially relevant research approach involves the study of mentoring microprocesses. Insights from relational leadership theory (UhlBien, 2006) could be helpful. Relational leadership "does not focus on identifying attributes of individuals involved in leadership behaviors or exchanges, but rather on the social construction processes by which certain understandings of leadership come about and are given privileged ontology" (Uhl-Bien, 2006, p. 655). While current mentoring research is most concerned with individual characteristics, cognitions, and behaviors, future research could benefit from a focus on the relational dynamics that talk mentoring relationships into being (Weick, Sutcliffe, \& Obstfeld, 2005). This enables the investigation of how relationships emerge in communication, rather than taking communication as the vehicle to express preexisting realities 
(Brummans, Cooren, Robichaud, \& Taylor, 2014; Christensen \& Cornelissen, 2011). Portraying relationships as ongoing and precarious accomplishments that are realized, experienced, and identified mainly -if not only-in communication processes (Cooren, Kuhn, Cornelissen, \& Clark, 2011) could unveil their underlying dynamics. From this perspective, mentoring is not just the result of a combination of members' individual properties, but a selforganizing process of interactions. The positions of both mentor and protégé are constructed and sustained in interaction (cf. DeRue \& Ashford, 2010). These interactions continuously define and redefine mentoring. This approach allows us to study the complex dynamics of interactions between mentor and protégé. For example, researchers could use conversation analysis to explore how agreements between mentors and protégés get negotiated, how protégés' developmental needs are diagnosed, and how developmental strategies are enacted. This way, we may get a grip on how such microprocesses contribute to developmental growth.

\subsection{Relational Motivations of Both Mentors and Protégés}

Social exchange theory (Blau, 1964; Emerson, 1976) is one of the most influential paradigms in organizational behavior literature, and also strongly influenced mentoring research. A basic assumption of this paradigm is that individuals form social relationships because they expect them to be rewarding. As such, it imposes a transactional view on relationships: There has to be a balance between the exchanged (expected) costs and benefits. Mentoring relationships are then about exchanges of support behaviors throughout the relationship (Young \& Perrewé, 2000).

Social exchange theory leads to a cognitive and instrumental view on mentoring. As Ragins and Verbos (2007) critiqued, scholars often see mentoring relationships as one-sided relationships leading to instrumental outcomes for the protégé. The influence of this view is highly visible in current mentoring literature. First, when studying how and why people engage in mentoring relationships, scholars often focus on members' attractive characteristics (Olian, Carroll, \& Giannantonio, 1993; Olian, Carroll, Giannantonio, \& Feren, 1988). The willingness to mentor is proposed to be based on a weighing of costs and benefits, a rational calculation (Ragins \& Scandura, 1999). Developmental network research also adopted this 
instrumental view on relationships. Drawing on a social exchange model, researchers form ideas of developmental networks as instrumental means for career mobility, and typically focus on the use of networks to benefit protégés' careers. As a result, relational motivations to engage in mentoring relationships, such as the need for connectedness and belonging, are neglected.

Career development is traditionally seen as an individual process, aimed at individual mastery, differentiation from others, and vertical progression. Protégés' development is optimal when the protégé is a competent and independent professional. This "show me the money approach" (Ragins and Verbos, 2007, p. 95) leaves little space for relational outcomes such as mutual growth and one's ability to function in a context of interdependence and connection (Fletcher, 1996).

Mentors' needs and benefits are usually neglected in this approach. In their meta-analysis, Allen et al. (2008) showed that mentoring research is overshadowed by single-source data, with a strong focus on protégés. As a reaction to this imbalance, some scholars recently shifted towards the mentor as a research object. For example, mentors' positive outcomes (Allen, Lentz, \& Day, 2006b; Bozionelos, 2004), negative experiences (Eby et al., 2008b), and willingness to mentor (Allen, 2003; Hartmann, Rutherford, Feinberg, \& Anderson, 2014; Van Emmerik, Baugh, \& Euwema, 2005) were studied. However, the protégé is still the primary member to include in studies, also in developmental network research (Dobrow et al., 2011). Researchers have not yet studied developers' perspectives, experiences, and expectations.

\subsubsection{Relational Mentoring Theory}

Current discourse about vocational behavior involves the importance of relationships in organizational life and increasingly focuses on relational skills and competencies, aimed at interdependence and connection with others (Blustein, 2011; Blustein, Schultheiss, \& Flum, 2004; Flum, 2001; Hall, 1996b). In the upcoming stream of Positive Organizational Scholarship (Cameron, Dutton, \& Quinn, 2003; Cameron \& Spreitzer, 2011) and inspired by Stone Center Relational Cultural Theory (Jordan, Kaplan, Miller, Stiver, \& Surrey, 1991; Miller, 1976), relational mentoring theory questions instrumental approaches towards mentoring held by traditional mentoring literature, and provides an alternative lens for looking at mentoring (Ragins and Verbos, 
2007). The theorizing of relational mentoring underlines the positive, mutual developmental experience of being in a connection, rather than exchanges of resources based on expected benefits. Relational mentoring shows that current studies ignore a large array of phenomena associated with mentoring. For example, traditional mentoring research tends to ignore relational skills such as empathy, authenticity, and vulnerability, while these are special research areas in relational mentoring (Fletcher \& Ragins, 2007).

In line with the "positive deviance" of Positive Organizational Scholarship, relational mentoring focuses on so called "high-quality mentoring relationships". However, concepts of relational mentoring should not necessarily be limited to the study of high-quality mentoring relationships. Ideas coming from relational mentoring could inspire scholars to broaden their view when studying traditional mentoring relationships. We agree with Allen and Eby (2007b) that the need to belong could be a basic motivational factor to engage in mentoring relationships. Relatedness is then seen as a key need for both mentors and protégés.

Integrating a relational perspective on mentoring would lead to a balanced view on mentoring. First, insights from relational mentoring theory could broaden our scope when examining motives of members to engage in mentoring relationships, and mentoring outcomes. Until now, most researchers have used social exchange theory to explain why mentors and protégés engage in mentoring relationships. However, this leaves little space for motives such as human strivings for connection and the need to belong. Second, relational mentoring stresses the importance of seeing mentoring as a mutual relationship. Incorporating a relational approach would shed light on the interplay between mentors and protégés. In the following sections, we show how these ideas from relational mentoring theory can help us to create a balanced view on mentoring, with room for relational processes and motivations, for mentors' perspectives, and for dyadic processes.

\subsubsection{Future Directions: Towards a Balanced View on Mentoring}

\section{The need to belong as motivational factor}

In their theoretical contribution, Allen and Eby (2007b) showed that their idea of how the need to belong serves as a driving mechanism for the engagement in 
mentoring relationships. A felt sense of belonging makes being connected in a mentoring relationship effective in that mentoring processes create positive affective, cognitive, and behavioral outcomes. This fulfillment of the need to belong is comparable to what SDT calls relatedness. According to SDT, this need to feel connected to others is one of people's basic needs. Especially for protégés who are newcomers in their organizations, it may be important to feel a sense of connectedness with others (e.g. with their mentors). SDT could inspire scholars to focus on relatedness as a central aspect in mentoring relationships. For example, Janssen et al. (2013) highlighted the importance of including support functions aimed at relatedness in their study about developmental relationships, by adopting a SDT perspective. Their SDT framework complements Kram's (1985) classic set of career and psychosocial support functions. The SDT categories competence and autonomy have been included in previous mentoring studies, but relatedness has mostly been overlooked. Although relatedness functions can be tracked in Kram's (1985) support functions (e.g. friendship and protection), Janssen et al. (2013) showed a broader picture of belonging and interpersonal sensitivity, with functions such as intimacy, self-disclosure, and caring. These outcomes underline the importance of the need for relatedness in mentoring relationships. Future research could more closely examine how mentors' needs for relatedness are fulfilled in their mentoring relationships. For example, Janssen et al. (2014) show how relational motivations (e.g. the need to form and maintain close relationships with others) play a role in mentors' motives to mentor.

In addition, future studies could deepen our understanding of relational functions and processes of mentoring, for example by focusing on processes such as personal learning, mutual respect, and identity formation (Ragins, 2012). Especially when including developers from various social spheres, the diversity of support functions provided could be large. Future studies could explore if nonwork developers, for example, mainly provide support functions aimed at relatedness, while work developers mainly focus on competence.

\section{The mentor's needs}

Although progress is made in getting insight in mentors' perspectives, this line of research could be further extended. For example, scholars could examine developers' needs and motives for engaging in a developmental relationship. Again, SDT could be helpful to study both members' motives to engage in 
mentoring relationships (Haggard et al., 2011; Janssen et al., 2014). SDT sees motivation as a continuum from noninternalized (controlled) to internalized (autonomous) reasons. According to SDT, both contextual and interpersonal factors can promote the internalization of external requirements into autonomous motivations. The more internalized an extrinsic motivation, the more autonomous the person will be when performing the behaviors (Deci \& Ryan, 1985). As shown by Janssen et al. (2014), this means that some informal mentors have mainly extrinsic motivations to help the protégé (e.g. "I do this because it is part of my job"), while others have mainly intrinsic motivations (e.g. "I enjoy doing this"). Researchers may extend this line of research by examining motives of for example formal mentors. These mentors are likely to describe different extrinsic motivations, as previous studies using SDT show that more controlling social contexts (e.g. formal mentoring programs with prescribed formats) may inhibit the internalization process (Deci \& Ryan, 2000). SDT could also be helpful when examining mentors' needs. In their study, Janssen et al. (2013) showed how being engaged in developmental relationships helps protégés to fulfill their needs for autonomy, competence, and relatedness. However, it is likely that mentors' basic needs are also fulfilled by their interactions with protégés. Future research could examine how mentors' need fulfillments are similar to or different from those of protégés.

\section{Mutuality in mentoring relationships}

Although scholars increasingly include the mentor as a research object, developmental relationships are mostly still conceptualized and measured as if there are two detached actors, instead of focusing on the interaction between those two actors (Dobrow et al., 2011). Most mentoring studies focus on members' individual behaviors, attitudes, or characteristics, instead of their interactions. Concepts of relational mentoring could inspire researchers to focus on both members. This theory sees mutuality as central in mentoring processes, and therefore understanding the concept of mentoring needs a direct focus on the interaction between both members. One way of carrying out this relational focus in studies is by sampling both members. In their review, Wanberg, Welsh, and Hezlett (2003) encourage scholars to adopt a dyadic approach to data collection and analysis. However, only few mentoring researchers actually included such a dyadic approach (Allen et al., 2008). We discuss some examples to give an outline of this emerging research line. Although studies in which one member of the dyad provides information about 
both members could also be seen as dyadic studies (e.g., Kao, Rogers, Spitzmueller, Lin, \& Lin, 2014), we only discuss studies in which the sampling procedure of the study involves both members of the relationship.

Researchers have predominantly conducted dyadic studies in which both protégés and mentors report on their own and partner's individual characteristics. This way, similarity and differences between those characteristics can be calculated. For example, (Allen et al., 2006a) examined design features of formal mentoring programs and perceived program effectiveness from both mentor and protégé perspectives. Specifically, they examined how program experiences of the protégé (e.g. input into the mentoring process, program understanding, and perceived mentor commitment) relate to mentor perceptions of program effectiveness. They found that protégés' reports of mentor commitment and program understanding related to perceived program effectiveness. Godshalk and Sosik (2000) examined if the degree of similarity between mentor and protégé about mentor transformational leadership behavior would influence the perceived quality of mentoring relationships. Based on difference scores between protégés and mentors, they classified mentors as (1) underestimators of their transformational leadership behavior, (2) being in agreement with their protégé, or (3) overestimators of their transformational leadership behavior. They found that mentors who agree with their protégés were indeed associated with higher levels of relationship effectiveness and psychosocial support, compared to mentors who were overestimators. However, contrary to their hypotheses, underestimators were associated with the highest quality of mentoring relationships. In another study, Godshalk and Sosik (2003) examined whether mentor-protégé agreement about learning goal orientation would influence the level of mentoring functions received by the protégé. Results showed that protégés who hold high levels of learning goal orientation similar to their mentor were associated with the highest level of psychosocial support.

Although these studies provide insight in how similarity of mentors' and protégés' characteristics influence perceived quality and relationship effectiveness, they have two limitations. First, these studies focused on individual characteristics only, such as behaviors, attitudes, and demographics. They do not give insight in how both members agree or differ in relationship 
properties. Only a handful of studies have included relational characteristics, such as relationship length (Waters, 2004), loyalty (Raabe \& Beehr, 2003), frequency of meetings (Waters, 2004), and contact time with the mentoring partner (Lankau, Riordan, \& Thomas, 2005). Second, most often only group differences between mentors and protégés were analyzed. Protégés' responses as a group are compared with mentors' responses as a group. Although this provides insight in how, for example, perceptions of protégés as a group differ from mentors' perceptions, these results do not necessarily mean that these differences occur within any particular mentoring relationship (cf. Maguire, 1999).

As we can see, scholars mostly addressed mutuality by including individual characteristics of both members in their studies, rather than studying their relational properties. Although progress is made in this way, many dyadic questions are still left out. A dyadic approach which also addresses relational characteristics would allow for a better understanding of the factors involved in the process of mentoring.

\subsection{Concluding Notes}

The purpose of this article was to review prior research on informal mentoring at work and to identify research opportunities for future research. Based on two basic premises of interpersonal relationships we explored research areas that represent fruitful avenues for future research. We discussed how current developments in mentoring literature can cultivate these research areas and thus can contribute to a fuller picture of the concept of mentoring. We showed how insights from adjacent fields can contribute to the advancement of mentoring research. In this final section, main conclusions from this review are drawn.

First, this review shows that the context of mentoring deserves more research attention. Although developmental network researchers incorporate multiple developmental relationships in their studies, other work relationships and the organizational context are most often left out. Moreover, most developmental network research focuses on the network as a whole, and focuses less on the specific individual dyads within such a network. This review offers various suggestions to extend the developmental network approach. We believe it 
would be fruitful if mentoring research zooms in onto the specific dyads within networks, to carefully examine (e.g. with in-depth studies) the circumstances of and processes within these various dyads. This will lead to a better understanding of the broader context in which mentoring processes are embedded, and the influence of how a context sets boundaries and provides opportunities for the occurrence of mentoring processes. It also provides insight into how these mentoring processes influence their context.

Second, this review shows that only few mentoring studies incorporate temporal influences in their conceptualization and measurement. As a result, there is limited knowledge of how mentoring processes evolve, how interpersonal processes between mentors and protégés unfold, and how previous mentoring behaviors influence one's current mentoring behaviors. We discussed various research suggestions to include temporal factors in mentoring studies, in both conceptualizations and measurements. These suggestions will lead to a better understanding of the full life cycle of mentoring relationships and thereby will enable the broader contextualization for studies focusing on one mentoring phase.

Third, mentoring literature has a strong focus on studying outcomes of mentoring. However, it provides little insight into the underlying developmental mechanisms that cause these outcomes. Future research needs to illuminate the processes that form the basis of developmental changes. We suggest that researchers adopt need-perspectives (e.g. self-determination theory) in their conceptualizations of underlying mechanisms, in addition to social exchange paradigms. Although social exchange rules apply to mentors' and protégés' motives to engage in mentoring relationships, other motivations may be important as well.

Fourth and finally, this review shows that more research is needed that incorporates both members in conceptualizations, sampling, measurements, and analyses. For example, we have shown how insights from relational mentoring theory could be helpful in examining relational motivations of both members. Also, it would be valuable if researchers invest in conducting observational studies, as this would permit scholars to get a view of how both members enact their mentoring relationship. 
Apart from the conclusions directly derived from our review, we call for taking alternative ontological assumptions about mentoring into consideration. We chose to review the available literature and make suggestions to move on from there, rather than stressing the relevance of the alternative paradigmatic conceptualization of relationships of process studies. In the concluding section of this article, we want to come back to this blind spot in the literature and sketch two possible starting points for exploring a more constructionist approach to mentoring studies. First, we encourage colleagues in the field of mentoring studies to familiarize themselves with the process approach and the questions it poses. This exploration challenges basic assumptions of a more traditional take on the social sciences from a constructionist view (Berger \& Luckmann, 1966; Burrell \& Morgan, 1979; Langley \& Tsoukas, 2010; Rescher, 1996; Van de Ven \& Poole, 2005; Weick, 1995). A good starting point could be to think through the three questions Pratt (2012) posed in rethinking the concept of 'identity' as a construction process, but now for (mentoring) relationships. First, can we meaningfully talk about relationships and process (stressing change, flux and becoming rather than cohesive and enduring characteristics)? By answering this question with 'yes', one would learn to "view those things that appear stable and persistent as actually comprised of multitude of activities, expressions and small (or not so small) changes" (Pratt, 2012, p. 24). Second, if we can meaningfully talk about (mentoring) relationships and process, how should we talk about them? This would draw attention to new vocabulary to describe how people engage in relationships, like doing relationships, relationship construction, and relationship work (cf. Pratt, 2012, pp. 28-30). By taking this perspective -largely overlooked in mentoring research-studies would stress how individuals participate actively in practicing relationships rather than conforming to relationship information given by others. Third, if we know how to talk about (mentoring) relationship processes, what is missing from current conversations? The underexamined processes Pratt (2012) identified (i.e., intertwining dynamics of expecting, accepting, expressing, and reflecting) could be very informative for mentoring studies as well. By exploring such questions, scholars could evaluate their position within this discussion.

Second, next to conceptual explorations of a process philosophy, a more practical starting point would be considering constructionist research designs for studying mentoring. Several authors (Hernes \& Weik, 2007; Van de Ven \& 
Poole, 2005) propose taxonomies of approaches in which entity and process are two ends of a continuum. As our review has shown, the entity approaches are well-established. We invite scholars to pose research questions about mentoring relationships within the more processual quadrants, which opens up new avenues for research. For example, studies on relationships as process (approach III, in Van de Ven and Poole, 2005) enables a sensemaking perspective of the ways in which people enact scripts that inform their expectations and hopes for the mentoring relationship. Through these scripts about what it means to be a mentor or a protégé, meaningful interactions emerge. Alternatively, stressing "process as connectivity" (Endegenous view 1, in Hernes and Weik, 2007) takes the mentoring relationship as a process of connecting which evolves and stabilizes. This stresses the co-construction of relationships, avoiding the trap of (in Alfred Whitehead's terms) the fallacy of misplaced concreteness and thereby make the relationship (in Bruno Latour's terms) the explanandum (what has to be explained) rather than the explanans (what explains). Exploration of transformation processes of informal contacts into mentoring relationships may explain how a historically filled label influences their interactions. In all, this sketchy overview of available process approaches points in new directions for mentoring studies which fundamentally could redefine the underlying assumptions of what it is to engage in the kind of relationships people happen to call developmental relationships. 


\section{CHAPTER 3}

\section{Identifying support functions in developmental relationships: A self-determination perspective}

Janssen, S., Van Vuuren, M., \& De Jong, M. D. T. (2013). Identifying support functions in developmental relationships: A self-determination perspective. Journal of Vocational Behavior, 82, 20-29. 
"In the beginning, my two senior colleagues were very important to me. My peer colleague quitted after a couple of months. And I got insecure: he opted out, so am I next? They taught me what is important as an alderman. It's a strange field. I mean, you just paid backyour student loan and then you're responsible for a budget of a couple of millions. I had no idea where to start. And they really shaped me. And I think when I look back, they shaped me in how I am now: as advisor, politician, but also in many ways as a person."

-Anonymous protégé

\subsection{Introduction}

Employees who are ambitious and want to increase their professionalism benefit from the help of others. Therefore, researchers and practitioners have paid much attention to the relationships that promote individuals' professional and personal growth, in particular, to mentorships. The prevalence of formal mentoring programs and the flourishing field of mentoring research reflect the importance placed on mentoring relationships at work.

In the last decade, mentoring researchers have broadened their scope to developmental networks (Higgins \& Kram, 2001) acknowledging that one specific mentorship may not provide everything a protégé needs. In developmental networks, attention is paid to various developmental relationships, from traditional mentorships to relationships that only provide limited developmental support. This "microsystem perspective" (Chandler et al., 2011) has proven its usefulness in the mentoring literature, especially by extending our understanding of factors that influence the structure of developmental networks (Dobrow et al., 2011). However, insight into the specific content and full range of processes in developmental networks is still limited (Cotton et al., 2011). In this paper, we contribute to the understanding of how protégés perceive the specific types of support provided by intraorganizational and extraorganizational work developers. By applying selfdetermination theory (SDT), we present a theory-based framework for identifying these support functions.

This study contributes to mentoring theory in two ways. First, previous qualitative research has shown that the content of exchanges between parties 
in developmental networks is broader than in traditional mentoring dyads (Cotton et al., 2011; Murphy \& Kram, 2010). These studies added new subfunctions to Kram's (1985) original mentoring functions, showing that the generalizability of mentoring support functions to other developmental relationships may be more limited than previously thought. This research line is still in its infancy, and we aim to contribute to a detailed description of the full range of developmental support functions in developmental networks.

Second, we suggest the adoption of SDT as a framework for identifying developmental support functions. This adoption will contribute to a comprehensive view regarding the types of support provided by developmental relationships. Central to SDT is the fulfillment of people's basic needs, which are autonomy, competence, and relatedness (Deci \& Ryan, 1985). The use of SDT in this study is in response to the recent call of relational mentoring researchers (Ragins \& Verbos, 2007) to include not only processes and support functions aimed at individual mastery (i.e., autonomy and competence), but also those aimed at interdependence with others (i.e., relatedness). A better understanding of these three needs together, will provide new insights into the types of support that are provided by developers.

Our research question is the following: How are protégés' needs for autonomy, competence, and relatedness fulfilled by their developers? To address this question, we conducted a qualitative study among protégés from various organizations. Before we describe the design and results of our study, we will first discuss the theoretical background.

\subsection{Theoretical Background}

\subsubsection{Developmental Support Functions}

In her seminal work, Kram (1985) identified a set of mentoring functions and classified them into the following two broad categories: (1) career support, which includes sponsorship, exposure and visibility, coaching, protection, and challenging assignments, and (2) psychosocial support, which includes role modeling, acceptance and confirmation, counseling, and friendship. This set of mentoring functions created the foundation for a wide range of mentoring studies. Yet, it is still unknown how these support functions change when a 
broader range of relationships in addition to the traditional mentor-protégé relationship is included. In developmental network research, all people who are "taking an active interest in and action to advance the protégé's career by providing developmental assistance" are viewed as developers (Higgins \& Kram, 2001, p. 268). Studies that examine the generalizability of traditional mentoring functions show that including such developers adds several subfunctions to Kram's (1985) classic set. For example, Murphy and Kram (2010) examined the support functions of work and non-work developers and added subfunctions, such as encouragement and emotional support, and worklife interface failure. Further, Cotton et al. (2011) showed the importance of freedom and opportunity for skill development, and inspiration and motivation. These studies show the relevance of extending traditional mentoring functions to developmental networks. This study aims to contribute to this line of research by qualitatively examining protégés' developmental networks to identify specific types of developmental support functions. We classify these support functions using SDT, as we believe this will lead to a comprehensive view of developmental support functions.

\subsubsection{Self-Determination Theory}

SDT is a theory of human motivation (Deci \& Ryan, 1985) that suggests that humans have three basic needs: autonomy, competence, and relatedness. Autonomy refers to having the experience of acting with a sense of choice, volition, and self-determination. Note that a SDT perspective on autonomy differs from "independence". Acting autonomously does not rule out a sense of relatedness, but means a sense of self-directedness in one's actions (Stone et al., 2009). Competence means feeling capable and refers to a felt sense of confidence and effectiveness during actions. Individuals experience competence when they feel that they can influence important outcomes. Finally, individuals experience relatedness when they have satisfying, supportive social relationships. Relatedness reflects the need to feel connected, as in to love and care, and to be loved and cared for (Baumeister \& Leary, 1995). Individuals experience relatedness when they have satisfying, supportive social relationships. The central idea of SDT is that opportunities to satisfy these three basic needs facilitate people's self-motivation and effective functioning. SDT conceptualizes motivation as a continuum ranging from non-internalized (controlled) to internalized (autonomous) reasons. When people internalize external requirements into autonomous motivations, they will be more self- 
determined and motivated. According to SDT, both contextual and intrapersonal factors can facilitate this internalization process. In organizational research, one of the important questions for SDT is how work environments can best support psychological need satisfaction (Sheldon, Turban, Brown, Barrick, \& Judge, 2003). Recently, Haggard, Dougherty, Turban, and Wilbanks (2011) suggested to apply SDT to mentoring research. In this study, we examine how developers can support their protégés' psychological need satisfaction. For example, a mentor who understands the protégé's perspective, provides choice, and encourages self-initiation, is autonomy supportive and could facilitate the protégé's self-motivation and performance. To our knowledge, this paper is the first to empirically evaluate the usefulness of SDT in mentoring research.

The application of SDT could broaden the scope mentoring research.

Traditionally, vocational psychology has conceptualized career development as a process leading to individual mastery, differentiation from others, and vertical progression. In mentoring research, this view has led to a strong focus on support functions that promote competence and independence. However, current discourse about vocational behavior is concerned with relational dimensions, such as human strivings for attachment, connection, affirmation, and support (Blustein, 2011; Blustein et al., 2004; Flum, 2001; Hall, 1996a). The call for a relational perspective on mentoring (Ragins \& Verbos, 2007) resonates with a basic feature of SDT, i.e., the holistic and theory-based understanding of support functions that define developmental relationships, as it examines the fulfillment of the three basic needs - autonomy, competence, and relatedness - together.

\subsection{Method}

\subsubsection{Participants}

A total of 18 participants from 17 organizations based in the Netherlands were selected using purposive sampling (Patton, 1990). Participants had to meet four selection criteria to be invited. First, we aimed at white-collar employees holding clerical and professional positions, which limited the possibility of varied occupational group characteristics that might influence the nature of developmental relationships. Second, participants had to have at least 18 
months of working experience, as we assumed that this period was sufficient for developing meaningful work relationships. Third, we strived for a balance between males and females. Last, we selected participants across three career age groups: early (age: 25 - 35 years), middle (age: 36 - 45 years), and late (age: 46 - 65 years) (following Kram \& Isabella, 1985). This full career perspective (Cotton et al., 2011) provided us with the opportunity to focus on both current and past mentorships. All of the invited participants agreed to take part in this study. Participants were not rewarded for their participation.

All participants (10 men, 8 women) worked full-time and held at least an educational level of a four-year college degree. Participants were aged between 26 and 64 years (mean age $=38$ years). Most participants were White $(N=17)$. We interviewed 7 participants ( 5 women) in the early career stage, 6 participants ( 2 women) in the middle career stage, and 5 participants ( 1 woman) in the late career stage. Average tenure within an organization was 5.7 years, with a range from 18 months to 29 years, and average job tenure was 3 years. The organizations represented a diverse range of industries, including banking, consulting and municipal government. Employees represented job categories such as General Manager, Communications Manager, and Junior Consultant. None of the participants were involved in a formal mentoring program.

\subsubsection{Semi-Structured Interviews}

Since this is the first study to apply SDT in a mentoring context, there were no validated scales or taxonomies to rely on. Therefore, a qualitative approach is most appropriate. Interviews enabled us to get a deep understanding of how protégés get support from their developers. During the interviews, the first author invited participants to share their career history in order to explore their developmental network(s). Interviews typically lasted $90 \mathrm{~min}$. All of the interviews were audiotaped with permission. Participants were assured that their responses would remain confidential and anonymous.

We started each interview by asking the participant to describe his or her job and to discuss daily work activities. Then, we asked the participant to describe his or her career history, from leaving school to the present day. In this way, we gained insight in the important steps in each participant's career, and a broader view of the context in which the participant worked. Next, we focused on the 
participant's past and current developmental networks. Following the definition of developmental networks by Higgins and Kram (2001, p. 268), we asked the participant to name a set of people, "who you believe (currently or in the past) takes or took an active interest in and concerted action to advance your career." We encouraged the participant to think broadly when considering his or her developmental relationships at work (i.e., "they may be people with whom you currently work, have worked with in the past, and from within your organization, or outside"). Participants were not limited in the number of developers they could mention. In this way, we were able to get a deep understanding of the full range of developers who are perceived to give support during a protégé's career.

We used a graphic interview method for elicitation purposes. We asked the participant to write down the names or pseudonyms of these persons on cards and then to arrange the cards in a relational map (Bagnoli, 2009), consisting of an inner and outer circle. We posed the following question: "If you imagine standing here in the middle, how would you order those people you mentioned, such that their positions in the circles reflect their importance to your career?" After the participant had placed the cards, we asked for an explanation regarding the position of the cards. To help participants focus on concrete examples, we asked for examples of how the developers provided support. As we did not want to prime participants' answers with SDT concepts, we did not ask whether the developers fulfilled the concepts of autonomy, competence, and relatedness.

\subsubsection{Data Analysis Procedure}

All of the interviews were transcribed verbatim, leading to 133 transcript pages, and were analyzed with the help of ATLAS.ti software for tracking code creation. Using a multistep content-analytic procedure, we analyzed the data with three coding rounds. In the first round of coding, the first author read the transcripts and generated a list of comments that reflected the ways that developers fulfill protégés' needs for autonomy, competence, and relatedness. Next, the second author assigned the selected comments to the three SDT categories (autonomy, competence, and relatedness). In the next round of coding, both researchers looked for subcategories in the data while keeping an open discussion regarding the categorization of the comments. These subcategories were then compared with the need-supportive behaviors from 
the existing literature regarding SDT (e.g., La Guardia \& Patrick, 2008; Stone et al., 2009). Additionally, the researchers searched for words such as self, own, want (autonomy), knowledge, experience, can (competence) together, both, and common (relatedness) in the transcripts. Applying an iterative procedure, we moved back and forth between the data and literature on SDT, and added to and adjusted our framework when necessary. The resulting subcategories were labeled to capture the meaning reflected by the group of comments (e.g., "Creating Freedom" as a subcategory of "Autonomy"). All of the (sub)categories were then carefully defined in a codebook. Since the purpose of our analysis was to look for common ideas and patterns in participants' responses, (sub)categories represented by a single comment made by one participant were deleted from further analyses.

In the final coding round, the codebook was given to an independent coder. This coder recategorized each of the comments into the defined subcategories. This coder recategorized each of the comments into the defined subcategories. This independent coding resulted in initial kappas of .60 (autonomy), .80 (competence), and .72 (relatedness). After extensive discussion with the first author and several adjustments to the classification of comments, the (unweighted) kappas increased to .92 (autonomy), 1.00 (competence), and .93 (relatedness). The quotes presented in the Results section are illustrative of the 18 interviews.

\subsection{Results}

In total, 95 developers were identified. The average number of developers per participant was 5.28 (SD = 3.64). The smallest developmental network had 1 member, and the largest had 15 members. Interestingly, several participants addressed the importance of negative developers, even though the interview questions focused on positive developmental relationships. These negative examples served as role models in a different way, in that they were examples of how someone would not want to behave (cf. Murphy \& Kram, 2010). We will discuss the ways that developmental partners fulfilled the three needs by distinguishing between several forms of developmental support. 


\subsubsection{Autonomy Support}

In SDT, autonomy support is obvious when need-supportive partners actively try to understand a person's interests, preferences, and perspectives (La Guardia \& Patrick, 2008). Our analysis revealed that developers respond to protégés' initiatives and encourage protégés' exploration. Table 3.1 shows the types of autonomy support that is provided by developers.

\section{Creating freedom}

Participants often stated that their developers were persons who provided them with a sense of freedom. Protégés experienced freedom in the nonprescriptive advice provided by their developers, in the freedom that their developers gave them to perform their jobs, and in the ways they felt free to develop and express their own opinions in discussions. One protégé noted that he preferred the way that his informal mentor provided advice compared to his supervisor because of the supervisor's directive style:

"He (developer) had an easy manner. He just told me some things about home, or about life, and we chatted a bit. She (supervisor) had a more directed style. You started a conversation and in the end, so to speak, she had a training company's brochure for you."

Consistent with the literature regarding autonomy support (e.g., Gagné \& Deci, 2005; La Guardia \& Patrick, 2008), negative relationships involved developers who controlled their protégés:

"Well, in my second job, my supervisor was very important but in a negative way. From her, I learned everything about how I don't want to supervise. I was under strict supervision, everything had to be done her way. It was a real straitjacket."

\section{Encouraging self-initiation}

Another form of autonomy support discussed by the participants was encouraging protégés' self-initiation. Participants described how their developers encouraged them to act in ways that they had never done before (e.g., apply for a job or participate in new projects), even if they hesitated to do so: 
Table 3.1 Results of the Content Analysis for Developers' Autonomy Supportive Behavior

\begin{tabular}{|c|c|c|}
\hline Category & Definition & Sample comments \\
\hline $\begin{array}{l}\text { Creating } \\
\text { freedom } \\
18 \text { comments }\end{array}$ & $\begin{array}{l}\text { Developer provides } \\
\text { the protégé with the } \\
\text { feeling that (s)he has } \\
\text { the right to do or say } \\
\text { what (s)he wants } \\
\text { without being } \\
\text { controlled }\end{array}$ & $\begin{array}{l}\text { For me, an informal mentor is someone who does not have an opinion about } \\
\text { what you should do; rather, based on your own strengths, the mentor helps } \\
\text { you make your own choices without exerting pressure or saying what you } \\
\text { should do }\end{array}$ \\
\hline $\begin{array}{l}\text { Encouraging } \\
\text { self- } \\
\text { initiation } \\
8 \text { comments }\end{array}$ & $\begin{array}{l}\text { Developer persuades } \\
\text { the protégé to decide } \\
\text { and act on his/her } \\
\text { own, and to engage in } \\
\text { new actions }\end{array}$ & $\begin{array}{l}\text { She said to do other things and to do crazy things. Organize something. Yeah, } \\
\text { she was a creative person and that helped me. It stimulated my own } \\
\text { creativity. Also, in my own workshops, I do something that is completely } \\
\text { different from what you normally do in workshops. So, I try to do things a } \\
\text { little bit differently. }\end{array}$ \\
\hline $\begin{array}{l}\text { Congruency } \\
\text { with } \\
\text { personal } \\
\text { values } \\
3 \text { comments }\end{array}$ & $\begin{array}{l}\text { Developer helps the } \\
\text { protégé decide } \\
\text { whether the behavior } \\
\text { (s)he is performing is } \\
\text { in line with his/her } \\
\text { own interests }\end{array}$ & $\begin{array}{l}\text { He taught me to think of what was important, that I had to look back at my } \\
\text { career and think about what suits me, what makes me enthusiastic. }\end{array}$ \\
\hline $\begin{array}{l}\text { Confirming } \\
\text { and praising } \\
\text { autonomy } \\
3 \text { comments }\end{array}$ & $\begin{array}{l}\text { Developer shows } \\
\text { approval of or } \\
\text { admiration for the } \\
\text { autonomous behavior } \\
\text { of the protégé }\end{array}$ & $\begin{array}{l}\text { I went to a conference, and I wrote some notes for practices on paper (and) } \\
\text { sent these notes to everyone. Then, (developer) came to me, and said: Wow, } \\
\text { this is cool. This really made me happy. It is so good that you did this. I used } \\
\text { that freedom, which was then rewarded. }\end{array}$ \\
\hline $\begin{array}{l}\text { Emulating } \\
\text { autonomous } \\
\text { behavior } \\
3 \text { comments }\end{array}$ & $\begin{array}{l}\text { Developer is admired } \\
\text { by the protégé } \\
\text { because (s)he makes } \\
\text { his/her own } \\
\text { decisions without } \\
\text { being controlled by } \\
\text { anyone else, and the } \\
\text { protégé tries to copy } \\
\text { this }\end{array}$ & $\begin{array}{l}\text { She was an incredible, atypical ...creative nonbureaucrat. She opposed } \\
\text { everything, did everything differently from how it was or should be done } \\
\text { within the government, and she succeeded. Because of her creative way of } \\
\text { thinking, it became ok to go left when } 80 \% \text { of the group went to the right. } \\
\text { That inspired me. }\end{array}$ \\
\hline
\end{tabular}

"She really encouraged me to do things by myself, besides my work at (organization). I developed a workshop on my own and provided training at four or five other organizations and she encouraged me to do so. When I worried about going to the Chamber of Commerce to arrange things, she suggested that I could begin by providing these trainings for book tokens. Then, I thought: Yeah, why not? I'll try it!"

\section{Congruency with personal values}

According to SDT, self-determined employees engage in their work for several reasons, including integrated ones, such as the value served by a particular behavior being consistent with other personally important values. Developers 
help their protégés by encouraging to reflect on and assess whether their behavior aligns with their personal values. Participants described how developers encouraged these reflections: "He would state that this way of working was my style, or he would pose questions such as: What gets you really enthusiastic?" Protégés in the older age groups might need this form of autonomy support less, as the following quote from a participant in the middle age group reflects:

"I have a few people that I can consult. However, most of the time, I do this when I have already made a choice, and then I test whether this was actually the correct choice. In the beginning of my career, there was a contrast in experience that meant I really needed to ask for advice. But now, I am someone who does, thinks, deduces, and then asks people: Is this correct? Is this my style?"

\section{Confirming and praising autonomy}

Protégés experience appreciation of their autonomous behavior from their developers. Developers may note the autonomous behavior of their protégés and then encourage them to behave in this way, by both confirming and praising their protégés' autonomous behavior. As one protégé noted,

"And he was also affirmative. He said to me: In this way, you stand out. This is different from how other people will do it. Here, you have your own personal approach ... He also said: This is correct. You are on the right track."

\section{Emulating autonomous behavior}

Lastly, protégés see their developers as role models whose behavior reflects autonomy. By observing their developers, protégés develop tacit knowledge regarding how autonomous people behave, which they can use in their own roles (Ibarra, 1999) by copying the developers' behavior: "My developers are completely different. They have one thing in common and that is their passion gained from their own values. From their own, authentic, self-will. Yeah, I think that is the correct word. I admire their authenticity."

\subsubsection{Competence Support}

Developmental relationships are important for meeting competence support needs, as reflected by Kram's (1985) subfunctions of career support. Table 3.2 
shows several ways that developers provide clear, consistent, and reasonable expectations, which support competence needs (La Guardia \& Patrick, 2008).

\section{Emulating effective behaviors}

Previous research shows that protégés try to copy the career behavior of their developers (Kram, 1985; Murphy \& Kram, 2010). Also in the current study, participants reported several ways in which their developers serve as role models whose behavior reflects competence. Participants discussed how they admire their senior developers' positions, experiences, and skills. Some of the quotes in this category involved developers such as CEOs or important persons in the field, with whom there was no reciprocal relationship: "I see him for about one hour a month, and we have email contact, but he is the one I appreciate the most as an ideal model." When protégés do not have a role model, they express that they miss this type of developer:

"This (organization) is a bit disappointing. I miss interacting with a person who inspires me. I don't have that kind of person here. I would like to know someone who is five, six, or seven years further than I am in this organization."

\section{Familiarizing with the working environment}

Employees have to learn the ropes of an organization. Protégés discussed how their developers helped them navigate in the organizations correctly. Developers told their protégés to put events in perspective, thereby familiarizing the protégés with the attitudes within an organization or work field: "This is just the way it is done here. Don't get upset about that." Compared to the visibility and exposure functions reported in previous mentoring studies (Kram, 1985; Murphy \& Kram, 2010), data suggest that developers introduce their protégés to the field or organization by providing the protégés with opportunities to show competence. The following quote is an example of how a protégé earned respect because her developer familiarized her with several projects:

"He took me along as a junior-consultant. He asked me to join him when he went to a client. I was the only junior-consultant who didn't have time for the orientation course because of all the projects I was involved with. I 
immediately earned the respect of my colleagues: Oh, she is good because she already has clients and works claimable hours."

Participants discussed their visibility with peers and provided examples of opportunities created by developers to prove their competence to seniors in the organizations. Negative developers did not introduce their protégés into the organization or work field, which caused the protégés to be overwhelmed by challenges and tasks: "I was thrown in at the deep end. I mean, he (supervisor) has not helped me, in my opinion."

\section{Confirming and praising competence}

Participants discussed the various ways that their developers showed appreciative behaviors. Protégés are rewarded by their developers with kind words and other informal rewards:

"When I left, there was no money for a farewell drink but he gave me a big bouquet of flowers with a card that thanked me for my quickness, understanding, profundity, and those kinds of things. He was good at saying: This is what you do well. This is your strength."

Moreover, developers provide protégés with a feeling of self-confidence when they are performing their jobs. In particular, protégés at the beginning of their career are likely to be insecure about their performance. Participants discussed how their developers helped them being positive about their performance and having faith in their success during a certain task. As one protégé noted: "I often thought: am I good enough to do this? There are huge differences in the levels of expertise between mathematicians and because of him (developer), I thought: Well, at least I can try!" Lastly, developers often praised protégés in public, which is comparable to Kram's (1985) sponsorship function:

"She spoke very appreciatively of me. I liked that. She gave me confidence by saying to others that if I participated in their projects, they would know for sure that the projects would be successful and that it would even go one step further than that."

This public support of protégés also occurred when developers recommended protégés for promotions or other jobs in discussions with (other) supervisors: 
"She is always willing to put in a good word for me to other managers, especially when I am looking for something new."

\section{Accepting one's own incompetence}

Another way to show competence support occurs when developers help protégés accept their own incompetence: "He helped me become self-satisfied. To find certain explanations but also to accept some things." Stating that the protégé does not have to be perfect might sound like a paradoxical way of providing competence support, but, in doing so, the developer provides the protégé with reasonable expectations. In this way, developers help protégés avoid becoming overwhelmed by their job requirements.

\section{Stimulating continuous development}

While acceptance of one's weaknesses was deemed important, a focus on development of protégés' competencies remained key. Some participants mentioned that their developers continuously stimulated them to work harder, aim for better results, and learn new skills: "He repeatedly got me out of my comfort zone. Every time I thought that I got it right, he would come up with something else." Though this 'pushing the boundaries' behavior from developers might contradict the principles of autonomy support, it seems to mobilize the protégés' resources (La Guardia \& Patrick, 2008), creating a sense of competence.

\section{Problem solving}

Protégés received help from their developers during difficult times, such as when they are experiencing problems at work or get stuck in a job. By helping the protégé, and providing the protégé with a step-by-step plan to solve a problem, the developer creates structure and gives the protégé the feeling that he or she can overcome these difficulties.

\section{Creating an environment for practice}

Finally, developers create environments for practice where they allow protégés to make mistakes: "He always said to me: You learn more from a game that you lose than from a game that you win." This is another way of setting reasonable expectations and providing the necessary foundation to face challenges (La Guardia \& Patrick, 2008). 
Table 3.2. Results of the Content Analysis for Developers' Competence Supportive Behavior

\begin{tabular}{|c|c|c|}
\hline Category & Definition & Sample comments \\
\hline $\begin{array}{l}\text { Emulating } \\
\text { effective } \\
\text { behaviors } \\
15 \text { comments }\end{array}$ & $\begin{array}{l}\text { Developer is admired by the } \\
\text { protégé because of the } \\
\text { developer's knowledge, skills, } \\
\text { and routine }\end{array}$ & $\begin{array}{l}\text { I really admire my colleagues. Yeah, I want to be like them. } \\
\text { Their work experience and knowledge, how much they know. I } \\
\text { look up to them, I want that, too. And their way of working is } \\
\text { very precise, professional, and reliable. And then I think: Oh, } \\
\text { how I wish I could work like that. }\end{array}$ \\
\hline $\begin{array}{l}\text { Confirming and } \\
\text { praising } \\
\text { competence } \\
15 \text { comments }\end{array}$ & $\begin{array}{l}\text { Developer fosters the } \\
\text { protégé's strong belief that } \\
\text { (s)he is able to perform } \\
\text { his/her job }\end{array}$ & $\begin{array}{l}\text { I think (developer) is very important, especially helping me } \\
\text { gain self-confidence. He gave me the feeling that others saw me } \\
\text { as competent. In the beginning, I was insecure about how to do } \\
\text { my job, and how I was seen? Am I good enough? Yeah, he } \\
\text { taught me how to have faith in myself. }\end{array}$ \\
\hline $\begin{array}{l}\text { Familiarizing with } \\
\text { the working } \\
\text { environment } \\
8 \text { comments }\end{array}$ & $\begin{array}{l}\text { Developer introduces the } \\
\text { protégé to the work field and } \\
\text { teaches him/her the ropes }\end{array}$ & $\begin{array}{l}\text { He showed me the ropes of our field and took me along to lots } \\
\text { of places, including court and those sorts of things. }\end{array}$ \\
\hline $\begin{array}{l}\text { Accepting one's } \\
\text { own } \\
\text { incompetence } \\
5 \text { comments }\end{array}$ & $\begin{array}{l}\text { Developer helps the protégé } \\
\text { accept his/her lack of ability } \\
\text { to do the job as it should be } \\
\text { done }\end{array}$ & $\begin{array}{l}\text { I always think that I have to work harder and better, you } \\
\text { know? When I look back, he often told me things such as: } \\
\text { Relax, take it easy, you don't always have to do the best you } \\
\text { can. You don't always have to work. }\end{array}$ \\
\hline $\begin{array}{l}\text { Stimulating } \\
\text { continuous } \\
\text { development } \\
5 \text { comments }\end{array}$ & $\begin{array}{l}\text { Developer encourages the } \\
\text { protégé to improve particular } \\
\text { qualities or skills }\end{array}$ & $\begin{array}{l}\text { And he alerted me that, besides your working life, you have to } \\
\text { keep developing by taking classes and reading because if you } \\
\text { don't develop, then you're just standing still. And be reflective } \\
\text { of what you're doing to keep informed about the developments } \\
\text { in your discipline. }\end{array}$ \\
\hline $\begin{array}{l}\text { Problem solving } \\
3 \text { comments }\end{array}$ & $\begin{array}{l}\text { Developer helps the protégé } \\
\text { find ways of dealing with } \\
\text { problems in his/her job }\end{array}$ & $\begin{array}{l}\text { She said: You probably won't solve this, especially after the } \\
\text { feedback that you got, because she saw that I worried about } \\
\text { that. Then, she said: Meet me in two days. I will reschedule my } \\
\text { calendar and, together, we can make an outline for this } \\
\text { project.' We discussed the situation for two hours and then it } \\
\text { was solved. }\end{array}$ \\
\hline $\begin{array}{l}\text { Creating an } \\
\text { environment for } \\
\text { practice } \\
3 \text { comments }\end{array}$ & $\begin{array}{l}\text { Developer creates conditions } \\
\text { that allow the protégé to } \\
\text { practice his/her skills related } \\
\text { to performing the job }\end{array}$ & $\begin{array}{l}\text { That was one of my learning aims when the project started. He } \\
\text { told me: I want you to focus only on what you feel now and on } \\
\text { what happens in that conversation? Not on the content, but on } \\
\text { what happened? ... That was such a clear exercise that, at first, } \\
\text { I found it very difficult. }\end{array}$ \\
\hline
\end{tabular}

\subsubsection{Relatedness Support}

In line with a relational view of development, protégés often reported the importance of learning in the context of a caring relationship, like with a developer who provides positive regard and creates a warm, loving, nurturing environment (La Guardia \& Patrick, 2008). Table 3.3 shows the types of relatedness support that are provided by developers.

Intimacy

Although the levels of intimacy vary across the various developmental relationships described by participants, intimacy was the form of relatedness 
support that was reported most often. Protégés describe their relationships with important developers as close, warm, special, long-lasting relationships (e.g., "Nobody knows me better than he does.") Participants even reported being connected such that the developer and protégé empathize with each other, almost telepathically: "I don't have to explain anything to them. It is almost telepathic, especially with her (mentor). We recognize so many things. That is very intensely special."

Table 3.3. Results of the Content Analysis for Developers' Relatedness Supportive Behavior

\begin{tabular}{|c|c|c|}
\hline Category & Definition & Sample comments \\
\hline $\begin{array}{l}\text { Intimacy } \\
13 \text { comments }\end{array}$ & $\begin{array}{l}\text { Developer has a close } \\
\text { personal relationship } \\
\text { with the protégé }\end{array}$ & $\begin{array}{l}\text { This felt so intense and so warm. And that is very } \\
\text { special and beautiful. I don't think you have that with } \\
\text { many others ... I don't have to explain anything to him. }\end{array}$ \\
\hline $\begin{array}{l}\text { Self-disclosure } \\
8 \text { comments }\end{array}$ & $\begin{array}{l}\text { Developer and protégé } \\
\text { (both) share personally } \\
\text { relevant information. }\end{array}$ & $\begin{array}{l}\text { Because I can discuss my deepest doubts with my } \\
\text { (mentor) and, yeah, the feeling of being a hand in a } \\
\text { glove. (Supervisor) was also important, but I could } \\
\text { never discuss my emotions with him. }\end{array}$ \\
\hline $\begin{array}{l}\text { Relatedness behavior to } \\
\text { emulate } \\
5 \text { comments }\end{array}$ & $\begin{array}{l}\text { Developer is admired by } \\
\text { the protégé because of } \\
\text { the way (s)he has } \\
\text { significant relationships } \\
\text { with others }\end{array}$ & $\begin{array}{l}\text { For me, (developer) is a model for how to have good } \\
\text { interpersonal relationships. }\end{array}$ \\
\hline $\begin{array}{l}\text { Showing genuine interest } \\
5 \text { comments }\end{array}$ & $\begin{array}{l}\text { Developer provides the } \\
\text { protégé with the feeling } \\
\text { that (s)he sincerely } \\
\text { cares about the protégé }\end{array}$ & $\begin{array}{l}\text { (Mentor) is a counselor for some big consultancy firms } \\
\text { in (city). He calls me every week to ask me how I am } \\
\text { doing. Every week. I think that's fascinating. Very loyal. }\end{array}$ \\
\hline $\begin{array}{l}\text { Caring } \\
4 \text { comments }\end{array}$ & $\begin{array}{l}\text { Developer worries } \\
\text { about what happens to } \\
\text { the protégé }\end{array}$ & $\begin{array}{l}\text { My mentor took me under her wings. And sometimes } \\
\text { she took care of me. It is like she thought that she should } \\
\text { take charge of me or something like that. }\end{array}$ \\
\hline
\end{tabular}

\section{Self-disclosure}

The opinion that protégés could discuss almost anything with their developers was also an important form of need-supportive behavior. By disclosing emotionally relevant information to each other and by mutually responding to these disclosures, intimacy is formed between the protégé and developer. This disclosure process distinguishes reciprocal relationships (such as relationships with informal mentors) from nonreciprocal relationships (such as relationships with coaches): 
"He was a coach for me, so he kept me at a certain distance. I told him many things about myself, but it was not equally open. It was not a give and take type of relationship. And this type of relationship was also evident with my supervisor. It is just her job, and she supervised so many (employees) that she didn't talk about herself. She listens to you and lets you talk."

This specific quote shows how participants may regard the developmental support provided by supervisors as being just part of the supervisors' job. This makes the relationship less exclusive, and for relatedness, this may devaluate feelings of the developmental partner being sincerely interested or caring.

Additionally, some participants reported being cautious about disclosing personal matters in supervisory developmental relationships. Participants discussed feelings of vulnerability that were associated with disclosing emotionally relevant information to their supervisors. The following quote serves as an example from a participant who described her supervisor as being a role model, which caused a professional distance that led her to not be as willing to disclose personal information:

"With (supervisor), I only discuss work-related things because I admire her so much and place her on a pedestal. So, I won't talk about my personal troubles with her. I wouldn't go to her to talk about problems at home or something like that. She does something. I want to be that kind of woman. I would like to be that kind of mother and professional."

This specific quote also marks a spillover effect from private to work life. This protégé describes how she notes or imagines elements from her supervisors' private life and wants to copy these elements.

\section{Relatedness behavior to emulate}

Similar to role modeling in autonomy and competence support, participants identified role models whose relatedness supportive behavior they wanted to copy. Developers serve as role models for relatedness as they are persons who show that they care about others: 
"She was focused on her relationships with others. How do you enter into relations? And that it can be more important to have a good relationship than to get a project outcome of $100 \%$. I think she was somebody who stimulated this."

As noted by Kram (1985), the identification process in role modeling is complex. The protégé may mimic some aspects of the developer while rejecting others. Also in the current study, participants report using a form of 'selective imitation' (Ibarra, 1999). The next example shows a protégé who sees his supervisor as a role model for competence but not for relatedness:

"I also saw the downside. She and her husband worked hard. They had a son that they barely thought about. I had a glimpse of her private life and I really did not like it. There is no way that I am going to live like that. In that way, she was not really an example, but she was a good role model in business."

Additionally, in this quote, the protégé describes how he observed elements from his supervisor's private life, which suggests a spillover effect.

\section{Showing genuine interest}

Another way that protégés experience a warm, loving, and nurturing environment is by having developers who show genuine interest in them. Participants discussed how their developers always make time for them and sympathize with them. However, protégés sometimes have more ambivalent feelings about the interest shown by their developers:

"She once told me: Life is like a play, you know, a puppet show. Everything is a farce, and you can bend things to your own will, or something like that. That was her perspective. Yeah, sometimes I was a bit skeptical. It felt real and genuine, but sometimes I thought ... I don't know. It all felt real, but sometimes what she said rankled me. I think it is good that I am no longer there."

\section{Caring}

Lastly, participants reported that their developers, especially their informal mentors, cared for them, similar to how parents care for their children.

Protégés discussed their most intensive developmental relationships using 
metaphors, such as "He was the father of our company" and "She took me under her wings." Additionally, this caring behavior from the developer leads to feelings of being protected: "He cared for me. He gave me the feeling of having a bodyguard. That was so great, it felt like a partner, like police officers have." This behavior from the developers shows similarities with Kram's (1985) function protection, though it is not characterized by specific behaviors from the developer, such as taking blame and credit in controversial situations.

\subsection{Discussion}

The aim of this study was to examine the support functions provided by developers from a SDT perspective. Our study shows that adopting SDT in mentoring and developmental network research leads to a theory-based classification of support functions. The results show how developers fulfill protégés' basic needs for autonomy, competence, and relatedness. Data from our interviews enrich our understanding of how developmental relationships enable one's growth and development. The present study makes at least three theoretical contributions to the mentoring and developmental network literature.

First, the results showed the relevance of a self-determination perspective for mentoring research. Each of the basic human needs could be identified in the stories of the protégés, in different variations and subtleties. The richness of SDT can inform future research on developmental relationships. Our SDT framework complements the classic conceptualization in career and psychosocial support functions (Kram, 1985). For the category competence, the overlap with career support is most notable with its focus on "mastery". Autonomy has also been included in previous mentoring studies (e.g., Fagenson, 1992), although the subcategories identified in this study exceed previous conceptualizations. In current mentoring research, autonomy is conceptualized as individual mastery, as in getting a job done without the help of others. In contrast, SDT has a different take on autonomy, which protégés mention as they talk about their development in terms of 'doing things my way'. Autonomy is then about getting feedback on one's own actions. Developing autonomy in this sense not only means mastering, but also getting a sense of self as a professional. Studying autonomy in mentoring according to SDT raises new research questions, like 'How do mentors provide feedback on protégés' 
identity formation?' Of the three basic needs, relatedness is mostly overlooked in mentoring research. Although relatedness functions can be traced in Kram's conceptualization (e.g., friendship and protection), our study paints a broader picture of belonging, identification and interpersonal sensitivity. This is a promising contribution, because in this way the relationship becomes a need in itself, rather than the vehicle for individual mastery. This is in line with recentcalls for the importance of relationships in organizational life (e.g., Ragins \& Verbos. 2007). Following the conceptual proposition by Allen and Eby (2007b), we suggest scholars to consider 'the need to belong' (Baumeister \& Leary, 1995) in their theorizing and study of developmental relationships. Besides, our findings reiterate the importance of role modeling. The position of role modeling as a function of mentoring is ambiguous. Initially, role modeling was seen as a subcategory of psychosocial support (Kram, 1985). Later, it was found to be an aspect of career support (Noe, 1988), while Scandura (1992) found a three-factor structure, in which role modeling is a separate support function. In our interviews, participants related role modeling not only to emulating effective behaviors (a subcategory of competence support), but also with regard to developers' autonomous and relatedness supportive behaviors. Since we identified role modeling as relevant for each of the three basic needs, its prominence is striking. This is in line with Murphy and Kram's (2010) plea to consider role modeling as a broad category, relevant in different areas, making it a highly important support function in developmental relationships.

Second, our study offers new insights regarding the examination of the effectiveness of developmental relationships. Formally, SDT is a macrotheory consisting of five mini-theories. The current study is concerned with the fulfillment of protégés' basic psychological needs, in that way applying key aspects of SDT's mini-theory of basic psychological needs. One of the claims of this theory is that the three basic needs serve as the underlying mechanisms for well-being. From studies examining romantic relationships and close friendships using SDT, we know that need fulfillment in relationships leads to relationship functioning and well-being (La Guardia \& Patrick, 2008). If the three basic needs are not met, a relationship does not live up to its full potential. It might be that, in dysfunctional mentorships, mentors and protégés differ in their expectations regarding the need-fulfillment for basic needs. For example, in the taxonomy of negative mentoring experiences by Eby, McManus, Simon, and Russell (2000), distancing behavior seems to reflect a lack of 
relatedness support by the mentor, inappropriate delegation seems to reflect a lack of autonomy support, and a lack of mentor expertise seems to reflect a lack of competence support. It would be useful to examine how both mentor's and protégé's perceptions regarding the fulfillment of the basic needs within a specific relationship (mis)match can influence a relationship's effectiveness. We encourage mentoring researchers to explore the usefulness of the other minitheories of SDT. For example, cognitive evaluation theory addresses the effects of social contexts on intrinsic motivation. With regard to mentoring research, it would be fruitful if researchers examine how exactly developers can create an autonomy-supportive context for the protégé and foster intrinsic motivation. According to organismic integration theory, social contexts can enhance the internalization process. Future studies could investigate how mentors can help their protégés to feel a sense of identification with their work behaviors, even while doing extrinsic tasks. In such ways, SDT opens up new ways for understanding how and why developmental relationships can contribute to personal and organizational goals.

Third, this study contributes to the understanding of how various developers foster their protégés' development by providing insight into the specific types of developmental support. Previous research regarding developmental networks has mainly focused on the antecedents of developmental networks' structure (Dobrow et al., 2011). The current study joins the research lines of Murphy and Kram (2010) and Cotton et al., (2011) by examining the specific ways that developers support their protégés. This qualitative approach leads to a realistic evaluation of developmental relationships. Similar to Murphy and Kram (2010), participants discussed the importance of negative developers, although we focused primarily on positive developmental relationships. Further, our results reveal that protégés report various ambivalent feelings towards their developers. We showed that protégés use selective imitation when copying their developers' behaviors. For example, protégés explained that they appreciated and copied elements from their developers' work lives, while condemning elements from their developers' private lives. Moreover, in general, developers' autonomy supportive behaviors are important for providing support to protégés and protégés appreciate that developers create freedom for them. However, developers who were most important to the protégé were often described as hard disciplinarians who carefully recorded the protégé's learning process. To conclude, this qualitative inquiry shows a 
nuanced and theory based exploration of the underlying dynamics of developmental relationships and a better understanding of why relationships are considered as developmental.

\subsubsection{Limitations}

We note that this study is only a starting point in examining the usefulness of SDT in developmental networks and mentoring research. Several limitations should be noted. First, this is a typical single-perspective study, as we did not involve developers in our study. We encourage researchers to examine how developers' motivations could be explained using an SDT framework (see also Haggard et al., 2011). Most of the developmental relationships discussed in this study were described as reciprocal relationships. In particular, relationships with informal mentors were described as relationships with mutual exchanges and matching forms of need-fulfillment, including intimacy and self-disclosure. This is consistent with previous literature that assumes that mentoring relationships are reciprocal (Eby, Rhodes, \& Allen, 2007). However, we also found a number of nonreciprocal processes within the developmental relationships and mentorships. Caring is an example of a subcategory that is nonreciprocal in that mentors care for their protégés, but this caring is unlikely to be reciprocated. Thus, it would be useful to examine what motivates developers to engage in developmental relationships, and what specific forms of support functions they perceive that they are providing and gaining.

A second limitation is that we only focused on work relationships. Previous research (Higgins, 2000; Higgins \& Thomas, 2001; Murphy \& Kram, 2010) shows that developmental relationships are likely to exist both within and outside of work organizations. Although participants mentioned developers outside of their work context (family and friends), our analysis focused only on work-related developers. The developmental relationships perspective allows for a broader range of developers than we included.

Further, our findings are based on a small number of protégés $(n=18)$. Although theoretically data saturation can be achieved with 12 interviews (Guest, Bunce, \& Johnson, 2006), we do not state that the needs identified within this study are the only needs fulfilled with regard to SDT. We look forward to seeing similar studies conducted with other samples so that we may compare and extend our findings. Furthermore, we recognize that the types of 
support are not distinct in that there is an interplay between the different forms of need fulfillment. For example, the competence subfunction regarding creating an environment for practice relates to fulfilling autonomy in that, by providing an environment for practice, the developer is providing the protégé with the freedom to practice and make mistakes. Therefore, we believe that future studies should examine whether the fulfillment of the three basic needs together leads to an increase in a protégé's psychological health, relationship satisfaction, and career outcomes. 


\section{CHAPTER 4}

Motives to mentor: Self-focused, protégé-focused, relationship-focused, organization-focused, and unfocused motives

Janssen, S., Van Vuuren, M., \& De Jong, M. D. T. (2014). Motives to mentor: Self-focused, protégé-focused, relationship-focused, organization-focused, and unfocused motives. Journal of Vocational Behavior, 85, 266-275. 
"When I started working, it was really about me. I also sat in the train, thinking: don't those people see that there is a do-gooder sitting over here? And no one did see that, of course. I had the feeling that they just did not look good enough, otherwise they could have seen it. And that's something, I don't have that anymore. Now I can really get satisfaction of seeing other people grow. And that's now a part of me."

-Anonymous mentor

\subsection{Introduction}

Mentoring relationships are important in organizations, as they provide employees with a "sense of competence, identity, and effectiveness in a professional role" (Kram, 1985, p. 32). Since Kram's work, the number of mentoring studies has increased rapidly. Mentoring research has traditionally focused on the protégé (Allen et al., 2008) and examined, for example, how protégés can benefit from mentoring relationships (Allen et al., 2004), how protégés' characteristics influence the initiation of mentoring relationships (Singh et al., 2009), and how protégés' negative experiences influence their intentions to leave a mentoring relationship (Burk \& Eby, 2010). Various scholars have emphasized that the mentor is a neglected actor in mentoring research (e.g., Allen et al., 2008; Ghosh \& Reio, 2013) and as a result, we have a one-sided and incomplete understanding of mentoring relationships. Much more research is needed to examine mentors' attitudes, needs, motivations, and behaviors. Most often, mentoring is not mandated or rewarded in organizations. Since mentoring relationships are associated with several positive outcomes for both mentors and protégés (Allen et al., 2004; Allen et al., 2006b; Eby et al., 2008a), it is important to create insight into why mentors would perform this kind of extra-role behavior, so organizations can encourage or facilitate such developmental relationships. While the focus of most previous studies has been on the influence of individual variables (e.g., mentors' age and gender) on people's intentions to be a mentor, this study qualitatively examines mentors' motives to engage in specific mentoring relationships. Our research question is: "What are informal mentors' motives to provide developmental support to their protégés?" This study extends previous research on mentors' motives to mentor others in several ways. 
First, most previous studies examined general intentions to be a mentor instead of intentions to be a mentor for a specific protégé. The willingness to mentor is then measured by general statements such as "I would like to be a mentor in the future" (e.g., Ragins \& Scandura, 1994; Wang et al., 2009) instead of focusing on mentoring specific possible protégés. Although this gives a good insight into how people vary in their willingness to mentor others in general, it is questionable to what extent this general intention holds true for specific relationships. For example, previous studies (Allen, 2004; Allen, Poteet, \& Burroughs, 1997a; Allen, Poteet, \& Russell, 2000; Olian et al., 1993) show that mentors are more willing to help protégés with favorable characteristics (e.g., showing high-performance) than to help protégés with less favorable characteristics (e.g., showing need for help). Research in the domain of helping behavior (e.g., Anderson \& Williams, 1996) shows a positive relationship between the quality of the relationship between the helper and receiver, and the amount of helping behavior. Based on these studies, we argue that the willingness to mentor may vary across different relationships. Applying a developmental network perspective in our interviews, we asked mentors to describe various specific developmental relationships, to get insight into the various motives one can have for different relationships.

Second, mentoring research has thus far not explored the full range of motivations that mentors can have to engage in mentoring relationships. The idea that people can have different forms of motivations to perform a certain behavior, and that these forms of motivation depend on for example the specific circumstances (e.g., relationships) in which the behavior is performed, is the essence of self-determination theory (SDT) (Deci \& Ryan, 1985). SDT proposes that human motivation falls along a continuum, ranging from extrinsic motivation to intrinsic motivation. These two forms of motivation are comparable with mentor motives distinguished in earlier studies (Allen, 2003; Allen et al., 1997a). However, SDT distinguishes three other forms of extrinsic motivations (introjection, identification, and integration), which allow for a more specific understanding of mentors' motivations. As suggested by Allen et al. (1997a), insight into specific motives would be a first step in determining how specific motives are related to mentoring functions provided. Therefore, we applied SDT as framework in our data analysis, which allows us to deductively create a fine-grained picture of self-focused motives that influence mentors' willingness to mentor. 
Last, previous studies on mentor motives have paid little attention to which relational motivations play a role in one's willingness to mentor. Previous studies most often solely applied a social exchange perspective on mentoring. As a result, the willingness to mentor others is conceptualized as being the result of a cost-benefit analysis, where it is expected that mentoring would somehow be rewarding for the mentor (e.g., Olian et al., 1993; Ragins \& Scandura, 1999). However, as suggested by relational mentoring theory (Ragins, 2012), this instrumental approach leaves little room for relational motivations such as humans' need for connectedness and belonging (Baumeister \& Leary, 1995) as drivers for the willingness to engage in a mentoring relationship. Previous work already showed the importance of relatedness functions in developmental relationships (Janssen et al., 2013). The present study shows how, next to a social exchange orientation as for example shown in our deductive analysis based on SDT, mentors report relational motivations. Based on inductive data analyses, we distinguish four other main categories of motives, next to these self-focused motives: protégé-focused, relationship-focused, organization-focused, and unfocused motives. In these categories, we distinguish two subcategories with relational motivations that mentors have to engage in mentoring relationships. Based on our inductive data analyses, we not only show categories based on social exchange orientations, but also based on relational motivations. We show how affiliative motivations - the need to form and maintain close relationships with others(McAdams \& Constantian, 1983) and communal orientation-the focus on the well-being of others-(Clark \& Mills, 1993) play a role in employees' willingness to mentor.

\subsection{Theoretical Background}

\subsubsection{The Willingness to Mentor Others}

Providing developmental support to others is a form of helping behavior: "an action that has the consequence of providing some benefit to or improving the well-being of another person" (Dovidio, Piliavin, Schroeder, \& Penner, 2006, p. 22). Why people do or do not help other people is a long-debated question in social psychology. This question is also highly relevant for mentoring literature, as informal mentoring is a voluntary activity, not mandated or (directly) 
rewarded within organizations (Allen, 2003). We distinguish two research lines in the literature about the willingness to mentor others.

First, several studies have applied a social exchange paradigm to mentoring. According to social exchange principles (Blau, 1964; Emerson, 1976), individuals engage in relationships which they think are rewarding for them. Following this reasoning, mentors would be more willing to mentor others if they expect mentoring will have benefits for them than they would be if they expect drawbacks and obstacles. Indeed, Ragins and Scandura (1999) found that expected costs of being a mentor (e.g., time-consuming, bad reflection on one's reputation) are negatively related to intentions to mentor, while expected benefits (e.g., recognition by others, ego-enhancements) are positively related. Other studies applying this social exchange paradigm focused on favorable protégé characteristics. For example, studies found that mentors are more attracted to high-performing protégés than to average-performing protégés (Olian et al., 1993), and that mentors select their protégés on the basis of their ability rather than on their need for help (Allen et al., 2000). Other studies found that mentors are more willing to mentor protégés high in willingness to learn than those low in willingness to learn (Allen, 2004; Allen et al., 1997a).

Although each of these studies made a great effort in explaining one's willingness to mentor, a limitation of a social exchange approach is that it fails to take relational motivations into account (Ragins, 2012). Kram (1985) stated that both instrumental and psychological needs may drive mentors to help others. For example, Ragins \& Cotton (1993) found that, although women anticipated more barriers to becoming a mentor than men, they expressed equivalent intentions to serve as a mentor in the future. The authors explain that women may have a stronger desire for interpersonal relationships than men do, which means that they have stronger relational motivations. However, with few exceptions (e.g., Allen, 2003), mentoring research has predominantly focused on instrumental motives to engage in mentoring relationships, and neglected relational motivations to do so.

Second, a larger group of studies has examined how mentors' individual characteristics may affect their general willingness to mentor. Several studies examined the influence of mentors' demographics on their willingness to mentor. For example, several studies examined if gender is related to the 
willingness to mentor (Allen, Poteet, Russell, \& Dobbins, 1997b; Ragins \& Cotton, 1993; Ragins \& Scandura, 1994). These studies show that men and women in general have similar intentions to mentor others. Ragins and Cotton (1993) found that people's organizational rank is a significant predictor of their willingness to mentor. One would expect that age would also be of influence on the willingness to mentor. However, Ragins and Cotton (1993) found no support for this claim, and Allen, Poteet, Russell, and Dobbins (1997b) even found a negative relationship between age and willingness to mentor. There is also some evidence that mentors' personality factors are of influence on the willingness to mentor. For example, Allen et al., (1997b) found that internal locus of control is positively related to people's willingness to mentor: Individuals with an internal locus of control possibly view perceived barriers to mentoring as more controllable, and therefore express more willingness to mentor. In another study, Allen (2003) found that helpfulness relates to one's experience as a mentor, while empathy did not.

These studies provide insight into which types of mentors are more likely to provide support in general. However, they do not give insight into reasons or motives to mentor others. The qualitative inquiry of Allen et al., (1997a) is an important exception to this. Based on interviews with 27 mentors, the authors identified two types of reasons to mentor others: "self-focused reasons," such as the desire to increase personal learning and the gratification of developing others, and "other-focused reasons," such as improving the welfare of others and the desire to help the organization succeed. Later, Allen (2003) developed a measure to quantitatively operationalize these motives, and this has resulted in a refined three-factor structure of motives: benefiting others (other-focused motives), self-enhancement (extrinsically oriented self-focused motives), and self-gratification (intrinsically oriented self-focused motives). Moreover, this study showed how these various motives lead to the provision of different mentoring functions. The self-enhancement motive significantly related to the provision of career mentoring, but not to the provision of psychosocial mentoring. Intrinsically oriented self-focused motives related positively to psychosocial mentoring, but not to career mentoring. Last, the benefit-others motive related to the provision of both career mentoring and psychosocial mentoring. The present study builds on these previous studies. We aim to get a more comprehensive view of various mentor motives, including a fine-grained 
picture of mentors' self-focused motives to engage in mentoring relationships, by applying SDT.

\subsubsection{Self-Determination Theory and Motivation}

SDT represents a meta-theory for the study of human motivation (Deci \& Ryan, 1985). According to SDT, humans have three basic needs: autonomy (experiencing choice and volition of one's own actions), competence (experiencing that one can succeed challenging tasks and influence desired outcomes), and relatedness (experiencing connection, mutual respect, caring, and reliance in relationships with others). One of the key questions for scholars in the field of SDT is to examine how social contexts facilitate or undermine people's experience of autonomy, competence, and relatedness. SDT proposes that the satisfaction of these three needs together will facilitate people's selfmotivation and effective functioning (Deci \& Ryan, 2000). SDT conceptualizes motivation not in terms of a dichotomy but as a continuum from noninternalized (controlled) to internalized (autonomous) reasons. SDT organizes motivational dispositions or orientations by the extent to which behavior is characterized as being controlled versus autonomous.

According to SDT, people experience autonomy when they perceive their behavior to be volitional rather than driven by external controls (Deci \& Ryan, 2000). Whereas Allen (Allen, 2003) identified two types of self-focused motives (extrinsic and intrinsic motives), SDT can enhance our understanding of specific mentor motives by refining this picture of motives. According to SDT, behavior is externally regulated when the behavior is engaged to satisfy an external demand or reward contingency (Deci \& Ryan, 1985). Some mentors may be involved in mentoring relationships mainly for extrinsic reasons, for example because their supervisor asked them to help junior newcomers. The motive then comes from outside the person: This is the most controlled motive for acting. When the motive begins to be internalized, but the regulation of the behavior still depends on the evaluation against external standards, the behavior is introjected regulated. This often appears as ego involvement (Ryan, 1982). People often engage in activities that are socially acceptable, in order to avoid feelings of guilt (e.g., paying back a favor to the protégé), or to gain others' respect (e.g., meeting the work environments' expectations to take a junior under their wings). Introjection is the second most controlled motive for acting. The next step on the continuum of autonomy is identified regulated 
behavior (Deci \& Ryan, 2000). In this case, the behavior in itself might not be enjoyable (i.e., intrinsically motivating), but it is seen as serving an important purpose (e.g., spending time to help the protégé, because this will lead to less workload in the future) and is typically experienced as somewhat internal. When extrinsic motivation is most completely internalized, the behavior is integrated regulated (Deci \& Ryan, 2000): The person fully accepts and integrates the values guiding the behavior with other needs and values that define his or her self-concept (i.e., helping others is important in my life). Last, behavior is intrinsically regulated when the behavior is experienced as the result of free choice and therefore as fully autonomous. Adopting this continuum to mentors' self-focused motives is an important step in understanding the detailed motives one can have to engage in mentoring relationships and the factors that can influence these motives (Haggard et al., 2011).

\subsection{Method}

Semi-structured interviews were well suited to identifying various forms of mentors' motives. Although we had a general idea of mentors' motivations based on previous work (Allen, 2003; Allen et al., 1997a), these interviews enabled us to gain a deeper understanding of specific motives.

\subsubsection{Participants}

The first author interviewed 20 employees from 18 organizations based in the Netherlands. We asked personal contacts to recommend persons who serve as an informal mentor for others. Participants had to meet two selection criteria to be invited. First, participants had to hold senior or supervisor roles, as we assumed that those employees are most likely to act as an informal mentor on a regular basis. Second, participants had to hold clerical or professional positions, so the occupational group characteristics that might influence the nature of mentoring relationships were similar for participants. Participants received a letter with information about the study, and those who identified themselves as an informal mentor were subsequently interviewed. All participants were at least 37 years old (mean $=50$ years), with an education level of at least a fouryear college degree. The average years of work experience was 27 . The 
organizations represented a wide range of industries, including consulting, education, and manufacturing.

\subsubsection{Semi-Structured Interviews}

To start the conversation, the first author asked the participants to describe their career history. Participants were then asked to explain why they served as a developer or informal mentor for others in general. Next, participants named protégés they had supported during their career, described these relationships, and explained why they served as a developer or informal mentor for these protégés. Further, they selected at least two relationships to discuss in further detail. For each relationship, the first author asked them how the relationship started and why the participant supported the protégé, and to describe specific examples of how they helped the protégé. Next, participants were asked what the relationship meant to them. At the end of each interview, participants were asked to share any other information about their motives they felt was relevant. All interviews were between 45 minutes and two hours in length and were recorded after permission.

\subsubsection{Data Analysis Procedure}

All of the interviews were transcribed verbatim, leading to 209 transcript pages, and were analyzed with the help of ATLAS.ti software for tracking code creation. We used a multi-step content-analytic procedure consisting of six steps. First, the first author segmented the transcriptions into meaningful units of analysis, which consisted of single or multiple sentences. Second, the first author took the lead in proposing a set of themes. These themes were discussed with the other two authors and modified until there was agreement on five broad themes. The main criterion to classify a statement in one of these themes was the subject of the statement. First, we distinguished self-focused motives. This category consists of statements in which the mentor is the subject, without explicit references to the protégé, the organization, or the mentoring relationship (e.g., "I really like helping other people.").

Second, we distinguished protégé-focused motives. This category is different from the previous category, in the sense that the subject of the statements in this category is the protégé, instead of the mentor (e.g., "She is a talented junior."). Third, we distinguished relationship-focused motives. Different from 
the previous categories, statements in this category are statements in which mentors did not speak about themselves or the protégé, but about themselves and the protégé ("we"), and about the exchanges between themselves and the protégé (e.g., "We get along very well."). Next, we distinguished organizationfocused motives. These statements focus on interests that exceed the mentorprotégé dyad, such as the team or the organization as a whole (e.g., "Our team can benefit from it."). Last, we created a category with unfocused motives, which consists of statements in which mentors attribute their mentoring behaviors to a series of coincidence, rather than being the result of a rational, conscious choice (e.g., "I think it was just coincidence that I helped him.").

Third, the first and second author met several times to construct an initial codebook, which provided detailed definitions of different subcategories within these five broad themes. Based on the five stages of the motivation continuum of SDT (Blais, Sabourin, Boucher, \& Vallerand, 1990; Deci \& Ryan, 2000), we deductively created five subcategories for the self-focused motives and coded the data accordingly. For the other four themes (protégé-focused motives, relationship-focused motives, organization-focused motives, and unfocused motives), no existing taxonomy or model was available. Therefore, we looked for subcategories in the data and by applying an iterative procedure, we compared these subcategories with phenomena in the literature on relationship motivations and mentor motivations (e.g., Allen et al., 1997a; Clark \& Mills, 1993; McAdams \& Constantian, 1983). These subcategories were then labeled to capture the meaning reflected by each group of comments (e.g., "Communal Orientation" as a subcategory of "Protégé-focused motives," and "Affiliative Motivation" as a subcategory of "Relationship-focused motives"). While our deductive data analysis was based on SDT and was thus based on rather instrumental orientations, this inductive data analysis resulted in categories based on both instrumental (i.e., social exchange orientations) and relational motivations. Subsequently, all of the (sub)categories were defined in a codebook. We looked for common ideas and patterns in participants' responses, so (sub)categories represented by a single comment made by one participant were not included in the codebook.

Fourth, this codebook was given to an independent coder who was not involved in the previous stages of coding, and a quarter of the total sample of responses was individually coded by the first author and this independent coder. This 
initial coding round resulted in Cohen's kappa's of .72 (self-focused motives), .83 (protégé-focused motives), .58 (relationship-focused motives), .72 (organization-focused motives), and .86 (unfocused motives). Problems with the code definitions and problematic codes were then discussed and the codebook was modified. Fifth, the first author and the independent coder repeated the coding process with the modified codebook for another quarter of the total sample of the responses. This resulted in Cohen's kappa's of .76 (selffocused motives), .89 (protégé-focused motives), .88 (relationship-focused motives), .89 (organization-focused motives), and .84 (unfocused motives). Sixth, based on this final codebook, the remaining half of the total sample of responses was coded by the first author. The quotes presented in the Results section are illustrative of the 20 interviews.

\subsection{Results}

\subsubsection{Self-Focused Motives}

Motivations to engage in and maintain a mentoring relationship were categorized along a motivation continuum. On the one hand, there is intrinsic motivation. On the other hand, there are subtypes of extrinsic motivation falling along the continuum of internalization, when regulations remain external or are only partially internalized (Blais et al., 1990; Deci \& Ryan, 2000). Table 4.1 shows these various types of regulation.

\section{External}

Although all participants in this study were informal mentors, participants perceived some of their mentoring relationships as more extrinsically driven. This is the least autonomous form of motivation and mentoring behaviors in this category are driven by the desire to attain a favorable consequence, such as tangible rewards or to avoid a threatened punishment (Deci \& Ryan, 2000). For example, participants stated that mentoring others is part of their job, or that they are paid for doing this: "In our organization, it is just part of my job."

\section{Introjection}

Participants often stated that they perform mentoring behaviors because of ego involvements, which is typical for introjected regulated behavior (Deci \& Ryan, 2000). Mentoring behaviors are then performed to demonstrate that one can 
attain or preserve feelings of self-worth. First, mentors demonstrated that they can preserve feelings of self-worth from others. They help protégés to gain others' respect, to enhance their own reputation:

\begin{abstract}
"The fact that I was able to keep these people in till the end of their contract, and to keep them working, said something about my coaching skills. I like it when people speak highly of me when they leave the organization. Partly, this is driven by, well, self-interest."
\end{abstract}

Table 4.1. Results of the Deductive Analysis of Mentors' Self-focused Motives based on SelfDetermination Theory

\begin{tabular}{|c|c|c|}
\hline Category & Definition & Sample comments \\
\hline $\begin{array}{l}\text { External } \\
(11 \\
\text { participants) }\end{array}$ & $\begin{array}{l}\text { Mentoring behavior is performed because the mentor } \\
\text { sees it as part of his/her job, or because (s)he receives } \\
\text { an external reward (e.g., salary) for it. }\end{array}$ & $\begin{array}{l}\text { "This relationship was typical, because it } \\
\text { was also part of my job to help him." }\end{array}$ \\
\hline $\begin{array}{l}\text { Introjection } \\
(13 \\
\text { participants) }\end{array}$ & $\begin{array}{l}\text { Mentoring behavior is performed to attain or preserve } \\
\text { self-worth (of oneself and of others). The mentor helps } \\
\text { the protégé to promote oneself, or for ego- } \\
\text { enhancements (e.g., to experience feelings of pride). } \\
\text { The mentor's self-worth is central in his/her giving } \\
\text { behavior. }\end{array}$ & $\begin{array}{l}\text { "What you get in return is that people see } \\
\text { you as an important source for something. } \\
\text { And that strokes your ego. No need to make } \\
\text { it any more difficult than it is, it just strokes } \\
\text { your ego." }\end{array}$ \\
\hline $\begin{array}{l}\text { Identification } \\
\text { (8 participants) }\end{array}$ & $\begin{array}{l}\text { Mentoring behavior is performed because it is } \\
\text { instrumental in a beneficial outcome for the mentor } \\
\text { (e.g., mentor can enhance own competencies, mentor's } \\
\text { workload lowers because protégé can take over work). }\end{array}$ & $\begin{array}{l}\text { "So when everyone enjoys [working], that } \\
\text { positive energy, I need that to perform. .... } \\
\text { That gives me energy." }\end{array}$ \\
\hline $\begin{array}{l}\text { Integration } \\
\text { ( } 7 \text { participants) }\end{array}$ & $\begin{array}{l}\text { Mentoring behavior is performed because (s)he } \\
\text { believes it is important and this behavior is in harmony } \\
\text { with his/her personal values, beliefs, needs, and } \\
\text { identity. }\end{array}$ & $\begin{array}{l}\text { "Yeah, it's a little like religion, you're trying } \\
\text { to help thy neighbors. .... I believe you } \\
\text { should try to help others. But that's } \\
\text { something that, yeah, from childhood on, } \\
\text { that's almost been drilled into you." }\end{array}$ \\
\hline $\begin{array}{l}\text { Intrinsic } \\
(13 \\
\text { participants) }\end{array}$ & $\begin{array}{l}\text { Mentoring behavior is performed because of its } \\
\text { intrinsic value for the mentor (e.g., sense of enjoyment } \\
\text { that the mentoring behavior gives). }\end{array}$ & $\begin{array}{l}\text { "I love doing this. .... I just enjoy doing this } \\
\text { the most." }\end{array}$ \\
\hline
\end{tabular}

Second, mentors demonstrated that they can preserve feelings of self-worth from themselves. Participants stated that they help others because it makes them feel good about themselves: "When it eventually ends well, I can give myself a pat on the back, then I think I've done well. ... It is satisfying to know that I've done well."

Additionally, some participants reported that they help others to manifest and promote themselves. This form of helping behavior shows similarities to what is called "agentic generativity" in literature (Bradley, 1997; McAdams \& de St. Aubin, 1992): "a tendency to assert, expand, and develop the self in a powerful 
and independent way." (McAdams \& de St. Aubin, 1992, p. 1005) The manifestation of the mentor's self is then central in his or her helping behavior, as is characterized by the following statement:

"It could also be that you're thinking you know it all better, and that can be a reason for you to interfere. I don't know if that's helpful. Then it's more about manifesting yourself. And for me personally, that's definitely the case sometimes. Not doing it to help, but just to interfere."

\section{Identification}

Mentors reported that they perform mentoring behaviors because they are instrumental, for example because mentoring others is beneficial to their own development or because it lowers their own workload. As one mentor noted,

"Eventually, it's easier. And why? It's easier for yourself. When someone develops fully and you cannot work temporarily or have been away on vacation, then more issues will be resolved. So it benefits you when someone else develops himself. So also very practical, basic benefits."

Although this behavior is more autonomous than behaviors in the previous categories, according to SDT, it is still extrinsically motivated, as the relationship is instrumental rather than a source of satisfaction and enjoyment in itself (Blais et al., 1990; Deci \& Ryan, 2000).

\section{Integration}

Integrated regulation is the most complete form of internalization of extrinsic motivation (Deci \& Ryan, 2000). In this case, mentors not only identify with the importance of helping others, but they also integrate these activities in one's true self and identity (Deci \& Ryan, 2000). Mentoring behavior is then fully assimilated with the mentor's identity and is part of his or her personal values and needs: "Because I always go by the principle: if you want to live and work in a community, then you have to contribute to it. That also has to do with this. .... I think that's important."

\section{Intrinsic}

When intrinsically motivated, the mentor helps the protégé because this activity in itself is a source of satisfaction and enjoyment. Different from the 
previous categories, the intrinsically motivated mentor does not help the protégé because of a consequence of this behavior, but because of the intrinsic value of the activity at that moment. In line with Carbonneau, Vallerand, and Lafreniere (2012), we see three forms of intrinsic motivations. First, mentors report that they help the protégé because this helping in itself brings them feelings of pleasure, excitement, or enjoyment. As one mentor stated

"I just like doing it. This is 10 times more fun than managing a project. I'd rather sit with her in a restaurant, talking about how she can develop herself, than sit behind my computer, drawing a flowchart or describing a process. This is just a lot more fun."

Second, mentors support protégés for the satisfaction and pleasure derived from trying to accomplish something, in this case trying to motivate the protégé:

"I really liked starting out with her, to see if I could turn this around. And it was especially challenging for me, because I've never mentored anyone from a distance before. So we have to be very creative with Skype and new things, so that was a challenge for me personally, to find out if that would work out."

Last, mentors help their protégés because mentoring behaviors give them the pleasure and satisfaction of exploring and trying to understand something new:

"He is someone who just lingers a little. Doesn't make a clear choice, is a very intelligent boy in my opinion, but yeah, somehow he doesn't quite manage to rise above himself. And at that point, I just get curious, what's happening there? What's causing it?"

\subsubsection{Protégé-Focused Motives}

In line with previous work on mentor motives (Allen, 2003; Allen et al., 1997a), we distinguished protégé-focused reasons to mentor others. Mentors reported that the decision to help a protégé is based on a communal orientation towards the protégé, or because they admire characteristics of the protégé. Also, mentors reported that they sometimes do not initiate the mentoring 


\section{relationship themselves, but rather respond to a protégé's request to do so. Table 4.2 shows these protégé-focused motives.}

Table 4.2. Results of the Inductive Content Analysis for Developers' Other-focused, Relationshipfocused, Organization-focused, and Unfocused Motives

\begin{tabular}{|c|c|c|c|}
\hline Broad category & Category & Definition & Sample comments \\
\hline \multirow[t]{4}{*}{ Other-focused } & $\begin{array}{l}\text { Communal } \\
\text { orientation } \\
\text { (18 participants) }\end{array}$ & $\begin{array}{l}\text { The mentor has positive } \\
\text { attitudes toward benefiting } \\
\text { the protégé and has concerns } \\
\text { for the welfare of the } \\
\text { protégé. }\end{array}$ & $\begin{array}{l}\text { "For these people, getting that } \\
\text { diploma was the most important } \\
\text { thing. So, actually, that's what I } \\
\text { meant, it was more for them in } \\
\text { the end. .... Eventually, it has less } \\
\text { to do with self-interest." }\end{array}$ \\
\hline & $\begin{array}{l}\text { Protégé reflection } \\
\text { of self } \\
\text { (13 participants) }\end{array}$ & $\begin{array}{l}\text { The mentor and protégé } \\
\text { share values or } \\
\text { characteristics, or the mentor } \\
\text { recognizes the situation of } \\
\text { the protégé. }\end{array}$ & $\begin{array}{l}\text { "Yeah, I think I choose people } \\
\text { who look like me." }\end{array}$ \\
\hline & $\begin{array}{l}\text { Admiration } \\
\text { (6 participants) }\end{array}$ & $\begin{array}{l}\text { The mentor has respect for } \\
\text { the protégé or for what (s)he } \\
\text { is doing. }\end{array}$ & $\begin{array}{l}\text { "But also, and that might be the } \\
\text { most common one, sometimes } \\
\text { there's someone of whom you } \\
\text { think: That is real talent." }\end{array}$ \\
\hline & $\begin{array}{l}\text { Protegé chooses } \\
\text { mentor } \\
\text { ( } 6 \text { participants) }\end{array}$ & $\begin{array}{l}\text { The protégé asked the } \\
\text { mentor for his/her help and } \\
\text { the mentor agreed with this } \\
\text { request. }\end{array}$ & $\begin{array}{l}\text { "Or sometimes someone just } \\
\text { asks for help. It's not like I'm } \\
\text { always starting things, } \\
\text { sometimes people just ask for } \\
\text { help." }\end{array}$ \\
\hline \multirow[t]{2}{*}{$\begin{array}{l}\text { Relationship- } \\
\text { focused }\end{array}$} & $\begin{array}{l}\text { Affiliative } \\
\text { motivation } \\
\text { (12 participants) }\end{array}$ & $\begin{array}{l}\text { The mentor wants to } \\
\text { establish and maintain a } \\
\text { positive, affective } \\
\text { relationship with the } \\
\text { protégé. }\end{array}$ & $\begin{array}{l}\text { "We spend a lot of time together } \\
\text { and yeah, we get along. And then } \\
\text { you help each other forward." }\end{array}$ \\
\hline & $\begin{array}{l}\text { Exchange } \\
\text { orientation } \\
\text { ( } 7 \text { participants) }\end{array}$ & $\begin{array}{l}\text { The mentor expects there } \\
\text { will be an equity of } \\
\text { exchanges in this } \\
\text { relationship. By helping the } \\
\text { protégé, the mentor expects } \\
\text { smething in return. }\end{array}$ & $\begin{array}{l}\text { "Well, when you consider } \\
\text { development, I just called it win- } \\
\text { win. And that's the most } \\
\text { beautiful form to have. So people } \\
\text { come with practical ideas, which } \\
\text { I never could've thought of } \\
\text { myself. .... They have their } \\
\text { success, and I have the solution } \\
\text { to the problem. So it's also a } \\
\text { matter of give and take." }\end{array}$ \\
\hline $\begin{array}{l}\text { Organization- } \\
\text { focused } \\
\text { (17 participants) }\end{array}$ & & $\begin{array}{l}\text { The mentor helps the protégé } \\
\text { because this helping } \\
\text { behavior is beneficial for } \\
\text { their team, for the } \\
\text { organization, or for their } \\
\text { professional group. }\end{array}$ & $\begin{array}{l}\text { "Someone who's enthusiastic and } \\
\text { who contributes in a positive } \\
\text { way is of more use to the group." }\end{array}$ \\
\hline $\begin{array}{l}\text { Unfocused } \\
\text { (11 participants) }\end{array}$ & & $\begin{array}{l}\text { Mentoring behavior is the } \\
\text { result of subconscious } \\
\text { information processing, or } \\
\text { the mentor describes his/her } \\
\text { mentoring behavior as the } \\
\text { result of a series of } \\
\text { coincidences, without prior } \\
\text { intentions to perform this } \\
\text { behavior. }\end{array}$ & $\begin{array}{l}\text { "There's not an exact turning } \\
\text { point, but it grows gradually. It's } \\
\text { not like I'm thinking all day: How } \\
\text { can I help you? It works } \\
\text { subconsciously." }\end{array}$ \\
\hline
\end{tabular}




\section{Communal orientation}

Mentors discussed that their mentoring behaviors may be the result of feeling responsible for the welfare of the protégé and of focusing on the needs of the protégé. This communal orientation (Clark \& Mills, 1993; Mills, Clark, Ford, \& Johnson, 2004) towards the protégé is characterized by positive attitudes of the mentor toward benefiting the protégé. The mentor wants to give the protégé a good future ("Well, he is employed on a temporary basis. .... And I want to help him, so if I'm not able to keep him here, then he'll be off to a good start towards the future"), or wants to care for or protect the protégé ("I really can't stand injustice. .... So I want to give people a fair chance. .... Because I believe they're not getting what they deserve, from their manager."). Comments in this category are characterized by mentors stating that they did the protégé a favor, while disregarding their self-interest. This way, the focus is really on the welfare of the protégé, in contrast with agentic generativity, where the mentor is primarily concerned with asserting the self. Different from the category of "Integration", the subject of statements in this category is the protégé, rather than the mentor. Comments in this category also contrast with comments in the category of "Exchange Orientation," in which help is given because the mentor expects to receive comparable benefits of the protégé in the future.

\section{Protégé reflection of self}

Mentors often discussed that they want to help the protégé because they identify with the protégé. This is similar to what Allen et al. (1997a) call "protégé reflection of self." The mentor and protégé share values or characteristics ("Each of these people shares pieces of my values with me. So when I see those pieces, I recognize and understand those. Some of these people show an eagerness to be able to do something, and others show a certain kind of morale. Yeah, each of them has pieces that closely resemble your own."), or the mentor recognizes the situation the protégé is in ("Another thing is, when you've experienced it yourself, because you also developed yourself in difficult environments, then you can also imagine: that's not nice. I also liked it when I could turn to people for help and ask them how they would deal with things. So, why wouldn't you also do that for others?').

\section{Admiration}

Previous research shows that mentors are more willing to mentor protégés who show competence (Allen et al., 1997a; Ragins \& Cotton, 1999), desirable 
personality factors, or motivational factors (Allen et al., 1997a). In the current study, participants also reported that they want to support the protégé because they admire the protégé, because of his or her ambitions, personality characteristics, or talent:

"Yeah, sometimes I see something in someone which makes me think, I believe he is good at this, or I see a certain talent and think: you should do something with that. You often find your own talent normal. That obviously doesn't just apply to me, but also to other people."

\section{Protégé chooses mentor}

Another reason for getting involved in a mentoring relationship is because the protégé asks the mentor for help. Here, mentors stated that the primary initiative was not taken by themselves, but rather by the protégé: "I think it's very basic. Someone asks me to help and I respond. .... When someone requests my help, I will respond accordingly."

\subsubsection{Relationship-Focused Motives}

Besides self-focused and protégé-focused motives, we discovered motives that are characterized by their focus on the connection between the mentor and the protégé and their behaviors towards each other. These relationship-focused motives are shown in Table 4.2.

\section{Affiliative motivation}

Similar to what Atkinson, Heyns, and Veroff (1954) and McAdams and Constantian (1983) call "the need for affiliation," participants discussed how their need to establish and maintain a positive affective relationships with the protégé can serve as a motive to support the protégé. Often, the wish to continue or deepen an existing relationship (e.g., friendship between mentor and protégé) was mentioned as a reason to provide support to the protégé: "He was a friend of mine. .... So, being there, having a relationship, that's a very important one. So having a relationship, and discussing things based on that relationship. .... And the friendship deepens because of that."

\section{Exchange orientation}

While a communal orientation is characterized by helping the protégé while discarding the mentor's self-interest, sometimes, mentors help protégés 
because they believe there is or will be an equity of exchange within the mentor-protégé relationship. Reciprocity is the keyword here. Comments in this category follow social exchange rules (Cropanzano \& Mitchell, 2005) and are characterized by a balance between helping and receiving, or input and output. In a negative way, several mentors indicated that a lack of this reciprocity demotivates them to help the protégé: "Sometimes you have to push people...if they don't want to change...and you keep investing in someone, and you see no results of that, that's annoying." Comments in this category contrast comments in the category of "Communal Orientation," since help is provided contingently, in response to comparable benefits or results expected in the future. While in the category of "Identification" it is about the benefits for the mentor only, in this category it is about benefits or results for both the mentor and the protégé.

\subsubsection{Organization-Focused Motives}

Mentors also reported motivations that were directed towards their organization. Table 4.2 shows that mentors help their protégés because this benefits their team ("I help these people in general, because I want to propel the group. So not only individually, but also as a group. We have to reach a certain level as a group, so I tell them: we want to go there."). Others stated that mentoring helped their organization in general:

"Yeah, I do believe in a strengthening effect .... I have a lot of projects for trainees. I encourage that. And I believe it is helpful to the trainees, but the one who is training the trainee also learns from it. A trainee introduces new insights, knowledge, methods, causing others to think: well, this is interesting. .... So, it is partly also connected to the development of the organization."

Last, some mentors explained that they wanted to serve their professional group by mentoring others:

"You're trying to convey the love for your profession. To me, it's important to have good colleagues; most of the people you're training here will be your own colleagues in the future. .... And you just want to be sure that it will be carried out by the right people." 


\subsubsection{Unfocused Motives}

While the previous categories describe motivations resulting from conscious thinking (i.e., based on reflection and analysis), this category describes how mentors attribute their mentoring behaviors to unfocused motives. These motives are not aimed at a certain individual or a certain need that is fulfilled by engaging in mentoring relationships, but these are subconscious or unplanned. For example, mentors described motivations that rely on intuition and emotion (i.e., based on quick, automatic, and subconscious thinking), which is in line with dual process theory (Evans, 1984; Kruglanski \& Gigerenzer, 2011). Mentoring is then based on subconscious information processing, rather than on a rational, conscious choice: "Someone comes up to you to ask you something, and you have to decide right then, right there. At that moment, you follow your gut feeling. You really follow your gut feeling." Mentors also explained that their mentoring behaviors were the result of a series of coincidences, without having concrete prior intentions to do so. For example, mentors stated that the occasion arose because or proximity of the protégé: " $O f$ course, coincidence is a very important aspect, and her sitting at my table." Sometimes, mentors are not even aware of their mentoring role:

"You're just having a conversation with someone and a lot of unintended things may happen. And then you notice that, for instance, the same goes for [him or her]. After the conversation, he [the protégé] says: this helped me..... So you can be of significance to someone without being aware of it at the moment."

\subsection{Discussion}

In summary, this study uncovered several nuances in mentors' motivations to engage in mentoring relationships. It empirically illustrated five broad categories of motives: self -focused, protégé-focused, relationship-focused, organizational-focused, and unfocused motives. Data from our interviews enrich our understanding of these specific types of mentors' motives. This way, our study offers several key contributions to mentoring literature.

First, our study shows how the application of an SDT framework creates a finegrained picture of both intrinsic and extrinsic self-focused motives that mentors can have when mentoring others. While previous research (Allen, 
2003) already distinguished two broader categories of intrinsic and extrinsic motives, the current study extends this research by differentiating four types of extrinsic motives. Most quantitative studies on SDT do not measure integrated regulation, because it is hard to distinguish from identified and intrinsic regulations (cf. De Naeghel et al., 2012). However, our qualitative data allowed us to nuance integrated regulation from other forms of motivations. This way, our study gives a theory-based and detailed insight into the broader category of extrinsic mentor motives. The results also provide nuances in the types of intrinsic motives that mentors can have, as we showed how mentors can have intrinsic motives to know, to accomplish, and to experience when mentoring others. This SDT continuum creates new opportunities for continued research on mentors' motivations. Based on previous work (Allen, 2003), it is expected that the various forms of motives lead to the provision of different mentoring functions. In Allen's study, mentors motivated by self-enhancement reasons were more likely to report providing career mentoring, while mentors motivated by intrinsic reasons were more likely to report providing psychosocial mentoring. As our SDT continuum creates more insight into the specific motives one can have, future research may examine how these specific forms of motives differentially relate to the provision of specific mentoring subfunctions (e.g., sponsorship, friendship, exposure and visibility). Also, we encourage researchers to examine how the specific types of motives are related to relationship satisfaction and well-being. From studies building on a hierarchical model of motivation (Vallerand, 1997), we know that motivations for relational activities show a unique and significant contribution to relationship well-being (e.g., Gaine \& La Guardia, 2009). We encourage mentoring researchers to examine how motives for specific mentoring functions (e.g., creating exposure and visibility, providing challenging assignments) can vary within and across developmental relationships, and influence relationship well-being as experienced by both members. Moreover, we encourage mentoring researchers to examine which contextual characteristics at the workplace can promote mentors' autonomous motivations.

Second, our study shows a comprehensive picture of motives that mentors can have when mentoring others. Besides general motivations to mentor others (e.g., because it is seen as part of the mentor's job), we show how mentors describe more concrete motives concerned with a specific protégé (e.g., 
admiration for specific characteristics of the protégé), or the relationship between the mentor and the protégé (e.g., the wish to continue or deepen an existing work relationship). This has important implications for future research on mentor motives. While previous studies on mentor motives most often focused on the willingness to mentor others as a general intention, this study shows that, although we agree that some mentors would be more likely to mentor others in general, motives that are more situational of nature may also play a role in one's willingness to mentor others. Especially in developmental network research, it would be valuable to compare the various motives one can have to mentor specific protégés in terms of, for example, relationship functions and outcomes. With regard to the measurement of mentor motives, we encourage researchers to develop scales that measure one's motives to mentor specific protégés, in addition to general scales (e.g., Ragins \& Scandura, 1994; Wang et al., 2009).

Third, this study contributes to our understanding of how both instrumental and relational motivations complement in mentors' willingness to provide developmental support to others. For example, mentors in our study reported both exchange-oriented motivations and affiliative-oriented motivations to help others. While we acknowledge that reciprocity may be important in some mentoring relationships, other exchange rules could play a role as well (cf. Cropanzano \& Mitchell, 2005). Further, our study illustrates that the decision to mentor others may sometimes be a decision based on bounded rationality. Mentors described that their decision to mentor others was sometimes based on intuitive feelings rather than logical reasoning. While most previous studies mainly focused on instrumental and cognitive motivations to help others, we agree with Allen (2003) that we should conceptualize the willingness to mentor others as a process in which instrumental, relational, and psychological motivations play a role, rather complementary than competing with each other. To conclude, this wider lens of looking at mentor motives shows a nuanced and theory-based exploration of the underlying motivations of developmental relationships.

\subsubsection{Limitations}

We acknowledge certain limitations of our study. First, our findings are based on a small number of mentors $(n=20)$, so caution is needed in generalizing the results from this study. Furthermore, we recognize that the results from this 
study apply to informal mentors. Formal mentors may describe other forms of motives than the mentors in our study. Although most formal mentors are not likely to be externally rewarded, these mentors may describe different extrinsic motivations, as research on SDT shows that more controlling social contexts (e.g., a formal mentoring program with a prescribed format) are likely to inhibit the internalization process (Deci \& Ryan, 2000). We look forward to seeing similar studies conducted with other samples so that we may compare and extend our findings.

Second, there may be a social desirability bias in our results as we worked in face-to-face interview settings. For example, almost all our participants mentioned that they were mentoring others because it benefits their organization. Intuitively, this motive is likely to be perceived more socially desirable than, for example, an introjected motive (i.e., involving egoenhancements). It could also be that the nature of our sample, consisting of employees holding a senior or supervisory role, influenced the omnipresence of the category of organization-focused motives. We would like to stress that the aim of our current study was not to display the prevalence of mentors' motives, but to identify a fine-grained and complete picture of motives. Therefore, we do not believe that these issues pose a major threat to the validity of our findings. However, we encourage other researchers to work with methods that are less susceptible to social desirability.

Further, we relied on retrospective data only. It could be that mentors are influenced in their descriptions of motives by past and current experiences in those mentoring relationships. For example, it may be that mentors describe their motives for pleasant mentoring relationships in retrospective accounts as more relationship-focused (e.g., because the relationship is meaningful for them), although they may not have mentioned this motive beforehand (e.g., in advance of the mentoring relationship). Therefore, future research may examine mentor motives from mentors in various stages of the relationship.

\subsubsection{Practical Implications}

This study also has practical implications. Insight into possible mentor motives is a first step for managers in promoting the internalization of the values and regulations of mentoring behaviors. Our results can help organizations to 
facilitate the mentor's' internalization process. The results can also guide organizations working with formal mentoring programs in both their sampling of possible mentors and their design of the program. While mentoring others implies a broad activity, specifying various motivational aspects of mentoring others may help mentors to internalize the value and regulation of their behaviors. 


\section{CHAPTER 5}

Relational contracts for fulfilling supervisory mentoring relationships: A dyadic study of PhD candidates and their supervisors 
"Your mentors should not be exactly the same as you. They have to be a little bit different. Because that forces you to think about things, to think in different ways. So, they all match with me, but they are not exactly like me. If they would have been the same as me, I would not learn from them."

-Anonymous protégé

\subsection{Introduction}

Mentoring relationships are important in individuals' careers. Mentored individuals perform better on the job, get promoted more quickly, and report more job and career satisfaction (Allen et al., 2004). Various mentoring scholars have intensively examined these positive aspects of mentor-protégé relationships (Eby, 2007). Both objective and subjective outcomes of mentoring for protégés have been studied (Allen et al., 2004), and recently, mentoring scholars have moved from focusing on protégés' benefits to the study of positive consequences for the mentor (e.g., Ghosh \& Reio, 2013). Yet little attention has been devoted to creating insight into which specific relational skills, behaviors, and processes influence members' satisfaction and positive experiences with mentoring relationships (Ragins, 2012). According to the perspective of relational mentoring (Ragins, 2012; Ragins \& Verbos, 2007), one reason for this is that most empirical research on mentoring relationships has focused on relationships of average quality and in so doing has remained silent on the factors that may lead to high quality mentoring relationships. In conceptual work on relational mentoring, however, a shift is made towards the study of how, when, and why some mentoring relationships turn into highquality relationships while others may not.

It is argued that one of the variables that may influence the occurrence of a high-quality mentoring relationship is an individual's set of mentoring schemas (Ragins, 2012; Ragins \& Verbos, 2007), which is a collection of implicit mental maps that individuals hold of what the mentor and protégé should do in the relationship, what the relationship provides, and how it functions. Both mentor and protégé hold such expectations, which form the basis of a relationship contract on what the relationship should "look like" (cf. La Guardia \& Patrick, 2008). Although there will always be some divergence in the mentoring 
schemas held by both members, schema congruence is optimal and will more likely result in positive experiences with the mentoring relationship than when members hold incongruent schemas (Ragins \& Verbos, 2007). The challenge for members of any interpersonal relationship is that such schemas are most often not explicit, and as a result, relational contracts may change without explicit renegotiation by the members of the relationship. To date, we have no insight into such relationship contracts in mentoring relationships and how they guide mentors' and protégés' experiences in mentoring relationships.

Using insights from self-determination theory (SDT), we examine in this paper how protégés and mentors experience their relational contracts on protégés' basic need-fulfillment processes in their relationship. According to SDT individuals have three basic psychological needs: a need for autonomy, competence, and relatedness. Autonomy refers to the experience of acting with a sense of choice, volition, and self-determination. Competence means to feel effective, skillful, and able to master challenges. Relatedness refers to feeling close and connected to important others, to experiencing a sense of belongingness, and to feel understood by others. Several studies on SDT showed that the fulfillment of these needs is related to both individual and relational well-being (e.g., Deci et al., 2006; Patrick et al., 2007; Sheldon et al., 1996). Moreover, SDT suggests that all three of these basic needs must be satisfied in order for people to experience high-quality relationships (Deci \& Ryan, 2014). It is therefore crucial to gain insight in the specific needfulfillment processes in interpersonal relationships. However, in the context of mentoring relationships, there is only little insight into how these basic needs are fulfilled and how these need-fulfillment processes are experienced by both members (Janssen, van Vuuren, \& de Jong, in press).

As an exception, a previous study showed how mentoring relationships can help protégés in several manners to feel a sense of autonomy, competence, and belongingness at work (Janssen et al., 2013). As such, that study provided a theory-based framework of developers' support functions. However, that study applied a one-sided view on the role of fulfillment of basic needs, as it only examined protégés' perceptions of developers' support. We have no insight into how mentors try to support protégés' basic needs and how this (mis)aligns with perceptions of protégés. To get more insight into which relational contracts between mentor and protégé on protégés' need-fulfillment processes 
are enacted during mentoring relationships and how the (in)congruency of expectations influences the experience of these basic need-fulfillment processes, a dyadic approach is needed. By conducting 18 individual interviews with couples of protégés and mentors, we were able to get a more complete understanding of the role of protégés' basic needs satisfaction in developmental relationships, and how mentors' and protégés' perceptions and expectations of need-fulfillment harmonize with or differ from each other. Our research question is the following: How do mentors and protégés negotiate the ways in which protégés' basic needs for autonomy, competence, and relatedness are fulfilled in their supervisory mentoring relationships?

\subsection{Theoretical Background}

\subsubsection{Mentoring Schema Theory}

In every interpersonal experience, people hold and further develop cognitions about their relationships. Relational schema theory states that such cognitions-relational schemas-tell people what to expect from their relationships, how they should behave in any interpersonal interaction, and how the other is likely to respond (Baldwin, 1992; Planalp, 1985, 1987). According to relational schema theory, people hold a self-schema, an otherschema, and an interpersonal script for every interpersonal relationship. Selfschemas involve cognitive structures on "who I am when I'm with you." Otherschemas encompass cognitive structures of how a relational partner should behave in the context of the relationship. The interaction of these schemas results in an interpersonal contract or script: "a cognitive structure representing a sequence of actions and events that defines a stereotyped relational pattern" (Baldwin, 1992, p. 468). That way, relational schemas help people in their sensemaking of their interpersonal relationships (Baldwin, 1992; Weick, 2001).

Building on these principles of relational schema theory, relational mentoring proposes that mentors and protégés hold mentoring schemas about their mentoring relationships: "cognitive maps derived from past experiences and relationships that guide mentors' and protégés' perceptions, expectations, and behaviors in mentoring relationships" (Ragins \& Verbos, 2007, p. 101). Each member holds a general and specific self-schema. For example, protégés hold 
mental representations about their general role as a protégé (e.g., 'Protégés should follow their mentor'), as well as specific mental representations reflecting their role in specific mentoring relationships (e.g., 'When I am with this mentor, it is okay if I also talk about things from my private life'). The protégé also holds a general and specific other-schema. For example, protégés hold mental representations about what mentors generally are (e.g., 'Mentors are experts'), and they also have specific knowledge about what their mentor in this particular relationship does (e.g., 'My mentor helps me to build a network'). At the same time, the other member (the mentor) also holds such self-schemas and other-schemas about his or her role as mentor, and about the protégé. The interplay between these two schemas is established in an interpersonal script, which is an if-then expectation (e.g., 'If I feel stressed, I can turn to my mentor, who will then give me advice and listens to me, to calm me down').

Relational mentoring (Ragins, 2012) conceptualizes that when mentoring schemas of mentors and protégés align, it is more likely that they will develop a high-quality mentoring relationship than when both members have different views of their own role and the role of their relational partner. However, in practice, it is possible that both members tend to have different perspectives and attitudes regarding their roles. From leader-member exchange literature we know that leaders are more likely to form work-related expectations of members (e.g., wfhether their subordinates are team players), while members tend to form social-related expectations from leaders (e.g., whether their supervisors are friendly) (e.g., Huang, Wright, Chiu, \& Wang, 2008). In the present study, we looked at how mentors and protégés agree on how protégés' basic needs for autonomy, competence, and relatedness are fulfilled. According to SDT, satisfaction of these three basic psychological needs is necessary for high-quality relationships to develop (Deci \& Ryan, 2014) and therefore we propose SDT as a framework for studying how relational contracts are negotiated between mentors and protégés.

\subsubsection{Need-Fulfillment in Mentoring Relationships}

SDT is a theory of human motivation and sees people as innate growth-oriented organisms, striving towards intrinsic functioning (Deci et al., 1997). However, it depends on their social environments to what extent these growth-orientations become manifest. The social context can either facilitate or impede this intrinsic functioning, by supporting or thwarting individuals' basic need-fulfillment. 
When individuals' basic needs for autonomy, competence, and relatedness are fulfilled, their functioning, well-being, and motivation will be optimal (Deci \& Ryan, 2000). For example, Deci et al. (2001) showed that a work climate that allows satisfaction of the need for autonomy predicts the overall need satisfaction, which in turn predicts both task engagement and employees' wellbeing.

Interpersonal relationships play an important role in these need-fulfillment processes, as relational partners can actively attempt to understand the person's preferences and perspectives (autonomy), provide clear and consistent expectations and structure (competence), and show interest in and convey that the person is significant and cared for noncontingently (relatedness) (La Guardia \& Patrick, 2008). Previous work already showed the relevance of the fulfillment of basic psychological needs in the context of mentoring relationships (Janssen et al., 2013). First, mentors respond to protégés' needs for autonomy, for example by encouraging self-initiation and provide protégés with a sense of freedom. Next, they provide reasonable expectations, for example by creating an environment to practice, which support protégés' competence needs. Last, they provide several types of relatedness support as they create a warm, loving, nurturing environment, for example by showing genuine interest. So, in its best form, a mentoring relationship would form a social context in which protégés' three basic needs are fulfilled. SDT shows that for high-quality relationships to develop, it is necessary that satisfaction of all three needs is experienced (Deci \& Ryan, 2014).

However, we conceptualize that in practice, it is most likely that in developmental relationships not all needs are fulfilled equally. It is likely that there will be differences in the relative importance of the three needs between various dyads (Custers, Westerhof, Kuin, Gerritsen, \& Riksen-Walraven, 2012; La Guardia \& Patrick, 2008). Although SDT research shows that the presence of support for all three needs is important, some developmental relationships may be especially important for meeting the need for competence. In the fulfillment of the other two needs, it is likely that some developmental relationships may be more important for meeting the needs for autonomy (e.g., supervisory developmental relationships), while others may be more important for meeting the needs for relatedness (e.g., coworker developmental relationships). To date, 
we have no insight into how mentors' and protégés' role-expectations (mis)align, how this contributes to differences in mentoring experiences, and how mentors and protégés build a relational contract based on these expectations and experiences. When protégés for example expect their mentoring relationship especially to be important in the fulfilment of their need for relatedness, but the mentor perceives his or her role as mainly supportive in the protégé's need for competence, this will likely result in a relationship with more negative experiences than when both mentor and protégé see their relationship as mainly important for fulfilling the protégé's need for competence. By using a dyadic design, we aimed to get more understanding in how both mentoring partners perceive and experience such need-fulfilment processes in their relationship, and thus build relationship contracts on this.

\subsection{Method}

\subsubsection{Organization and Participant Selection}

For triangulation purposes (Patton, 1999), we aimed for a dyadic view on protégés' need-fulfillment in developmental relationships so we looked for pairs of mentors and protégés to include in our study. We chose for a specific supervisory mentoring relationship and selected alumni PhD candidates of our home university, and their supervisors. This relationship forms a natural context for participants to talk about developmental needs and processes. The university is located in the Netherlands and in the year 2014, it employed 1676 scientific staff employees and $244 \mathrm{PhD}$ candidates did receive their doctor's degree. Unlike in many other countries, most $\mathrm{PhD}$ candidates in the Netherlands are paid by their university as a regular employee with a set salary level. Most PhD candidates in the Netherlands work full-time or nearly full-time on their PhD thesis and have an employee contract of anywhere between three and five years (Van de Schoot, Yerkes, Mouw, \& Sonneveld, 2013). They are hired by and supervised by a Full Professor, often in cooperation with an Associate or Assistant Professor.

Alumni PhD candidates were invited to participate by receiving a letter at their home address. Names of these possible participants were obtained from a central alumni records office of the university. We sampled PhD candidates who had finished their dissertation between 2011 and 2015. To ensure a safe 
context to talk about their supervisory mentoring relationship, we only sampled PhD candidates who found a job outside the university, after their contract had ended. In the letter, we explained the purpose of the study and provided them a broad definition of mentoring, based on the definition of Kirchmeyer (1995, p. 72): “A senior manager who provides emotional support, guidance, and sponsorship to a less experienced person." This way, we focused on mentoring supervisory relationships, instead of on regular supervisoremployee relationships. Alumni PhD candidates identifying themselves as being mentored by one of their supervisors and willing to participate provided us with a name of their former supervisor. While we focused on positive mentoring relationships in our recruitment letter, we also got responses from alumni PhD candidates who regarded their mentoring relationship as more neutral (having both positive and negative feelings about their mentoring relationship) and in one case as negative. To include a full range of possible cases and in that way improve the quality of our study (Patton, 1999), we chose to include such neutral or negative cases in our final sample as well. Next, we informed correspondent supervisors about the study and invited them to participate. Although all supervisors were initially willing to participate, one of them did not respond to the invitation to make an appointment for the interview and (s)he and the corresponding protégé were thus not included in the sample.

Our final sample of 18 participants consisted of 9 dyads, consisting of alumni PhD candidates and their supervisors. Protégés ( 7 men, 2 women) were aged between 28 and 59 years (mean $=35$ years), and average years spent on their dissertation was 4.7 years. Protégés represented current job categories such as Postdoc Researcher, Policy Advisor, and Lecturer. Supervisors (6 men, 3 women) were aged between 49 and 67 years (mean $=55.6$ years). Average tenure within the organization was 14.3 years, with a range from 7 to 24 years, and average job tenure was 10.1 years. They consisted of 1 Senior Researcher, 1 Emeritus Professor, 1 Associate Professor, and 6 Full Professors.

\subsubsection{Data Collection}

Mentors and protégés were interviewed separately because it was assumed that they would talk more openly about their relational experiences if their mentoring partners were not present. All interviews were conducted in person 
by the first author, and were recorded after permission. Two comparable semistructured interview protocols were developed (one for the protégés and one for the mentors). The interview protocols were designed to reveal the experiences and perspectives of participants through stories, accounts, and explanations (Lindlof \& Taylor, 2002, p. 72). To start the conversation, the first author asked participants to introduce themselves and give an outline of the PhD-project. After that, three themes were explored during the interview. First, participants were asked to describe positive and negative events or periods of time in their mentoring relationship, and to describe the role of the other in these events. Second, we examined support functions provided by the mentor. We asked protégés to describe how their mentor supported them and accordingly, we asked mentors how they supported the protégé. We probed for specific examples on career support, psychosocial support, and role modeling (Kram, 1985). We also asked both protégés and mentors what the relationship meant to them, in both instrumental (e.g., supporting career development) and relational (e.g., a sense of belongingness) ways (cf. Janssen et al., 2014). Third, we focused more deeply on the fulfillment of the needs for autonomy, competence, and relatedness in the relationship. We explained the meaning of these basic needs, based on previous work on basic need-fulfillment processes in developmental relationships (Janssen et al., 2013). We asked protégés to describe the role of each of the basic needs in their relationship with their mentor, and to what extent their mentor supported their need-fulfillment. In the version of the mentors, we asked participants to describe the role of each of the basic needs in the relationship, we asked them how important the three basic needs were for the protégé, and to what extent they were able to support this need-fulfillment. Again, we probed for specific examples of (non)supportive behaviors. At the end of each interview, we asked participants to what extent their expectations were met in the relationship, to describe their current relationship, and to share any other information about the relationship that they felt was relevant. Interviews typically lasted about 1 hour.

\subsubsection{Data Analysis}

All of the interviews were transcribed verbatim, leading to 203 transcript pages, and were analyzed with the help of ATLAS.ti software. Given the open-ended nature of our research question, we believed that working with categories derived from a content analysis would be too restricting. Instead, we conducted a more holistic approach of analysis. Based on a constant comparative method 
for dyadic interviews as described by Boeije (2002), the data analysis occurred in four phases.

In the first phase, the first author read all transcripts and marked any segments that revealed information about participants' views of the role of autonomy, competence, and relatedness in their relationship. In the second phase, all three authors conducted analyses on these interviews. The authors separately conducted comparisons within the single interviews to examine the consistency within the interviews and to formulate memos with core messages of the interviews with regard to the role of autonomy, competence, and relatedness. These memos were then discussed during meetings to complete the picture of how participants experience the fulfillment of basic needs and to enrich the analyses conducted by the individual authors. As a third phase, we also conducted comparisons in pairs at the level of the couple during several discussion meetings. For each couple, we reconstructed the relational contract between mentor and protégé from what they said about each other's role in the fulfillment of the needs for autonomy, competence, and relatedness, and about their relationship. This analytical phase produced insights into mentors' and protégés' similarities and differences in expectations and perspectives with regard to the fulfillment of the need for autonomy, competence, and relatedness. These discussions were recorded and based on these discussions and the previous memos, the first author composed a conceptual summary for each of the basic needs in each mentoring relationship. As a fourth step, these conceptual summaries were discussed by the three authors in multiple other discussion meetings to look for themes and patterns within and between the accounts of the dyads. In this phase, we formulated central questions that guide the relationship between mentors and protégés. For example, for autonomy, one of the questions that guided the relationship was the question: "Who takes the lead?" Applying an iterative procedure, we moved back and forth between the data and literature on mentoring and SDT, and added to and adjusted our central questions when necessary. The resulting questions all reflect mentors' and protégés' relational contracts on how their relationship "looks like or should look like" with regard to the fulfillment of the need for autonomy, competence, and relatedness. 


\subsubsection{Researchers' Positions}

As we sampled alumni PhD candidates and supervisors from our home university, we had prior views on the subject. We had our own perspectives about how a relationship between a PhD student and a supervisor should look like, and which supporting behaviors would be necessary or desired. Such prior perspectives can bias data collection and data analysis. Moreover, because of our proximity to especially the supervisors in this study, some participants may not want to share information to the interviewer, in fear of their reputation and anonymity. We took several steps to minimize methodological limitations caused by our preconceived conceptions about the research context and our proximity to the participants.

A first challenge for doing insider research is preunderstanding of the researchers (Brannick \& Coghlan, 2007). This has both advantages and disadvantages. On the one hand, we believe that the first author had extensive knowledge of participants' everyday jargon and their experiences, and was therefore better able to follow up on replies during the interviews, and to obtain richer data. On the other hand, we believe that such preunderstandings may have created preconceptions about our research topics. To limit this, we worked with three coders during the analyses and held extensive discussions about our independent analyses, to foster our self-awareness of such preunderstandings.

Another challenge was the first authors' role duality as organizational member and interviewer and the other authors' roles as organizational members and research team members (Brannick \& Coghlan, 2007). As an advantage, we believe that the interviewer was able to build rapport with the participants more easily. However, we also believe that our proximity could have disadvantages in terms of trust relations between the interviewer or the researcher team, and the participants. Especially the supervisors, who wereexcept one Emeritus Professor-still working for the university, might have given more socially desirable responses, to not disclose information that is against the social norms. To diminish this limitation, we ensured that the participants were no direct colleagues of our own department. We also assured participants that the research would not affect them academically or personally in any way: only the first author knew the names of the participants, and all names and any other identifying information were changed by this first author 
during transcription to protect the privacy of participants. Also, because we worked with pairs, we chose to not present coupled data in our results section as our participants would then be able to identify their own quotes and thus, what their corresponding mentoring partner had said.

\subsection{Results}

In this section, we present our findings of how mentoring dyads negotiate the ways in which protégés' basic needs for autonomy, competence, and relatedness are fulfilled in their supervisory mentoring relationships. For each basic need, we reconstructed how mentors and protégés try to find an agreement on the ways in which this need has to be fulfilled in their mentoring relationship. Based on their alignments and misalignments on perceptions of need-fulfilment processes, we show the satisfaction, challenges, and difficulties they experience. Table 5.2. gives a summary of the negotiations on which mentors and protégés try to find agreement.

\subsubsection{Autonomy}

To feel a sense of autonomy, employees need to experience choice in their work and need to feel that they are the initiator of their own actions (Deci et al., 2001). In the context of this study, the satisfaction of protégés' needs for autonomy is complicated because autonomy turned out to be both a basic need of protégés and a requirement that mentors set for protégés' competence. Participants expressed that protégés who show autonomous behavior (e.g., come up with own research ideas, make own choices that they value) are seen as optimally functioning researchers. In this way, autonomy is highly intertwined with competence. This link between autonomy and competence results in two themes on which mentors and protégés have to find agreement during their relationship.

First, agreement has to be found on who takes the lead during the research project. For protégés, it is important to feel a sense of autonomy in that they are allowed to make self-directed (instead of controlled) decisions during their dissertation project. For the success and completion of the project (i.e., protégés' sense of competence), however, it may sometimes be necessary that mentors take decisions and take a leading role in the project. Second, mentors and protégés need to align their perceptions of when a protégé should be able 
to show autonomous behavior in the research project. While some mentors expected their protégés to make autonomous choices from the beginning, other mentors and all protégés regarded the dissertation research project as a pathway in which the protégé gradually becomes competent and thus learns to deal with more autonomy.

\section{Who takes the lead?}

When mentors and protégés work together, they have to construe a form of cooperation with regard to autonomy that will satisfy them both. Our findings reveal that, during their cooperation, mentors and protégés seem to implicitly negotiate on who takes the lead during the dissertation project, and thus, is the owner of the research project. Two needs play a role in these negotiations. First, although protégés differ in the extent to which they express their need for autonomy, they all want to experience a certain sense of autonomy. This involves that their mentors offer opportunities for choice and encourage protégés' self-initiation (Janssen et al., 2013). At the same time, protégés want to experience a sense of competence, and therefore it is needed that they experience some successes and progress in their research project. According to protégés, this requires that their mentor sometimes takes decisions and in that way gives direction to the project. However, this may limit protégés' sense of autonomy. The result of such negotiations on how much autonomy is given during the project is visible in the accounts of mentors and protégés when they describe their forms of cooperation. We found that most protégés initially expected their mentor to take the lead during the project, as mentors have authority, based on their experience: "...of course he already went through this process, because he already got his PhD." Protégés also expected their mentor to take the lead based on their mentor's formal leadership function:

"[Mentor] is the leader and she knows what she wants and what not and if something is a good idea or not. And probably, she is right in that [laughs]. I never experienced that as something annoying. .... No, I think, maybe I don't have that need to really follow my own path. Like, I want this and this in my research, no, I don't have that."

As this example shows, protégés may grant their mentor to take a leader identity, and perceive their own role as one based on a follower identity (cf. DeRue \& Ashford, 2010). When both mentor and protégé have such a schema of 
the mentor as leader who manages the protégé through the project, this works very well. Mentors' and protégés' expectations then seem to be aligned on this specific point regarding their autonomy. For example, the following mentor explained that she formed an expert-apprentice relationship with her protégés, to intensively teach them how to conduct research and write about it:

"Well, in the beginning, you have to be quite demanding. Because then you have to teach them to focus. .... So we had an expert-apprentice relationship. .... I think that's beneficial to PhD-students. ... If you write together with your professor, you'll learn the tricks of the trade. ... So you'll learn to conduct research and to publish your articles, because you work together."

This protégé also explained that she accepted such a leading and somewhat demanding role of her mentor, because she had professional respect for her mentor and perceived her mentor as a role model, whom she wanted to follow:

"That also means, for me, that I also adopt a learning attitude when I have contact with her. And that I realized that I had the opportunity to learn a lot from how someone else works. .... So, it is not entirely self-managing."

Protégés may find themselves not to be in the position to give direction to the project, as they have little experience in conducting research projects. It may be safer then to rely on their mentors' expertise and thus to grant their mentor a leader identity.

However, in some other dyads, the expectations of the mentor and protégé on who should take the lead during the project did not align, and this resulted in difficulties in their cooperation. While most protégés seemed to have an idea of that the mentor has authority and thus should take the lead, some mentors perceived their cooperation with their protégé as a side by side project, in which they both had equal participation on how the project would look like. Mentors may struggle with their authority, are highly autonomy-supportive, and may be reluctant to tell their protégé what to do:

"And that you also work together in your research. I like that the most. .... And that is also the way I work with people and even with students: side by side and shoulder to shoulder, to get things done. .... That you really work together. And not in the same role, but in an equal position. 
Table 5.2. Questions that Guide Mentors' and Protégés' Relational Contracts on the Role of Basic Need-fulfillment in Their Mentoring Relationship

\begin{tabular}{|c|c|c|}
\hline Basic needs & $\begin{array}{l}\text { Questions that guide } \\
\text { relational contracts }\end{array}$ & Illustrations \\
\hline \multirow[t]{2}{*}{ Autonomy } & Who takes the lead? & $\begin{array}{l}\text { "Well, [Mentor] had always ideas and thoughts about how it } \\
\text { should be. I think he got a clear vision about what should } \\
\text { happen in the project. But at the same time, I also got } \\
\text { enough freedom to accomplish it in my way." }\end{array}$ \\
\hline & $\begin{array}{l}\text { Is this protégé able to make } \\
\text { autonomous decisions? }\end{array}$ & $\begin{array}{l}\text { "In the beginning, I was quite demanding, I think. Later on, } \\
\text { she took more the lead. She knows the criteria, so she has a } \\
\text { more proactive attitude now. And I like that. I think it should } \\
\text { be that way, because it is a test of you as a researcher. So, } \\
\text { [the protégé] should take that lead." }\end{array}$ \\
\hline \multirow[t]{3}{*}{ Competence } & Is this mentor a real master? & $\begin{array}{l}\text { "He was very good. He is also well known in the industry. So, } \\
\text { if they knew that you were a PhD-student of [Mentor], it was } \\
\text { easier for you. So that was nice." }\end{array}$ \\
\hline & $\begin{array}{l}\text { Is this protégé a real member } \\
\text { of the community? }\end{array}$ & $\begin{array}{l}\text { "...he is able to, he knows the rules, but I don't think that he is } \\
\text { a real curious researcher, intrinsically. It's something you } \\
\text { have, or you don't have, you know? Do I really want to know, } \\
\text { a kind of curiosity. And I did not always sense that from } \\
\text { him." }\end{array}$ \\
\hline & Am I good enough? & $\begin{array}{l}\text { "She was invited to give a talk about her work. And she } \\
\text { mentioned me in that. So I was in the same room and yeah, I } \\
\text { thought: she really gives me recognition. ... She mentioned } \\
\text { that I was important, to her, or to the field. And not, because } \\
\text { you sometimes hear about professors who don't give the } \\
\text { credits to their students, and really take advantage of them." }\end{array}$ \\
\hline \multirow[t]{3}{*}{ Relatedness } & How close do we get? & $\begin{array}{l}\text { "He knows my wife, and I know his wife, I met her also a } \\
\text { couple of times. So, you know each other in other ways than } \\
\text { only professional, or work-related." }\end{array}$ \\
\hline & $\begin{array}{l}\text { Who is responsible to take } \\
\text { care? }\end{array}$ & $\begin{array}{l}\text { "Well, she, [Mentor] does not have a real sense of empathy, } \\
\text { so to say. Our relationship was quite businesslike. .... So if } \\
\text { there are some private mattes, she will not ask you about } \\
\text { that." }\end{array}$ \\
\hline & Am I like you? & $\begin{array}{l}\text { "We called ourselves the éminence grises of the group, } \\
\text { because we were older than the rest. So, we had something } \\
\text { in common." }\end{array}$ \\
\hline
\end{tabular}

.... And yeah, what I found a little bit disappointing was that he, I would have liked it if he would have delved a little deeper. .... And he didn't do that. And of course I can tighten the screws on then and say: 'I think you should do this again.' But I also think that someone has to follow his own path, has his or her own style in that. .... And who am I, .... to say: 'No?'” 
In the role-taking processes between mentor and protégé, protégés may discover after some time that their mentor will not take a leader role during the project. This may cause dissatisfaction by protégés who initially had the expectation that their mentor would do so. The following negative example shows how a protégé got lost during his dissertation project. He expected his mentor to take the lead, to provide him with safe opportunities for selfinitiation, and to have a clear idea of the ideal direction of the project. His mentor could not fulfill these needs in the ways the protégé expected, and this resulted in the protégé feeling lost and feeling overwhelmed by research opportunities and directions:

"And especially in the beginning I was like, [Mentor] is going to tell me what to do. I was a little bit obedient in that sense. [Mentor] is professor, he will know what to do. He is the leader. And I will follow. ... It's like you're walking in a forest, and .... I would have expected that [Mentor], well, not that he would take me by the hand, but that he would have walked behind me, and would say: 'Take this side-path,' and that he would wait on the path and would say: 'Then you know where to come back. Have a look, is that something? If it is, then we go back to our initial path with a detour, and if it is not, then this is the way back.' And well, at a certain point, he walks in front of me, so to say. And he takes a side-path, I walk behind him, but then he has another idea and I follow another side-path and all of a sudden you cannot find each other anymore. And that's exactly, that's what's happened... I noticed that I lost the way, [Mentor] also noticed that, that I lost track, maybe he lost the same path also, I don't know, but we never ... said: 'Okay, we're lost in this together, let's make a new start, from where we can begin again and we'll see if we have to follow another path than our initial path, but we'll do it together.' That moment never came."

This example shows the difficulties in finding an optimal balance between providing a protégé with enough autonomy to make own choices, and at the same time, protect the protégé from being overwhelmed by the project by giving clear directions on what to do.

In few dyads, we found that the research was owned and directed by the protégé and the mentor was keeping a low profile. In some cases this ownership is granted to the protégé by the mentor. As one protégé explained: 
"Autonomy is actually a requirement of [Mentor]. So you have to come up with your own plan. .... And he delegated responsibilities. So he said: 'Well, it is your research, right?'" In other cases, the ownership is claimed by the protégé. For example, the following quote from a mentor shows how the protégé's autonomous attitude guided the research:

"What I really liked about [Protégé] was that she was very honest about her opinions. She really didn't like some things. I once suggested to use a certain scale. .... And then she said: 'No, I really don't like that, it's vague stuff.' .... I found that, I was fed up for a while, but actually I also found it very good. It was her research, so I understood."

\section{Is this protégé able to make autonomous decisions?}

For every mentor, the protégé's autonomous behavior (e.g., making own decisions during the project, after consultation of the mentor) is seen as a proof of competence of a mature researcher. Becoming an autonomous researcher is mentioned as ultimate goal of the dissertation period by mentors, and by most protégés. However, mentors' schemas on when a protégé has to show this autonomous behavior varied. Most mentors perceived the dissertation project as a developmental process in which autonomy gradually develops. In the beginning protégés need a lot of guidance and direction, and when they become more confident, know the ins and outs of conducting research and experience a sense of competence, they are trusted by their mentor to make own research decisions. Similarly, protégés also talk about such developments in their behavior:

"Yeah, to keep your own focus and also, that you not necessarily have to do everything anyone else is telling you, or if someone says: 'Go find out this and this.' You are allowed to have a discussion about that. So that's something I learned, to not just bow to something, but to discuss things and to be not afraid of that."

Although most mentors seemed to have a schema on autonomy as something that is gradually evolving during the developmental process of the protégé, some mentors seemed to demand an autonomous attitude of their protégé from the start, making it a conditional ingredient for a successful cooperation: 
"My style is that someone, I assume that someone will shape that project by him or herself. And by monitoring that, you make an accurate assessment if that is correct, your assumption. .... So my way of working is not that I say, that I tell them beforehand what to do and that I give then more freedom after a while. No, I try to find out what someone has to offer and based on that I will adapt my guidance. So initially, I already assume a certain amount of autonomy."

In some dyads, this high amount of autonomy given by the mentor worked very well. Protégés then explained that they had a high need for autonomy, liked to design their work in their own ways, and thus could deal with the freedom created by their mentor. As one protégé told us,

"I really needed that autonomy. Not so much because I really wanted to do it alone, but because I had certain views on what was possible. And I wanted to do my research unhindered, with a positive or a less positive result, but that was the way I wanted it to do."

In other dyads, the expectations between the mentor and protégé on when the protégé should show autonomous behavior misaligned and this caused problems in their relationship. Although protégés in general appreciated their mentors' autonomy supportive behaviors and how they created freedom for them (Janssen et al., 2013), protégés may also struggle with this freedom, as they may have the feeling of being thrown in at the deep end. This protégé explains that the amount of autonomy given or demanded by the mentor formed a threat to the success of the project:

"I was able to do my work quite autonomous. .... In the beginning, it was like I was being dropped, I was just being thrown in the deep end and there was no guidance. .... It is nice to do what you think is best, but you also have to gain experience and soon you'll experience that you're going in the wrong direction and you miss focus. .... And in the end you have to, because time is running out and then you are forced to focus and to say: 'That's something we will do and that's something we won't.' .... [so] it went from very autonomous to less autonomous. That's been an important development in my dissertation project. ... If that would have stayed the same, I don't know if it all turned out well." 
Although one would say that this protégé may experience a great sense of autonomy in his project, we see that the lack of providing competence support to this protégé (e.g., by giving structure and guidance) caused time pressure, which may be experienced as an external pressure and control. This may hinder the satisfaction of one's need for autonomy (Deci \& Ryan, 2000).

\subsubsection{Competence}

To feel a sense of competence in their work context, employees need to accomplish optimally challenging tasks and realize desired outcomes (Deci et al., 2001). One way of being able to do so, is by acquiring skills and competences that are relevant for their specific work context. The Association of Dutch Universities (Vereniging van Samenwerkende Universiteiten) has set an extensive list of competences (such as conceptual clarity, analytical clarity, and accuracy), which are needed for employees of the Dutch universities to perform their jobs successfully (Association of Dutch Universities, 2010). One would say that mentors and protégés use such criteria to evaluate their mentoring partners' skills (i.e., that their relational contracts are built on such competences), and to make sense of protégés' needs for competence. Our results reveal that protégés and mentors constantly evaluate their partner's skills during their mentoring relationship, however, the criteria they use for this are only vaguely described in their accounts. Mentors and protégés rely on tacit knowledge for this, consisting of broad and vague descriptions of competences. Their negotiation on relational contracts regarding competence becomes visible in three struggles, on which they have to find agreement during their relationship.

First, our findings reveal that protégés expected their mentors to be masters in a full spectrum of research skills. However, during their dissertation project, most protégés found out that their mentor is and cannot be an expert in all these fields. Second, our findings reveal that mentors and protégés used their mentoring relationship as a litmus test to see if the protégé is a real scientist and thus belongs to the scientific community. These criteria for classifying a protégé as a real scientist are however vague and often unspoken. Last, most protégés explained that they were, at some point of time, insecure about their dissertation project. However, most mentors find it difficult to estimate the extent to which their protégé's need for competence is fulfilled in the 
relationship, as basic needs and need-fulfilment processes remained implicit in most cases. We found that mentors' attempts to confirm their protégés' sense of competence in many cases did not meet the needs and expectations of their protégés.

\section{Is this mentor a real master?}

Protégés seem to enter the relationship with their mentor with high expectations. During their interviews, protégés explained that they looked for "a master, someone you look up to, where you can learn from", and whose career behavior they can and will emulate. In other words, protégés expect their mentors to be role models (Kram, 1985). As we have seen in previous work (e.g., Ibarra, 1999; Janssen et al., 2013), it is most likely that this role modelling process results in 'selective imitation', as it is rare to find one single person who can meet all of one's mentoring needs. However, our findings reveal that protégés expected their mentor to be a role model in a comprehensive set of fields: being a content expert (mastering the specific knowledge field of the protégé), a process expert (providing structure in the process of conducting research), and a skills expert (being a specialist in for example writing, presenting, and statistics).

Sooner or later, however, protégés experienced that the expertise of their mentor has limitations. As a consequence, protégés had to make sense of how far their mentors' expertise reached and where they had to look for role models and mentors in other developmental contexts. Strikingly, only a few participants perceived their mentor as a content expert, with extensive knowledge in a specific literature domain. In these cases, mentors were able to give in-depth feedback on the work of their protégé and they functioned as an inspiring role model. In several other dyads, however, the mentor took the role of process expert. This expert knows the ins and outs of doing research, but not necessarily in the very specific field of the protégé's research. The role of the mentor was then to provide clear, consistent, and reasonable expectations (cf. La Guardia \& Patrick, 2008). Protégés appreciate it when mentors guide them during their dissertation project, and provide structure in the process of conducting research and writing a dissertation by telling "how you have to plan your dissertation," and when it is time to "put one chapter aside and continue with the next chapter" of the dissertation. This way, mentors prevent their protégés to be overwhelmed by the challenges and tasks of their dissertation 
project. For some protégés this worked very well, as they tried to find other developers for specific knowledge and skills that their mentor was lacking:

"... we both had our weaknesses in programming skills. .... And that was a weakness of both of us and I really had to search for help from elsewhere to do things with that. Well, luckily I found that, because [Mentor] could not support me in that, actually."

During the interviews, mentors also acknowledged their limitations. They discussed how important it is for protégés to build a solid developmental network (Higgins \& Kram, 2001), to come into contact with other experts, who complement the mentor's expertise and skills. As one mentor told us:

"That you give guidance now and then, but also give him freedom to look for competences from others. Yeah, instead, you sometimes notice that a professor has an attitude of: you are my PhD-student. You do what I tell you to do."

Again, competence and autonomy are intertwined needs here, as it may be required for the success of the project that mentors provide their protégés with autonomy to search for appropriate expertise outside their primary mentoring relationship.

Of course, there were also protégés who explained that they missed the feeling of having a role model, for example because their mentor was not an expert in their specific knowledge field:

"In terms of technology, I really had to consult other people. He could not really help me with that. So that was a pity. Some people do have a professor who really is an example in that, or someone who is really good with theory and literature, or in setting up experiments, but I didn't have that."

Other protégés questioned their mentor's expertise and competence, finding the difference between their own knowledge and that of the mentor too small. For example, as one protégé explained, "Concerning my prior education, I actually had better education in that specific field." Another protégé was highly critical about his mentor's competence: 
"At some point of time, I noticed that I had the same level as her. .... And of course that's the aim in the end, .... but I noticed that, I had that quite fast. Actually after half a year, or year, I noticed that I was on the same level. So that's something I found difficult."

As this example shows, this protégé seemed to have the expectation that it is the purpose of the mentoring relationship to get at a comparable level as his mentor, however, the knowledge difference between this protégé and his mentor was too quickly closed. This resulted in characterizing his mentor as not being a real master.

\section{Is this protégé a real member of the community?}

Our findings reveal that most mentors see the mentoring relationship with their protégé as a period in which they can determine if the protégé is someone who belongs to the scientific community and deserves a place in academia. Mentors try to get clues during the dissertation project to estimate if their protégé is what they call 'a real scientist'. Apparently, mentors hold schemas of how a real scientist would look like, and they judge their protégé according to this set of schemas. These fuzzy sets of attributes (cf. Hogg \& Reid, 2006) define protégés as real scientists and distinguish them from a group of protégés not belonging to the scientific community. Similar to protégés, mentors ask themselves if their protégé is good enough. The competences and characteristics belonging to the schema of real scientists were however only loosely described in mentors' accounts. Most mentors described competences of protégés that turned out not be real scientists. When a protégé is not a real scientist, according to the mentors, he or she can be characterized by no intrinsic drive to investigate problems in real depth, an impatience to investigate things accurately and thoroughly ("... to really work at a university, that didn't suit her. ....It also has to do with her impatience, to really want to, to really investigate things, she's a little bit too pragmatic for that, I think."), and not looking for challenges during the dissertation research but choosing the line of least resistance:

"I think he's never a really fundamental researcher. .... What I would have liked, was that he would have done real experiments in our lab. And he never got there [laughs]. .... He never went into the lab. .... That was not his cup of 
tea. ... And well, I think that you just choose to do what is most easy for you then."

In contrast, protégés who show ambition, an eagerness to learn and to excel, look for challenges during their dissertation research, are curious, and reflective are most appreciated by their mentors:

"... he was really driven, he was really curious about things. .... He could really sink his teeth into a subject. Really great to see that. ... But he was also very curious, read a lot to catch up his knowledge, yeah, great to see. So he really was driven by curiosity, he just wanted to know everything."

Protégés lacking these competences were described as competent workers, but no real scientists. In line with self-categorization processes (Hogg \& Terry, 2000; Postmes \& Branscombe, 2010), protégés who did not meet the mentor's schema of how a scientist would behave, were seen as prototypes of the outgroup. Similar to ingroup favoritisim and outgroup antagonism processes (Mummendey \& Wenzel, 1999), some of these prototypes were experienced as negatively deviant. This deviance of the protégé was then explained through the perception of belonging to a different social category:

"He once said: 'Yeah, all those intelligent and complicated things, it does not necessarily makes you happy.' So, he's not someone who complicates things. And I think that's something he got from his family. Like, we have a home, we put flowers on the table, we have enough food, we have our hobbies, a couple of friends, well, then it's good. We're satisfied. And yeah, why would you complicate things then? Yeah, I think that's just the way he sees things in life."

Some mentors also devaluated their protégé and explained that their protégé was provincial (instead of cosmopolitan), and simple (instead of striving for profundity).

Protégés also used the period of their doctoral research to estimate if they would pursue a career in academia after finishing their dissertation. Knowing the ambitions of protégés sometimes influenced the expectations and competence-supportive behaviors of mentors. As one mentor explains, her protégé told her once that she had the ambition to become a professor one day. 
Based on this, the mentor explained that she raised her standards with regard to output requirements:

"She once told me: 'I would like to publish this in a highly ranked journal, because I want to become a professor too.' And I thought that was maybe a little too ambitious, that journal, because of the material she collected, but I don't say that then. ... But then I can be demanding. If you want to publish in a highly ranked journal, yeah, it has to be such and such. So because of her high ambitions. .... I think I have set the bar high for her. And I'm not sure if she appreciated that in the beginning. I think that she sometimes thought that it was unnecessarily difficult."

Of course, some protégés had the feeling that they did not belong to the academic community. As this mentor explained, as long as mentors' and protégés' expectations regarding the protégé's ambitions align, this is not a problem:

"It is nice if you have the same view on that. Because then you don't have troubles. Look, if she thinks that she is a highly talented scientist, and I think, well, I don't see that, then you have kind of a problem. You don't want to discourage someone, so you have too, well, I wouldn't say lie, but if you agree with each other, you can talk about that and for example say that it is good to gain some experience outside academia."

Similarly to mentors, protégés who found themselves not belonging to the scientific community described their mentor as prototypes of an outgroup. As one protégé told us:

"And actually I came to the conclusion that, they are scientists, have a lot of good ideas, the ideas that they held weren't not bad at all. And they are nice people, very social. ... But they are not people who can give direction, or keep an eye on the planning, or are open to: how is our PhD-student doing? Does he understand it all? .... He is really a scientist, and I am not, I'm not a real scientist. I thought I was, but it appeared to be different. I am more practically oriented." 
As this example shows, the mentor was seen as prototype of a scientist, while the protégé categorized himself in the category of workers putting something in practice. Similar to what mentors did, this protégé devalued his mentoring partner, and in that way he could make sense of the perception of his mentor as being deviant to his expectations of what a mentor should do.

\section{Am I good enough?}

The essence of the need for competence is the need to feel self-efficacy, to feel self-confidence, and to have a sense of optimism regarding goals (Sheldon et al., 1996). The dissertation project was for protégés a time in which they often reflected on their need for competence, or the extent to which they felt confident and efficient in their role as researcher. In other words, they often questioned themselves: 'Am I good enough?'

The extent to which they could confirm this question varied. For most protégés, the period of doing doctoral research was an uncertain period filled with many challenges. In almost every protégé account, the participant told to have had, at some point of time, doubts about the dissertation project. These concerns were sometimes related to their own competencies, as for example this protégé explained:

"[Because I] didn't have a real technological background, but I entered a technological field. And especially in the beginning, I had conversations about that with [Mentor], that I didn't feel comfortable in that. .... I asked myself the question sometimes: am I good enough? That's a question I sometimes asked myself, yeah."

Other protégés were more concerned about the added value of their research: "Well, I sometimes questioned, you know: is this really a domain in which I can specialize, or what's worthwhile? Something that also helps science?", or about their planning and finishing their project in time:

"At some point of time, I just wondered: where is this going to? And am I going to make it at all? I had some extension, but in my last year, I had no time off and really just worked very hard and made something good of it. But it was ... at a certain point in time you think, I'm already halfway time, where is this going to?" 
An important need-supportive function of the mentor is then to confirm protégés' competence as junior researcher and to give them enough confidence to succeed their dissertation project. Mentors and protégés described a number of ways in which mentors can do this. One important way in which mentors helped their protégé was by providing structure to the project. Participants explained that mentors did this by "working with clear agreements", "making regular appointments, keep these appointments and always have read everything." This makes their mentor reliable. Also, mentors prioritized research activities on which the protégé should focus, to help their protégés to have a grip on their dissertation project. Next, an important need-supportive behavior of mentors was to help their protégés to set realistic expectations (Janssen et al., 2013), without demotivating them:

"I remember, ... that she, I think she was working on her project for a year, and she said: 'Well, that chapter, I think I will be done with it in half a year.' .... She had little writing experience, little experience with the review process, and she actually had no idea of the high standards that journals have when you submit your manuscript. And she said something like: 'Maybe I'll finish my PhD in two years.' .... And well, I just made a joke about that, because you don't want to say something like: 'That's absolutely impossible' .... demotivating someone, ... you don't want that. ... But I found it kind of funny, that she was so optimistic. And that's something I notice quite a lot with PhDstudents, that they think that they can finish it sooner, that they're not realistic about that."

Also with regard to publications, mentors talked about their challenge to find a right balance between ambitions (aiming for a high-ranked journal) and realistic and motivational expectations:

"How ambitious are you? ... Because, at some point of time, you want success, you need that. And you just know that the higher your ambitions are with respect to journals, the more often you will hear: 'No.' .... And sometimes you have to have the courage to say: 'Let's submit to a lower ranked journal', and then hope that it will be accepted." 
This theme was also present in some of the protégé accounts: "We were always aiming for the highest level, that's what you initially try, but that also means that the chance of a rejection is quite high."

Next to that, mentors affirmed their protégés' sense of competence by showing their appreciation for the protégés' work, for example by giving compliments (cf. Janssen et al., 2013), or by increasing their exposure and visibility (cf. Kram, 1985) when mentors mentioned the protégé's qualities in meetings with others. Last, when protégés got a rejection from a journal or a request to revise and resubmit a manuscript to a journal, mentors helped them to value this feedback and to look forward on how to improve the manuscript and to not give up.

However, in almost every dyad, protégés' needs for confirmation could not completely be fulfilled by their mentors. Sometimes this was because protégés and mentors were demanding, and the essence of practising science was for them to continually improve their research and research skills:

"I think also, that is science, at least that's how I learned it: you can always do better. And sometimes that causes a feeling of: hmmm, am I good enough? So that's something, you notice, the focus of [Mentor] is: how can we improve this? ... she does not say that often: 'You're doing very well.' .... So that's something I actively have to look for myself. .... [But] it is also one of my personality traits that I'm always thinking: How can I improve myself. Very critical."

As one mentor also explained: "We don't think that way, do we? [laughs] We always think like, this has to improve, good text, but this is not right, this has to be better." In other accounts, protégés explained that their mentor did not give them enough feedback or confirmation in their competencies as researcher. When protégés' needs for competence were not completely satisfied within their mentoring relationship, they looked for other clues, externally to their mentoring relationship to get a sense of competence on where they stood in their project and to confirm their competence. Especially publications formed an important source of feedback for them, as the following protégé also explained: 
"The first year, two years maybe, my papers were rejected. And at a certain point in time, you notice that you're losing control. That you think like: hmmm, if this is continuing this way, it will get problematic.... And she never, she never took care of .... she never gave me that confirmation I was looking for. Actually she never contributed to that..... And I only got that control back when I got my first publications."

In their turn, mentors explained that it was sometimes difficult to judge the extent to which they confirmed their protégés' need for competence, as this need was mostly implicit and was not a subject of conversation between the mentor and protégé. Some mentors thought of their protégés as highly confident researchers, while their protégés explained that they had doubts about themselves as researcher. This mentor explained that especially with successful projects, it can be a pitfall of mentors to think that their protégé needs no confirmation:

"I think she was quite convinced of herself. .... It was not a big issue in that I thought: I have to pay special attention to that..... Yeah, maybe I underestimated that sometimes, her need for that, because it was such a smooth project. So then you think: It's going to be alright with [Protégé], and that you maybe confirm her not enough then. Although I'm actually not short of compliments, I often notice it if someone is doing things well and I tell them that, but yeah, it could be that you then give too little attention to that."

\subsubsection{Relatedness}

To feel satisfied in their need for relatedness, employees need to experience a sense of mutual respect, caring, and reliance with others (Deci et al., 2001). Our results imply that mentors and protégés follow interpersonal scripts that assume that it is necessary to build a personal relationship to create this sense of belongingness, and that keeping a strictly professional relationship is not an option. However, they experience several tensions between engaging in a personal or professional relationship on which they have to find agreement during their relationship.

First, agreement has to be found on the extent to which mentors and protégés will disclose personal matters. Participants differed on the extent to which they felt comfortable to show their personal identity in addition to their professional 
identity, and as a result, dyads differed in their extent of intimacy. This tension is furthermore complicated by the hierarchical relationship between mentors and protégés in this context. Second, our findings reveal that mentors and protégés seemed to have an implicit belief that especially the mentor is responsible for creating a sense of belongingness and a more personal relationship. Participants expressed that relatedness-supportive behaviors were mainly fulfilled in a one-way direction instead of in mutual ways. Third, the essence of a mentoring relationship is a difference between the mentor and protégé in their knowledge and expertise, and in most of the times inherently also in their ages and stages of life. This discrepancy causes that mentors and protégés sometimes find it hard to identify with each other, and that closeness or personal relationships with more like-minded colleagues are more likely.

\section{How close do we get?}

An important theme in their accounts on relatedness, was the extent to which self-disclosure occurred between mentors and protégés. To create intimacy, it is necessary to disclose personally relevant information (Laurenceau, Barrett, \& Pietromonaco, 1998). When asked about the role of relatedness in their relationship, most participants talked-next to "a connection based on a shared research interest" - about the extent to which they shared private matters and disclosed emotionally relevant information to their mentoring partner, or the extent to which they got along with each other in private time. In dyads where mentoring partners expressed to have a more professional relationship, participants came up with explanations and excuses for this. As one mentor told us when asked about the role of relatedness in the mentoring relationship: "I don't think it was that many. I mean, I don't even live here, I live in [city]. So I even could not come with them when they were going out or something." Apparently, mentors and protégés have expectations that it is necessary and common to share private matters and private time with mentoring relationships, to feel a sense of belongingness.

The extent to which mentors and protégés did so differed across the dyads in this study. Some participants explained that they intentionally separated their professional and private identity. For example, a mentor told us to allow selfdisclosure of the protégé, however, he was reluctant to reciprocate this behavior: 
"Most of the times I'm a little bit reluctant with extending things in private time. .... We talked about things, private things, hobbies, or what I did. But I feel that's a little bit a one-way direction. So I want to know something about the PhD-student, but my personal worries, that's not their business, of course."

In some dyads, this worked well as protégés still felt that their mentor was interested in them. In other dyads, however, protégés missed this feeling of real interest of their mentor. Showing genuine interest is a way for developers to create a warm and nurturing environment for their protégés (Janssen et al., 2013), which will likely satisfy their need for relatedness. In their accounts on relatedness, we found various ways in which especially protégés make sense of the extent to which their mentor really cared about them and was interested in them. In some dyads, there were only low levels of self-disclosures between the mentor and the protégé, which can lead to feelings of disinterest and lower levels of relatedness. Sometimes this can be disastrous for their need of relatedness, as protégés experienced the relationship with their mentor as being more instrumental than relational. As one protégé explained:

"I think that she just thinks like: I need to have PhD-students, and by chance, that was me this time, but if it were you, it was exactly the same, so to say. I realize that, in that way, I was replaceable with everyone else. .... She is never someone who is maintaining relationships."

Several participants explained how they struggled with finding the right extent of informal contact in their mentoring relationship, partly because there was also a professional and hierarchical relationship between mentor and protégé. As this protégé told us:

"We didn't see each other that often, but you don't have to, because you know you're okay. So, I think it is very good, with respect to our connection. And the funny thing is, when I did go to her, it was always like three kisses, you know, and just: 'Hi', and sometimes you don't do that, because you also think: well, it is of course a professor." 


\section{Who is responsible to take care?}

Our findings revealed that most mentors and protégés hold a mentoring schema that says it is the mentor's responsibility to fulfill their protégé's need for relatedness and to create a sense of belongingness between the mentor and protégé. As is shown in Table 5.2, in several dyads, the protégé noticed that the mentoring relationship is inherently more meaningful for the protégé than for the mentor. As a consequence, in the sense of relatedness, most participants see their mentoring relationship as a one-sided relationship in which the mentor gives and cares, in favor of the protégé. This is also illustrated by the following example, in which the mentor is almost surprised that her protégé also shows genuine interest in her: "We come together and then she always asks: 'How are you doing?' And I find that very special. So not only like, I want something from you, but also a little, that personal touch. And I really like that." This example, in which the protégé also shows to care for the mentor, is in line with a relational view on mentoring (Ragins, 2012).

The feeling of responsibility to take care of the protégé is sometimes strengthened by protégés' personal circumstances, which require mentors to pay special attention to their protégés. When mentors feel that they do not actively support their protégés' needs for relatedness, they also attribute that to the fact that there were no personal circumstances that required more involvement with their protégé:

“Well, of course, but that didn't happen with [Protégé], but with some PhDstudents, I had a deeper relationship. But yeah, then you also have to think of heavy private matters, stories of the PhD-students. For example a refugee. So yeah, it also depends on the circumstances."

Also in the more negative accounts, protégés seemed to evaluate their mentor's need-supportive behaviors as if their mentor was responsible to create a sense of belongingness. For example, one protégé told us that the relationship with his mentor was not optimal, and he blames his mentor for not taking his perspective:

"But what you also see is that it does not comes to an alignment .... It didn't fit. And I think it has to do with, that [Mentor] did not make an effort to, maybe that's something unconscious, I think it's really something unconscious 
for him, did not make an effort to place himself in my position. And to think: hey, how does he sees things actually?"

Last, most mentors see relatedness not necessarily as something occurring between the mentor and protégé, but as something that they have to take care of for the protégé. Mentors talked about how they take care of their protégé by monitoring that their protégé's need for relatedness is fulfilled by other colleagues and PhD-students:

"What was really good about having a large group of PhD-students is that, I mean, he had an important role in that group. And then you think: oh, thank goodness. You almost feel like, you have to understand that I don't want to take a motherly role, .... especially with male PhD-students, that's something you shouldn't do. But you are of course responsible for somethings, for someone's development. And if you see the dynamics with the other people in the group, if you notice that, I thought, that's lovely."

\section{Am I like you?}

Contrary to previous findings (Janssen et al., 2013), intimacy was not necessarily present as a theme in the accounts of mentors and protégés. Participants had various explanations for this, and in line with a similarityattraction paradigm (Byrne, 1971) they often referred to their (dis)similarities when they talked about their levels of relatedness and intimacy. Previous studies suggest that the degree of perceived similarity between a mentor and protégé is one of the strongest predictors of successful mentoring relationships (Eby et al., 2013; Hu et al., 2014). Also in the present study, felt demographical and deep-level (e.g., personality, values, and attitudes) similarities were often used as explanations for and signs of a sense of relatedness:

"It was just like, we were a match..... Yeah, mainly because of our interests. But also because of our views on how do you look at people? How do you look at developments in organizations and what do organizations have to do? How can you jointly come further? .... Of course I was a little bit older than other PhD-students. .... So, in our life experiences, we were more equal. And I think that was also an important aspect of our relationship." 
In dyads where participants experienced a low sense of relatedness, mentors and protégés talked mainly about their dissimilarities. Mentors and protégés told us about their differences in ages ("As a first reaction I would say that maybe our age difference is too large for that. ... We did not build a relationship that way, and sometimes that can happen, but with [Protégé] it didn't happen. And I think that's because, well, the difference in ages. PhD-students are not your friends who come at your birthday or parties, no. .... Age, it is because of age."), ways of communicating ("We were quite different persons. In our way of communicating and that kind of things. .... I didn't really like his way of communicating. And also his writing style for example. I'm better in that, I think. .... He can sometimes be a little too direct, a little crude"), and differences in personalities ("As persons, we were totally different. We got along with each other quite well, but it was not a real close relationships, not really deep, also not really a match as persons. So, it was quite business-like, in that way.").

\subsection{Discussion}

\subsubsection{Theoretical Implications}

Our findings provide several insights for research on mentoring relationships, especially regarding supervisory mentoring relationships, and how mentors and protégés come to agreements on how to fulfill protégés' basic psychological needs for autonomy, competence, and relatedness. As such, this study complements previous work on basic need-fulfillment processes in mentoring relationships (Janssen et al., 2013). Mentors' need-supportive behaviors and protégés' basic need satisfaction were assessed by conducting individual indepth interviews with pairs of mentors and protégés. Analyses of the interviews showed how mentors and protégés construe their relational contracts on the fulfillment of autonomy, competence, and relatedness. This study shows the importance of including pairs of mentors and protégés as data sources. Although many mentoring studies have relied on a dyadic conceptualization (Bozeman \& Feeney, 2008), only few studies actually incorporated dyads in their measurement and analyses (Allen et al., 2008; Dobrow et al., 2011; Janssen et al., in press). To fully understand the relational aspects of a mentoring relationship, we believe such a dyadic view is needed. Previous research has begun to explore the match between mentors and protégés on for example perceived program effectiveness (Allen et al., 2006a), 
mentor's transformational leadership behavior (Godshalk \& Sosik, 2000), and learning goal orientation (Godshalk \& Sosik, 2003). The current study contributes to this research line by investigating how members' experiences and evaluations of the mentoring relationship with regard to protégés' basic need-fulfillment (mis)align.

The main contribution of this study is that it shows the usefulness of a selfdetermination perspective on mentoring schemas and contributes to our understanding of how individual's mentoring schemas (Ragins, 2012; Ragins \& Verbos, 2007) may influence mentoring processes. According to SDT's relationships motivation theory (Deci \& Ryan, 2014), satisfaction of all three basic needs is required for experiencing high-quality relationships. In line with this, we conceptualized optimal mentoring relationships as relationships in which mentors and protégés reach agreement on their mentoring schemas regarding protégés' basic need-fulfillment processes. The results of our study show, however, that the implicit negotiation on the ways in which protégés' basic needs for autonomy, competence, and relatedness are fulfilled in mentoring relationships is a highly complex process. Our findings show the difficulties that mentors and protégés experience in this. In many accounts of mentors and protégés, relational expectations and experiences regarding protégés' basic need-fulfillment differed between mentors and protégés. As such, the idea of schema congruence in mentoring relationships may be too simple. For each of the three needs, we found complicating factors.

With regard to autonomy, our results show that the satisfaction of the need for autonomy in the context of PhD-students and their supervisory mentors is closely related to competence. Autonomy is not only a basic need of protégés, but is also set as requirement for competence by mentors in this context. A challenge for mentors and protégés is then to find a right balance between those two needs. This relationship between autonomy and competence raises the question of how SDT's basic psychological needs are related to each other, complement each other, or may be conflicting with each other. Future research may examine the specific conditions and situations in which mentors and protégés are able to satisfy all three needs, and those that may engender conflicts between basic needs. 
Regarding competence, our results show that it is difficult to reach schema congruence for mentors and protégés because PhD-candidates and their mentors tend to build their relational contracts on rather broad and vague competencies. Based on such competencies, mentors and protégés use their relationship as a context in which they can decide if the protégé holds the right competencies for being a scientist and thus belongs to the scientific community. However, most mentors seem to have difficulties in estimating the extent to which their protégé's need for competence is fulfilled in the relationship and protégés' need for competence are almost never completely satisfied by their mentor. The fulfillment of protégés' need for competence is further complicated by protégés' expectations of their mentors: they expect them to be a role model in many aspects, and most mentors cannot meet these expectations. This finding supports the idea of conceptualizing mentoring as a multiple relationship phenomenon (Higgins \& Kram, 2001). For protégés it may be necessary to get support from various developers and future research may examine more closely what acceptable need-fulfillment levels are for mentoring relationships and how protégés look for complementing support functions from other developers.

In terms of relatedness, we found that most mentors and protégés have the belief that it is required to share private matters and to get along with each other in private time, as they associated these characteristics with the satisfaction of the need for relatedness. In terms of SDT, satisfaction of the need for relatedness in the work context does however not necessarily require such a personal relationship, but rather a relationship in which one feels mutual respect, caring, and reliance with others (Deci et al., 2001). Future research may more closely examine on which dimensions mentoring schemas regarding for example the need for relatedness are build and how these schemas influence one's experiences with need-fulfillment processes in mentoring relationships. Furthermore, participants described how they had to find a right balance between showing their professional and personal identity. This balance between building a personal relationship (creating closeness) and keeping a professional relationship (respecting hierarchy) suggests that supervisory mentors may experience multiplexity (Verbrugge, 1979, p. 1286), as they have to fulfill different roles in their mentoring relationships. Future research may examine how such overlap of roles and exchanges in mentoring relationships may, for example, influence mentors' identity formation. 


\subsubsection{Limitations}

Several limitations to the present study should be noted. First, the current study was conducted by interviewing alumni PhD-students and their supervisory mentors. This specific context should be considered when generalizing the results. We believe that many of the findings will be relevant to individuals engaged in supervisory mentoring relationships in a variety of settings. Nevertheless, we encourage mentoring scholars to examine basic need-fulfillment processes from a dyadic viewpoint using other samples, so that we may compare and extend our findings.

Second, in line with relational mentoring (Ragins, 2012; Ragins \& Verbos, 2007), we conceptualized that mentors and protégés build their relationships around mentoring schemas. However, much of what defines a relational schema may not be accessible to awareness and therefore, is difficult to identify with conventional research methods (Baldwin, 1992). Future research examining mentoring schemas may use the repertory grid technique developed by (Kelly, 1955). This technique may be helpful to identify the relational expectations of a person, even if the research participant is not aware of these expectations (Huang et al., 2008). For example, in the context of mentoring schemas, protégés would be asked to recall some good and poor mentors they have experienced. After that, these mentors are presented to the participant in sets of three and the participant is asked to think of a property or quality that makes two of the mentors alike and discriminates them from the third. Based on such similarity-dissimilarity judgments, bipolar constructs (e.g., experienced vs. inexperienced) can be identified. Through laddering (probing), researchers will then be able to identify the construct systems underlying the procedural and schematic knowledge regarding participants' mentoring experiences. This way, we may get a fuller understanding of similarities and differences in mentors' and protégés' mentoring schemas.

\subsubsection{Practical Implications}

This study also has practical implications for mentors and protégés, for supervisors, and for organizations working with mentoring programs. It shows the importance of basic need-fulfillment processes in members' satisfaction with supervisory mentoring relationships. Most mentors and protégés may not be aware of their expectations regarding the fulfillment of protégé's needs for 
autonomy, competence, and relatedness. However, our study shows that it is important to come to a shared understanding of the role of these three needs in work relationships. For mentoring partners, it is important that they discuss their expectations and experiences with regard to the fulfillment of autonomy, competence, and relatedness in their relationship, because it will then be more likely to come to a workable relational contract regarding these basic needs. This way, mentors and protégés can actively shape and monitor their mentoring relationship by means of the three basic needs. 


\section{CHAPTER 6}

\section{Outsiders' perceptions of mentoring relationships:}

A qualitative exploration

Janssen, S., Tahitu, J., Van Vuuren, M., \& De Jong, M. D. T. Outsiders' perceptions of mentoring relationships: A qualitative exploration. 
"Yeah, maybe a little jealous. My expertise is quite unique, especially in this organization. So, I have no role model for that. It's nice to be the only expert in this field, but it also means that I have to find out things by myself. I miss that sometimes, and when I see that my colleague has someone for that, I can get a little jealous."

-Anonymous participant

\subsection{Introduction}

Mentoring relationships are intense work relationships between senior (mentor) and junior (protégé) organizational members. The mentor actively supports the career development of the protégé (Chao et al., 1992). Organizations sometimes formalize this relationship to meet the organization's needs, however, in almost every organization informal mentoring relationships exist, initiated by the members themselves and driven by their specific needs (Blake-Beard et al., 2007; Ragins \& Cotton, 1999). These mentors and protégés may or may not formally work together and the bond between them is usually closer and stronger than of those involved in other work relationships (Allen \& Poteet, 1999).

Most studies on mentoring have been concerned with its consequences (Allen et al., 2008) and show that mentoring is associated with numerous individual and organizational benefits. For example, protégés receiving mentoring report faster promotion rates, higher compensation, and higher job satisfaction (Allen et al., 2004). Mentoring others is associated with several career outcomes including greater job satisfaction and organizational commitment (Ghosh \& Reio, 2013), and perceived levels of peer mentoring in organizations are associated with higher perceived levels of knowledge creation and sharing (Bryant, 2005). The overall picture is that benefits accrue to all parties involved in mentoring.

In contrast, consequences for those not involved in a formal or informal mentoring relationship have been investigated less frequently. The few exceptions to this show that nonprotégés may not benefit from mentoring relationships in their direct context. They may experience feelings of unfairness or injustice (Scandura, 1997), and lower levels of power (Fagenson, 1988). 
Despite recent calls for more research focusing on the social context of mentoring (e.g., Chandler et al., 2011), researchers have paid little attention to the embeddedness of mentoring relationships within their larger organizational context (Janssen et al., in press). As a result, there is limited insight into how mentoring relationships influence their direct work context. The purpose of this study is to begin to address this gap in the literature. This study extends previous work on perceptions of nonprotégés by offering insight into a broader spectrum of both positive and negative perceptions that workgroup members can have of informal mentoring relationships in their work context.

Our research question is the following: How do workgroup members identify and experience informal mentoring relationships in their direct work environment? To address this question, we conducted a qualitative study among 21 employees from various organizations.

\subsection{Perceptions of Mentoring Relationships}

In literature, there are two main types of mentoring relationships: formal and informal mentorships. Not every organization works with formal mentoring programs, however, informal mentoring relationships are present in almost every work setting where people work closely together. This study focuses on the perceptions that workgroup members hold of informal mentoring relationships. These relationships differ from formal mentoring relationships in a number of aspects (Ragins \& Cotton, 1999) and two of these aspects may be of influence on the way workgroup members perceive and experience informal mentoring relationships. First, the two types of mentorships differ on the way they are initiated. Informal mentoring relationships are initiated on the basis of mutual identification and on personal preferences. Informal mentors often explain that they engage in a relationship with the protégé because of recognition or identification: the protégé reminds them of themselves (Allen et al., 1997a; Janssen et al., 2014). Protégés are often selected because they are high-performing, showing desired expertise (Allen et al., 1997a; Janssen et al., 2014; Ragins \& Cotton, 1999), or supporting the 'rising star hypothesis' (Singh et al., 2009). Mentors and protégés enjoy working together and the initiation of their relationship is often explained by a mutual attraction or chemistry (Kram, 1985). On the contrary, in formal mentoring relationships, members are matched by a third party on the basis of similarities or mutual need-fulfillment 
(Ragins \& Cotton, 1999). So, while formal mentoring relationships are based on more objective and rational grounds, informal mentoring relationships are mainly based on personal preferences, mutual perceptions of competency, and a certain chemistry or attraction. As a result, issues of access (i.e., who gets a mentor and why) and fairness are at the heart of informal mentoring relationships (Scandura, 1997).

Second, the different processes involved in the two types of relationships may cause different perceptions by outsiders. In contrast to formal mentoring relationships, informal mentoring relationships are often not articulated by their members (Ragins \& Cotton, 1999). As a result, formal mentoring relationships are more visible than informal mentoring relationships. As Ragins and Cotton (1999) explain, formal mentors may therefore be more selfconscious about issues of favoritism as they serve a public function in the organization and their actions are monitored. In contrast, informal mentors are more likely to sponsor their protégés and directly help their protégés to advance their careers. As a result, it is reasonable to expect that informal mentoring relationships are more likely than formal mentoring relationships to lead to perceptions of favoritism and organizational injustice by workgroup members.

\subsubsection{Mentoring and Organizational Justice}

Organizational justice refers to employees' perceptions that they are treated fairly by their employing organization (Cohen-Charash \& Spector, 2001). Research shows that organizational justice is a multidimensional construct, consisting of three dimensions. First, distributive justice (Adams, 1965) refers to the perceived fairness of the outcomes that the employee receives (e.g., salary). Second, procedural justice (Greenberg, 1990) refers to the perceived fairness of the policies and procedures used to determine that final outcome. Last, interactional justice (Bies \& Moag, 1986) refers to the treatment that an individual receives as decisions are made and can be promoted by providing reasons for decisions and delivering news with sensitivity and respect.

In a survey study among 197 managers, Scandura (1997) showed that protégés and nonprotégés did not differ on their perceptions of distributive justice, suggesting that organizational outcomes were perceived as fair. However, protégés did perceive higher levels of procedural justice than nonprotégés. The 
received informal or formal mentoring support was related to procedural and distributive justice, which means that the engagement in a mentoring relationship could positively influence protégés' perceptions of organizational justice. Nonprotégés may perceive procedures as unfair, for example, because they have less access to information in the organization. Fagenson (1988) showed that employees having an informal or formal mentor also experience more organizational policy influence, greater access to important people, and greater resource power than nonprotégés. In another study, Fagenson (1989) showed that protégés reported having more positive work experiences (e.g., recognition, satisfaction, promotions) than nonprotégés. These studies show the importance of research that examines the impact of mentoring relationships on how workgroup members for example react to the protégé's success (Fagenson, 1989). However, mentoring research has provided only limited insight regarding this topic.

Related fields show that differentiations in workgroup relationships can have various consequences. On the one hand, studies show that such perceptions of differentiations may have positive consequences for the members who are having a special bond with each other. For example, Vidyarthi, Liden, Anand, Erdogan, and Ghosh (2010) show how individuals compare their leadermember exchange (LMX) with the LMXs of coworkers and how these social comparison perceptions explain unique variance in work behaviors. Members who feel they are close to the leader feel a sense of obligation and a desire to reciprocate to this special position, resulting in greater engagement in citizenship behaviors. On the other hand, several studies show that perceptions of differentiations in work relationships may have negative consequences as well. Employees could respond negatively to LMX differentiation due to perceptions of injustice when for example leaders provide different levels of support across members of their workgroups (Uhl-Bien, Graen, \& Scandura, 2000). Indeed, studies show that individuals' perceptions of the extent to which LMX relationships are perceived to vary within their workgroups were negatively related to employee job satisfaction and wellbeing (Hooper \& Martin, 2008). To conclude, perceptions of differentiations in workgroup relationships are likely to result in positive consequences for members involved in a special relationship (i.e., the mentor and protégé), however, the impact on outsiders in the workgroup may be more negative. 


\subsection{Method}

Since our goal was to examine a broad range of workgroup members' perceptions of mentoring relationships, a qualitative approach was most appropriate. Interviews enabled us to explore workgroup members' reactions to informal mentoring relationships.

\subsubsection{Participants}

A total of 21 participants from 21 knowledge intensive organizations based in the Netherlands were selected using purposive sampling (Patton, 1990). Participants were recruited by using one of the authors' network and by publishing a call on LinkedIn. Employees who identified themselves as being an outsider of an informal mentoring relationship could participate. Participants were told that the goal of the study was to explore workgroup members' attitudes towards informal mentoring relationships and the consequences of these relationships. We provided participants with a definition (in Dutch), based on Chao, Walz, and Gardner (1992, p. 620): "An informal mentorship is defined as intense work relationship between senior (mentor) and junior (protégé) organizational members. The mentor has experience and power in the organization and personally advises, counsels, coaches, and promotes the career development of the protégé. The relationship is not managed, structured, and formally recognized by the organization. It is a spontaneous relationship that occurs without external involvement from the organization." We strived for a balance between males and females. With respect to sample size, interviews were conducted until the point of theoretical saturation (Glaser \& Strauss, 1967) was evident. This point was reached with 21 interviews. Participants were not rewarded for their participation.

All participants (10 men, 11 women) worked full-time, held at least an educational level of a four-year college degree, and held clerical and professional positions. Participants were aged between 25 and 64 years (mean $=41$ years). Average tenure within a team was 5.5 years, with a range from 14 months to 20 years. The organizations represented a wide range of industries, including education, consulting, and health care. Participants represented job categories such as Senior Consultant, Policy Advisor, and Project Assistant. None of the participants had been involved in a formal 
mentoring program, however, several of them stated to have had an informal mentor during their career.

\subsubsection{Semi-Structured Interviews}

All interviews were audiotaped with permission. Participants were assured that their responses would remain confidential and anonymous. The second author conducted the interviews and started each interview by asking the participant to describe his or her job. Participants were then asked to describe what they think of mentoring relationships in general, and to describe advantages and disadvantages for the protégé, the mentor, and the organization. After this general part of the interview, participants were asked to describe one specific informal mentoring relationship in their workgroup in further detail. For this relationship, participants were asked how they perceive the relationship and what they feel when they think about this relationship. Participants also described specific experiences with this mentoring relationship. Furthermore, we asked participants to describe consequences of the informal mentoring relationship: for mentors and protégés, for other workgroup members and the organization, and for themselves. These consequences could be both positive and negative. At the end of each interview, participants were asked to share any other relevant information.

\subsubsection{Data Analysis}

The interviews were transcribed verbatim, leading to 167 transcript pages, and were analyzed with the help of ATLAS.ti software for tracking code creation. A multi-step content-analytic procedure consisting of four steps was used. First, the first author segmented the transcriptions into meaningful units of analysis, which consisted of single or multiple sentences. Second, the first author took the lead in proposing a set of themes. These themes were discussed with the other authors and modified until there was agreement on five broad themes. As a first theme, we distinguished the identification of informal mentoring relationships. This category consists of statements in which participants describe how they recognize informal mentoring relationships. Next, we distinguished categories reflecting the impact on the protégé (e.g., "I think it's a way to quickly know your way around in the organization"), the mentor (e.g., "For the mentor it is also good to practice leadership skills"), the organization and its members (e.g., "You save time, and time is money for organizations"), and 
themselves (e.g., "Sometimes I'm jealous, because they have such a strong relationship"). In the third step, the first author constructed an initial codebook, which provided detailed definitions of different subcategories within these five broad themes. We looked for subcategories in the data and by applying an iterative procedure, these subcategories were compared with phenomena in the literature on mentoring and LMX differentiation (e.g., Scandura, 1997; Vidyarthi et al., 2010). These subcategories were then labeled to capture the meaning reflected by each group of comments (e.g., "Enhances Competencies" as a subcategory of "Impact on the Mentor," and "Creates Feelings of Exclusion" as a subcategory of "Impact on Workgroup Members"). We looked for common ideas and patterns in participants' responses, so subcategories represented by a single comment made by one participant were not included in the codebook.

Last, this codebook was given to the third author, and a quarter of the total sample of responses was individually coded by the first author and this second coder. This resulted in Cohen's к's of .90 (Identification), .88 (Impact on the Protégé), 1.00 (Impact on the Mentor), .92 (Impact on the Organization), and .80 (Impact on Workgroup Members).

\subsection{Results}

\subsubsection{Identification of Informal Mentoring Relationships}

Participants reported that they identify informal mentoring relationships in their workgroup in several ways. First, almost every participant reported to recognize the informal mentoring relationship as the mentor and protégé keep close contact at work. Participants not only reported that mentors and protégés work together on a formal basis, but also that they have informal contact and small talk during breaks and meetings: "You can see that they form a good team. They work together on many projects. ... And because of their close cooperation, they also have more contact during breaks, teambuilding activities, and meetings." Next, participants stated that informal mentors and protégés hold a friendship, at work and sometimes also in private life. Last, informal mentoring relationships are recognized by supporting behaviors between the mentor and protégé. Participants explained that the protégé prefers the support from the mentor above support from other colleagues: "She [protégé] will never come to me with questions. She will always go to him [informal mentor] for that." 


\subsubsection{Perceived Impact of Informal Mentoring Relationships on the Protégé}

\section{Helps to familiarize}

Table 6.1 shows that participants see mentoring as an important way to familiarize protégés in their organization. Many participants assumed that a mentoring relationship helps protégés to socialize in the organization, to adapt to manners and practices in the organization, and to acquire experience in the work field. Participants discussed that protégés need to put theoretical knowledge into practice and that the mentor can help in this process: "I think that employees who are not that experienced in a certain field, or for example just left school...I think it's very helpful then to learn from someone who is more experienced."

\section{Creates dependence}

While most participants described positive consequences of mentoring for the protégé, participants also mentioned negative consequences. According to the participants, one of the negative sides of mentoring for protégés is that they run the risk of becoming too dependent on the mentor. Participants described how protégés can be too focused on their mentor and are sometimes not critical to their mentors' style of working:

"It also has disadvantages. I don't know if the new colleague is able to think for herself, because she hangs on to her mentor. I'm not sure if she is able to make decisions on her own, without falling back on her mentor."

Participants also mentioned that mentors can be too dominant in imposing their way of working on the protégé, providing protégés with only little autonomy (cf. Janssen et al., 2013). Participants described how protégés then become copycats of their mentors, because they do not learn to develop their own way of working.

\section{Provides a safe context to learn}

Participants described the important role of interpersonal comfort (cf. Allen, Day, \& Lentz, 2005) in informal mentoring relationships. As a positive aspect, participants stated that the informal nature of the relationship ensures interpersonal comfort, and in that way offers a safe environment to discuss 
Table 6.1. Perceived Impact of Informal Mentoring Relationships on Protégés, Mentors, Organizations, and Workgroup Members per Participant

\begin{tabular}{|c|c|c|c|c|c|c|c|c|c|c|c|c|c|c|c|c|c|c|c|c|c|c|}
\hline & 1 & 2 & 3 & 4 & 5 & 6 & 7 & 8 & 9 & 10 & 11 & 12 & 13 & 14 & 15 & 16 & 17 & 18 & 19 & 20 & 21 & $\mathrm{n}$ \\
\hline \multicolumn{23}{|l|}{ Protégés } \\
\hline Helps to familiarize & + & + & + & & & + & & & + & & & & + & + & & & + & + & & + & + & 11 \\
\hline Creates dependence & - & - & & - & - & & - & & & & & & - & - & & - & & - & - & - & & 11 \\
\hline Provides a safe context to learn & + & & & & & & + & + & & + & + & & + & + & + & & & & & & & 8 \\
\hline Impedes critical feedback & - & - & & - & & & & - & - & & & & & & & & & & & & - & 6 \\
\hline \multicolumn{22}{|l|}{ Mentors } & 3 \\
\hline Enhances competencies & + & + & & + & + & + & + & & + & + & + & + & + & + & + & + & + & + & + & & & 17 \\
\hline Causes higher workload & - & & & - & & - & - & & & - & - & - & & - & - & - & & - & & & & 11 \\
\hline Gives appreciation & + & & & & & & & & & & & & & + & & & & & & & & 2 \\
\hline \multicolumn{23}{|l|}{ Organizations } \\
\hline Threatens productivity & - & & - & & - & - & - & & - & & - & - & - & - & - & & & & & & & 11 \\
\hline Influences atmosphere & - & & & & & - & - & + & - & + & & & - & - & + & & & & - & & + & 11 \\
\hline $\begin{array}{l}\text { Facilitates induction of new } \\
\text { employees }\end{array}$ & & & & & & + & + & & & + & & + & + & + & & + & & + & + & & + & 10 \\
\hline $\begin{array}{l}\text { Contributes to organizational } \\
\text { development }\end{array}$ & + & & & & & & & & & & + & & & & + & & & & + & & & 4 \\
\hline Predominates group processes & - & & - & & & & - & & & & & & & & & & & & & & & 3 \\
\hline Empowers speaking up & + & & & & & & & & & & & + & & & & & & & & & & 2 \\
\hline $\begin{array}{l}\text { Improves organizational } \\
\text { reputation }\end{array}$ & & + & & & & & & & & & & & & + & & & & & & & & 2 \\
\hline \multicolumn{23}{|l|}{ Workgroup members } \\
\hline Creates feelings of exclusion & & - & - & - & & - & - & & - & & - & & - & - & & - & & - & - & & & 12 \\
\hline Reduces work motivation & - & & & & & - & & & - & & & & - & & & & & - & & & & 5 \\
\hline $\begin{array}{l}\text { Challenges organizational } \\
\text { justice }\end{array}$ & - & & - & & & & & & & & - & & & & & & & & - & & - & 5 \\
\hline Causes feelings of jealousy & & & & - & & & & & & & & & - & & - & & - & & & & & 4 \\
\hline Can be used strategically & & + & & & + & & & & & & & + & & & & & & & & + & & 4 \\
\hline Threatens confidentiality & - & & - & & & & & & - & & & & & & & & & & & & & 3 \\
\hline
\end{tabular}

Note: Plus signs indicate that the comment(s) made by the participant reflect(s) a positive perception, minus signs indicate that the comment(s) made by the participants reflect(s) a negative perception. 
things that matter for the protégé. In the context of a mentoring relationship, according to participants, it is allowed for protégés to make mistakes:

"I think it's especially nice for a new employee that he or she can fall back on the same person. That makes that you are a little less afraid to make mistakes. And that will give you more confidence, I think."

\section{Impedes critical feedback}

On the contrary, participants explained that this safe context could also hinder protégés in their career development. Because of the informal and comfortable nature of the relationship, participants questioned if there is enough professional distance between mentor and protégé, to provide each other with honest and critical feedback:

"When you are too closely associated with the protégé, or when the work relationship is more like a friendship. Then you act less critical and maybe you don't discuss important feedback anymore. Then the protégé would benefit more from a neutral person."

\section{Improves functioning}

Last, a small number of participants explicitly stated that the mentoring relationship is helpful for protégés as it improves their functioning and contributes to their personal and professional development: "An employee is then encouraged to work on things that he or she could improve. .... I think that through coaching, you can live up to a promise."

\subsubsection{Perceived Impact of Informal Mentoring Relationships on the Mentor}

\section{Enhances competencies}

Almost every participant noted that mentoring relationships may have positive consequences for mentors as well. Participants discussed how mentors can enhance their management competencies through their engagement in the mentoring relationship. They also explained how mentors learn new skills and knowledge from the protégé: "A new colleague can bring in new knowledge and insight and the mentor can be the first to benefit from this." 


\section{Causes higher workload}

When thinking about negative consequences of mentoring for the mentor, many participants came up with the aspect of time and workload, because informal mentoring is something that you do besides your normal job duties:

"And I think that in the case of informal mentoring you more easily pass a limit with work load and that you invest too much time in guiding your protégé, which may cause that your own tasks are put on the sidelines."

As this quote shows, especially in the case of informal mentoring relationships the mentor's work load may be higher, as there is no clear structure or agreements on how much time is spent on coaching the protégé.

\section{Gives appreciation}

Last, two participants mentioned that being a mentor for someone can be rewarding, as it may be a source of appreciation: "I think in our organization, the only benefit for the mentor is that gives you a kind of appreciation."

\subsubsection{Perceived Impact of Informal Mentoring Relationships on the Organization}

\section{Threatens productivity}

Efficiency is a core theme in the perceived consequences for the organization. However, participants explained that mentoring relationships actually may lead to an inefficient way of working. Partly this is because they believe that mentors and protégés spend too much time on other things than working: "What also is annoying is that they sometimes have a chat with each other for three quarters of an hour. I don't think that's something we want." Some participants explained that the guidance of the protégé takes too much time, and that this does not necessarily result in more output from the protégé. Last, participants questioned if mentoring is always needed: "Sometimes I'm wondering why they do things together and not solo. I mean, they are both highly paid professionals and now it costs twice as much because they do their jobs together." 


\section{Facilitates induction of new employees}

At the opposite of the foregoing findings, participants assumed that protégés work more efficiently than non-protégés:

"I think that for the organization, it is important that a new employee learns the ropes as soon as possible. Then he or she can function optimal. The sooner the better I think, because for the organization there is only one thing that counts: time is money."

According to participants, mentoring would save time and money for the organization, as the protégé is sooner able to be settled in a job and to work at full capacity.

\section{Influences atmosphere}

Participants discussed how mentoring relationships have both a positive and a negative impact on the atmosphere in the workgroup. As a positive consequence, participants reported that informal mentoring relationships are good for the atmosphere and the work relationships in the workgroup. They state that the positive work attitudes of mentor and protégé and their highquality relationship have a positive influence on the other team members: "It always has a positive contribution to the atmosphere. When they have good contact, this also is contagious for the rest of the department." At the opposite, participants stated that informal mentoring relationships can bring down the atmosphere in the working group, for example because the mentor and protégé make their presence felt: "You also notice that the atmosphere is completely different when we work with the whole team and the two of them are so prominent. You know, you see everyone looking like 'oh come on, really?" This leads to irritations by workgroup members and their colleagues.

\section{Contributes to organizational development}

Some participants see mentoring as a form of quality management for the organization, contributing to its future development. For example, mentoring relationships help organizations to keep their knowledge up to date: "I think for an organization, it's a way to keep your knowledge up to date, because mentors interact with new people." Participants also stated that mentoring relationships ensure organizations of highly qualified people and that these relationships encourage knowledge sharing among employees. As one participant states: 
"Older employees are sometimes a little bit stuck, so to encourage knowledge sharing, mentoring should be incorporated in an organization's policy."

\section{Predominates group processes}

Some participants explained that the mentor and protégé often share the same opinions and way of working and in that way, they can be too dominant in group processes: "They also have a very strong opinion and many times they have a colored view through each other's opinions. And as a result, they determine a certain atmosphere." This category shows how the mentoring relationship may give mentors and protégés more power in the organization.

\section{Empowers speaking up}

A few participants explained that it is a good thing that mentors and protégés share the same opinion and bring those opinions forward. They state that together they have the courage to raise matters in for example meetings: “...I remember that once there was a team leader who was low-performing. They were then the first who had the courage to give their opinion. Together they dared to come up with it, because of their shared opinion." In such a case, mentoring relationships may have positive consequences on work group voice (Morrison, 2011), and provide the organization with feedback.

\section{Improves organizational reputation}

Last, few participants mentioned that mentoring relationships can be beneficial for the organization's reputation, as they contribute to a good functioning of employees and a higher quality of work: "I think that if you take good care of your newcomers, this also leads to a positive image of your organization."

\subsubsection{Perceived Impact of Informal Mentoring Relationships on Themselves}

\section{Creates feelings of exclusion}

Table 6.1 shows that about half of the participants shared stories about the negative impact of informal mentoring relationships for themselves. The most common topic here was the feeling of being excluded:

"We work in a team, but within that team, you sometimes have sub teams. And as it happens, they often are placed in the same team. And if you're also 
in that team as a third person, that feels unpleasant. I don't want to be a third wheel. .... Actually, I feel left out."

Examples given of behaviors that made participants feel excluded were that the mentor and protégé only talk about a shared interest, speak another language, have private chats, or make insider jokes that only they understand.

\section{Reduces work motivation}

Some participants explained that the mentoring relationship has a negative impact on their motivation, because working together with the mentor and protégé leads to irritations: "I don't like working with them. Then I'm not looking forward to go to work. Because I know that they are getting under my skin."

\section{Challenges organizational justice}

As expected, several participants talked about feelings of injustice (Scandura, 1997). Participants described how mentors seem to back protégés up, even when they are not working well enough. Participants talked about having the feeling that the protégé benefits from the help of the mentor and can keep up appearances of good functioning:

"The protégé needs him, and he uses the mentor. That's the way I see it.... If they would disclose their mentoring relationship, it would be over for the protégé. So, if my supervisor would know that the protégé knows that little and is that little competent, he would be send away."

Some participants talked about favoritism, for example about protégés who have access to more information than they have: "Sometimes it feels unfair..... Because she is so close to her mentor, and her mentor is quite a prominent team member, I think she sometimes gets a preferential treatment. That's the feeling we get sometimes."

\section{Causes feelings of jealousy}

Related to these feelings of injustice and favoritism, participants talked about their feelings of jealousy. Especially participants who state that they have had no mentor in the past, or have no special colleague at the moment, reported jealousy of the special and intense bond between the mentor and protégé: 
"Sometimes I'm jealous, because they have such a strong relationship. I miss that sometimes."

\section{Can be used strategically}

A salient result from the data is that participants identified only one type of positive impact of mentoring relationships for themselves. That is, participants explained how they sometimes use the mentoring relationship for own purposes:

"I work in quite a political organization. There's a lot of decision-making going on. And suppose I would express my opinion and I speak the mentor or protégé about that, then I already have their approval. .... always get approval of both of them, because they'll discuss it with each other. Then it's a matter of lobbying to convince the rest of the team, but I already have the two of them on my side."

One participant notes that if he or she wants to provide feedback to either the member or protégé, it can be helpful to discuss that with the other member of the mentoring relationship, because he or she will discuss it with the other member as well.

\section{Threatens confidentiality}

Last, participants talked about feelings of distrust. Again, participants explained that they believe that the mentor and protégé share everything with each other. Because of this strong bond between the mentor and protégé, participants think that they also share matters told in confidence by the participants:

"Yeah, I think I am more careful in sharing things because I know that they tell each other everything. .... And that has to do with trust. Because you never know to what extent they discuss things with each other."

\subsection{Discussion}

The aim of this study was to explore perceptions of workgroup members describing mentoring relationships in their direct work context. Data from our interviews show how workgroup members describe the impact of informal mentoring relationships on protégés, mentors, organizations, and workgroup 
members. The results of this study further our understanding of mentoring relationships in several ways.

First, this study is the first to qualitatively explore the diverse perceptions that workgroup members can have of mentoring relationships. Our study extends previous research on consequences of mentoring relationships for those not involved in the mentoring relationship (e.g., Fagenson, 1988; Fagenson, 1989; Scandura, 1997). Workgroup members described a broad spectrum of both positive and negative consequences. Many of the positive consequences were also related to the mentor, which underscores the importance to more closely examine mentors' motives and outcomes (e.g., Aryee, Chay, \& Chew, 1996; Ghosh \& Reio, 2013; Janssen et al., 2014). A prominent result is that when participants talk about the impact on themselves, only one positive aspect can be derived: results show how informal mentoring relationships are sometimes strategically used for workgroup members' own purposes. Our results indicate that workgroup members experience several negative consequences of informal mentoring relationships. While most mentoring studies are narrowly focused on only the positive aspects of mentoring relationships (Eby et al., 2000 ), the present study extends a line of research in which mentoring researchers aim for a more realistic and balanced picture of mentoring relationships, mapping both positive and negative aspects of these relationships (e.g., Eby, Butts, Durley, \& Ragins, 2010).

Second, the feeling of being excluded by the members of the mentoring relationship was prominent. An explanation for this is that humans have fundamental needs for belongingness (Baumeister \& Leary, 1995) and feelings of interpersonal rejection form a threat to these needs (Molden \& Maner, 2013). Research shows that exclusion may produce both prosocial and antisocial reactions (Leary, Twenge, \& Quinlivan, 2006). Rejection may lead to efforts aimed at reconnection (e.g, doing favors, showing that one has high relational value), or to anger and frustrations. Future research may examine how workgroup members deal with their feelings of exclusion on the longer term. Do they make efforts to reconnection, or to further avoidance? Moreover, participants' feelings of exclusion, jealousy, distrust, and injustice support the value of applying an organizational justice perspective on mentoring relationships, as suggested by Scandura (1997). Future research could examine the exact conditions in which mentoring actions are being perceived as unfair. 
Likewise, it may be useful to examine how the quality of workgroup members' relationships with both mentor and protégé is related to justice perceptions.

Third, this study addresses previous calls to examine the interplay between mentoring relationship and their immediate social context (Chandler et al., 2011). This study shows that mentoring relationships may be not only influenced by the specific organizational context in which they occur, in turn, they also have an impact on their context. Results of this study show how workgroup members believe that mentoring relationships influence the atmosphere and communication climate in teams. We encourage mentoring scholars to further examine the ways in which developmental relationships influence their direct work context and how this is dependent on for example the centrality of a mentoring relationship in the organizational network and the density of a workgroup network.

\subsubsection{Limitations}

Several limitations of the current study should be noted. First, related to the methodology utilized, participants were asked to provide examples of experiences with informal mentoring relationships. A salient result was that they reported mainly negative consequences for themselves. An explanation for the omnipresence of these negative consequences is that positive forms of coworker behaviors are the norm in organizations (Chiaburu \& Harrison, 2008). So, when employees make sense of informal mentoring relationships in a more negative way, such perceptions and experiences stand out during retrospective research settings. Future research on this topic would benefit from the use of diary studies, for example with the Rochester Interaction Record (Reis \& Wheeler, 1991), which could cover positive, neutral, and negative experiences with a particular relationship in natural settings.

It is also important to note that the results may be limited to specific organizational or national cultures. As Ragins and Verbos (2007) explain, mentoring actions may be viewed as appropriate in one culture, while in other cultures it may be seen as a form of favoritism. This study is conducted in The Netherlands, where mentoring is more likely to be associated with negative favoritism than in for example the United States. Therefore, we encourage 
mentoring scholars to compare our findings with results obtained from other samples.

\subsubsection{Practical Implications}

Our findings are important for (HRM) managers since our results show that workgroup members report many positive consequences of mentoring. Managers may emphasize the positive consequences of mentoring practices in organizations, however, in doing this, they should also be aware that mentoring practices may bring perceptions of exclusion and organizational injustice to a workgroup. For managers and mentors, it is therefore important to clearly communicate about organizational justice, and to explain followed procedures (procedural justice), given rewards (distributive justice), and reasons for this (interactional justice). 
CHAPTER 7

General Discussion 
"He got a new position after a reorganization, and it did not fit. And I recognized that you want to proof yourself then. If your span of control is cut down, you want to proof that you were worth your previous function. I had that same negative experience in my previous job, and that changed when I decided: 'I have to stop doing this, this is not going to make me happy. I'll have to try my luck somewhere else.' So that's what I told him: 'Let it go, although it's one of the hardest things to do in life, let go, instead of hanging on in this situation.' And that was the moment for him to say: 'Okay, I'll let go, I'm focusing on the future.'”

-Anonymous mentor

\subsection{Summary of Main Findings}

Nowadays, employees are more and more held accountable for their own career. Todays' turbulent and complex business environments make it crucial for employees to develop themselves continuously. Development always takes place in a social environment, including family members, friends, and colleagues. These developmental relationships are essential in every career, as they impact how people function. The present dissertation focused on a specific developmental relationship: the mentor-protégé relationship. This is a relationship between "an older, more experienced mentor and a younger, less experienced protégé for the purpose of helping and developing the protégé's career" (Ragins \& Kram, 2007a, p. 5). Based on an extensive literature review, this dissertation identified several overlooked research areas, and in four empirical studies, it explored how to get more understanding of these overlooked areas. Below, the results of the studies are summarized.

Chapter 2 reported a review of the existing literature on informal mentoring at work to identify overlooked research areas. In this review, two basic premises of interpersonal relationships were applied to the mentoring literature. The first premise is that interpersonal relationships never exist in a vacuum, but rather are embedded in a broader social network that influences how each relationship with others is formed and developed over time. The second premise is that individuals not only engage in interpersonal relationships for instrumental purposes, but also have relational motivations. Based on these two premises, the review showed which research areas represent promising avenues for future research. First, the review showed that researchers should 
include the context of mentoring relationships in their conceptualizations and measurements. This would lead to a better understanding of the broader setting in which mentoring processes are embedded, and the influence of how this sets boundaries and provides opportunities for mentoring processes. It also provides insight into how these mentoring processes influence their context. Second, the review showed that mentoring scholars have only limited knowledge of how mentoring processes evolve, how interpersonal processes between mentors and protégés unfold, and how previous mentoring behaviors influence one's current mentoring behaviors. Third, the review showed that mentoring literature has a strong focus on studying outcomes of mentoring and provides little insights into the processes that cause these outcomes. The review showed how a need-perspective on mentoring (e.g., self-determination theory) would lead to a better insight of the underlying developmental mechanisms of mentoring. Last, the review showed that more research is needed that incorporates both members in mentoring studies, as the lion's share of the mentoring studies give only a one-sided view on mentoring. The empirical studies were intended to contribute to these shortcomings of current mentoring literature.

Chapter 3 described how protégés perceive the specific types of support provided by intraorganizational and extraorganizational work developers. In the review, the importance of contextualizing the mentoring dyad in a broader setting was discussed. In line with this, protégés were asked to describe the constellation of developers that support them (or have supported them in the past) to advance their careers. In this way, this study extended the most often used single-dyad approach to a developmental network approach (Higgins \& Kram, 2001). Previous qualitative research showed that the content of exchanges between parties in developmental networks is broader than in traditional mentoring dyads. The present study contributed to a detailed description of the full range of developmental support functions in developmental networks. These support functions were categorized along the basic needs of SDT. According to SDT, the satisfaction of all these needs is crucial for relational quality and individual well-being and functioning (Deci \& Ryan, 2014). The study showed the manner in which developmental relationships meet protégés' basic needs for autonomy, competence, and relatedness. For example, with regard to their need for autonomy, protégés identified the importance of how their developers encourage their self- 
initiation. With regard to their need for competence, protégés explained how developers help them to familiarize with and feel confident in their working environment, and with regard to their need for relatedness, they explained how their developers show genuine interest. The results of this study showed the relevance of SDT as a framework for developers' need-supportive behaviors, as perceived by protégés. This way, the study supports the idea of SDT as an underlying framework of mentoring relationships, as stated in the review.

Chapter 4 addressed the various motivations that mentors have for providing developmental support to their protégés. Based on interviews with informal mentors, five broad categories of mentor motives were identified: self-focused motives (based on their own personal reasons), protégé-focused motives (directed at the protégé), relationship-focused motives (directed at the relationship between the mentor and the protégé), organization-focused motives (benefiting the organization), and unfocused motives (mentoring as the result of unconscious information processing). In the category of selffocused motives, five sub-categories were identified, based on SDT. While previous mentoring studies distinguished intrinsic (e.g., desire to increase personal learning) and extrinsic motivations (e.g., seeing mentoring as part of one's job) that mentors may have to support others, the study presented in this chapter distinguished three other forms of extrinsic motivations, based on SDT. First, there is introjection, when mentors perform mentoring behaviors because of ego involvements (e.g., to attain or preserve self-worth, to promote oneself, or to feel pride). Second, there is identification, when mentors perform mentoring behaviors because they are instrumental in a beneficial outcome for the mentor (e.g., the mentor can enhance his/her own competencies, or the mentor's work load lowers because the protégé can take over work). Last, there is integration. Mentoring behavior is then performed because the mentor believes it is important and this behavior is in harmony with the mentor's personal values, beliefs, needs, and identity. The goals of these three mentoring motivations are still extrinsic, rather than reflecting the inherent enjoyment or interest in the task, so SDT would classify them as extrinsic motivations. By providing this extensive overview of mentor motivations, this chapter provided a fine-grained understanding of motives that may influence mentors' willingness to mentor. Moreover, the results of the study showed how the willingness to mentor others is a process in which both instrumental and 
relational motives play a role, which supports our claims for including a relational perspective on mentoring, as described in our review.

Chapter 5 reported a dyadic study in which couples of alumni PhD-students and their professors were individually interviewed about their supervisory mentoring relationship. As stated in the review, dyadic approaches are needed to better understand mentoring relationships. Based on ideas from relational mentoring, it was conceptualized that mentors and protégés build their relationship around mentoring schemas: implicit mental maps that individuals hold of what the mentor and protégé should do in the relationship, what the relationship provides, and how it functions. This study specifically examined how mentors and protégés come to a common understanding on the ways in which protégés' basic needs for autonomy, competence, and relatedness are fulfilled in their supervisory mentoring relationships. Mentoring relationships would be most optimal when mentors' and protégés' schemas are optimal, and thus, mentors' and protégés' expectations align. This study showed, however, that the implicit negotiation on the ways in which protégés' basic needs for autonomy, competence, and relatedness are fulfilled in mentoring relationships is a highly complex process. In many accounts, incongruence expectations regarding basic need-fulfillment processes were more the rule than the exception. For example, the study showed that the satisfaction of the need for autonomy in the context of PhD-students and their supervisory mentors is closely related to competence. Autonomy is not only a basic need of protégés, but is also set as requirement for competence by mentors in this context. A challenge for mentors and protégés is then to find a right balance between those two needs. Regarding competence, the study showed that it is difficult to reach schema congruence for mentors and protégés because $\mathrm{PhD}$-candidates and their mentors tend to build their relational contracts on rather broad and vague competencies. Last, for the category relatedness, the study showed how mentors and protégés have to find a right balance between showing their professional and personal identity. This study complements the findings of the study reported in chapter 3 , as it provides insight into how mentors' and protégés' experiences and evaluations of their mentoring relationship with regard to protégés' basic need-fulfillment (mis)align.

In chapter 6 , a shift is made to the context of mentoring dyads, by showing how workgroup members identify and perceive informal mentoring relationships in 
their direct work context. Mentoring research has widely investigated positive outcomes of mentoring relationships for the parties involved (i.e., protégés, mentors, and organizations). However, as stated in our review, less attention has been placed to the consequences for those outside of the mentoring relationship (i.e., work group members of the mentor and/or the protégé). This chapter described work group members' perceptions of informal mentoring relationships. Work group members were interviewed about their experiences with informal mentoring relationships. The results show that work group members associate both positive and negative consequences with informal mentoring relationships for protégés, mentors, and organization. For example, they described how mentoring relationships may improve protégés' functioning; however, it may also create a dependence on the mentor. When workgroup members described consequences for themselves, however, they predominantly described negative consequences. This chapter showed how employees experience negative feelings such as exclusion, jealousy, and organizational injustice as a result of informal mentoring relationships in their work group.

\subsection{Theoretical Implications}

The empirical studies make several contributions to the mentoring literature. First, the studies show the relevance of applying SDT as a framework to mentoring research. The satisfaction of protégés' basic needs for autonomy, competence, and relatedness could be recognized in both the interviews with protégés (Chapter 3, Chapter 5) and mentors (Chapter 5). Our qualitative approaches resulted in a fine-grained picture of the various ways in which needs for autonomy, competence, and relatedness are fulfilled in the context of mentoring relationships, in different variations and subtleties. Especially our dyadic study (Chapter 5) shows the complexities in these need-fulfillment processes, as this study shows how expectations and experiences on protégés' need-fulfillment processes may differ between mentors and protégés.

SDT as a framework complements previous conceptualizations of mentoring support functions. Traditionally, vocational psychology has conceptualized career development as a process leading to individual mastery (Hall, 1996a). In mentoring research, this view has led to a strong focus on support functions that promote protégés' competence and independence. While competence has been the focus of many mentoring studies, SDT sheds a new light on the role of 
autonomy and relatedness in the context of mentoring relationships. In contrast to prior mentoring studies in which autonomy has been defined as independence, SDT defines people as autonomous when they act in line with their authentic interests or integrated values and desires (Deci \& Ryan, 1985, 2000). So, in line with SDT, protégés can be autonomously dependent on their mentor, when they are willing to rely on his or her support. As such, SDT widens the scope for mentoring researchers to also focus on reliance on others. Of the three basic needs, relatedness is typically overlooked in mentoring research. Most mentoring research is built on social exchange principles (Blau, 1964; Emerson, 1976) and considers mentoring relationships as relationships in which there has to be a balance between the exchanged costs and benefits. Mentoring relationships are then about exchanges of support behaviors throughout the relationship (Young \& Perrewé, 2000). These views on mentoring have led to a cognitive and instrumental approach towards mentoring. In the upcoming stream of Positive Organizational Scholarship (Cameron et al., 2003; Cameron \& Spreitzer, 2011) relational mentoring (Ragins, 2012; Ragins \& Verbos, 2007) questions such instrumental views on mentoring, and provides an alternative lens for looking at mentoring relationships. In line with the current relational discourse about vocational behavior (Blustein, 2011; Blustein et al., 2004), relational mentoring is concerned with dimensions such as human strivings for attachment, connection, affirmation, and support (Ragins, 2012). However, ideas of relational mentoring have not been tested in empirical studies yet.

The studies in this dissertation show that mentoring scholars should indeed widen their scope to frameworks outside those belonging to a social exchange perspective when studying mentoring relationships. In our study on mentor motives (Chapter 4), mentors for example reported both exchange-oriented motivations and affiliative motivations to help their protégés. This shows the importance of viewing mentoring as a process in which instrumental and relational motivations play a complementary role. The empirical studies on basic need-fulfillment processes showed a broad picture of ways in which the need for relatedness is fulfilled in mentoring relationships, extending previous relational functions of Kram's (1985) classical set of support functions. As such, this dissertation helps to get a more elaborate understanding of the role of motivations and needs in mentoring relationships. 
Second, this dissertation contributes to mentoring research by the methodology used in the different studies. Throughout the dissertation, different participant groups were included in the studies to examine mentoring relationships. A shift was made from the protégé, to the mentor, to the dyad as focus of inquiry for studying members' perceptions of their mentoring relationships. Our dyadic study (Chapter 5) shows the relevance of including coupled pairs when studying work relationships, as this gives insights into how mentors' and protégés' perceptions (mis)align and it gives more insight into their interaction. Also, the mentoring relationship was placed in a larger social context, by including outsiders of mentoring relationships (i.e., colleagues belonging to the same work group as the mentor and protégé) in one of the studies (Chapter 6). The results of this study show how mentoring relationships certainly have an impact on their work context, predominantly in negative ways.

This dissertation also showed the value of using interviews as data collection method, instead of the more common use of surveys in studies on work relationships (Allen et al., 2008). One thing that our qualitative approach towards mentoring shows is that it is inaccurate to speak of "the mentor," "the protégé," or "the mentoring relationship" as homogeneous concepts. The specific ways in which protégés express their needs and how their needs are satisfied vary across the different dyads. For example, our dyadic study (Chapter 5) showed how some protégés expressed to find it highly important to have much autonomy in their work, while others expressed to prefer a leading mentor. With regard to the fulfillment of protégés' needs for competence, this study showed variations in the accounts of protégés on the extent to which they expected their mentor to support their needs for competence. Some protégés expressed quite a sense of self-efficacy in their job, while others were more insecure. The optimal fit of support provided to these protégés may differ. For example, protégés scoring high on competence need satisfaction (i.e., feeling competent in their job) may need a mentor who provides them with challenging tasks to develop new skills, while protégés scoring low on competence need satisfaction (i.e., not feeling competent in their job) may need a mentor who gives them mainly affirmation of existing tasks that are well performed. The rich data in this dissertation on how mentors and protégés experience their mentoring relationships and make sense of each other's 
behaviors, shows the importance of including qualitative methods to our standard range of research methods when studying mentoring relationships.

Last, this dissertation shows the importance of contextualizing the mentoring dyad in a broader setting. In several studies, mentoring was conceptualized as a process that could take place in multiple simultaneous developmental relationships (Chapter 3, Chapter 4), instead of focusing on one single mentoring dyad. This provides us with a richer understanding of how for example mentors can have different motivations for supporting different protégés. Most previous studies examined intentions to be a mentor instead of intentions to be a mentor for a specific protégé. Although this may give good insight into how people vary in their willingness to mentor others in general, it is questionable to what extent this general intention holds true for specific relationships. In our study on mentors' motivations (Chapter 4) mentors were asked to talk about various specific developmental relationships, which resulted in a broad spectrum of motives to support different protégés. Also, this dissertation showed that mentoring relationships have an impact on their work context. Outsiders of mentoring relationships may not always be fond of a mentoring relationship in their direct work context, as they may associate it with negative consequences for themselves, such as organizational injustice and distrust.

\subsection{Limitations}

Next to the limitations of each individual study as discussed in the previous chapters, certain general limitations of the research reported in this dissertation should be addressed.

First, our participants received rather broad definitions of informal (Chapter 3, 4,6 ) and supervisory (Chapter 5) mentoring relationships. As argued by Haggard, Dougherty, Turban, \& Wilbanks (2011), providing possible participants with such broad definitions may have both advantages and disadvantages. On the one hand, by providing participants with broad definitions, it is less likely that the researcher influences participants' reports on outcome variables. If participants would have received definitions containing phrases about the specific mentoring functions provided by the mentor, this could have influenced the need-supportive functions they would have reported. For example, by stating that a mentor provides opportunities to 
develop or gives challenging assignments, it would be likely to find more needsupportive functions regarding competence in the interviews than when stating that a mentor provides a safe context to learn and is someone with whom you have a special bond (which will more likely result in more need-supportive functions regarding relatedness).

On the other hand, the use of such broad definitions in mentoring studies will likely result in more self-identified protégés and mentors than when a more narrow definition is provided to participants (Haggard et al., 2011). By providing broad definitions, a broader range of mentoring relationships may have been included than when participants would have received more specific definitions. The concept of mentoring could mean different things to different people (Kram, 1985) and there are various forms of mentoring possible, ranging in for example the form of the relationship. For instance, some people may think of lateral mentoring relationships (concerning individuals who are at comparable organizational levels), while others may think of hierarchical mentoring relationships (concerning a senior organizational member and a junior organizational member) (Eby, 1997). This may have influenced our findings. For example, participants in a peer relationship may have stronger perceptions of reciprocity than those reporting on a supervisory mentoring relationship (Kram \& Isabella, 1985). With regard to autonomy, supervisors who mentor a protégé have more power and control over their protégé and autonomy-supportive behaviors may play a more important role here than for mentors who have no supervisory role. Future research may more closely examine differences in types of mentoring relationships, as well as differences between supervisory mentoring relationships and typical employee/manager relationships.

Second, in line with SDT, an underlying assumption of this dissertation was that the satisfaction of protégés' needs will lead to better mentoring relationships. However, in our empirical chapters, we relied on interviews only, so this assumption was not tested. Although the qualitative interviews suit our research questions, it would be beneficial to complement our findings with other data to provide a more elaborate picture of our topics. Based on the findings derived from our qualitative data, hypotheses regarding the relationship between the quality of mentor motives and variables such as 
protégés' need satisfaction and members' satisfaction with the relationship could be tested.

Third, we relied on retrospective accounts of participants to examine the fulfillment of their basic needs. In the interviews, some participants explained that they do not need 'a lot of autonomy' or 'do not have a strong need to connect with colleagues.' However, according to SDT, this is rather an attempt to cope with need deprivation or thwarting than it is an individual difference variable. Different from theories within social-personality psychology, in which needs are an index of how important or strong a desire or attribute is for the person, SDT proposes that satisfaction of the basic needs is necessary to function optimally, regardless of personal preferences (Deci \& Ryan, 2014). This means that people will suffer when their needs are not satisfied, even if they say and believe that they do not need a sense of autonomy, competence, or relatedness. The use of diary studies could give more insight into how needs fluctuate over time and how this is affected by need-supporting and needthwarting incidents in participants' context.

Last, as said before, the findings of each study are based on a small number of participants, so caution is needed in generalizing the results from our studies. The findings from qualitative studies are always highly context and case dependent (Patton, 1999). In most of our studies, participants from different organizations were sampled, to enhance the generalizability of our findings. In one study (Chapter 5), however, participants from a specific professional group, in a single organization, were sampled. Also, all studies have been conducted in the Netherlands. It is important to note that the results may be limited to this specific national culture, as mentoring relationship expectations and acceptable patterns of interaction vary considerably across cultures (Allen et al., 2008). Therefore, we encourage mentoring scholars to compare our findings with results obtained in other contexts.

\subsection{Future Research on Mentoring and Self-Determination Theory}

Given the outline of key questions to address in mentoring research as presented in our review (Chapter 2), still many questions need to be addressed in future research. In this section, first, future research suggestions are given that could further contribute to the overlooked research areas as identified in our critical review of mentoring literature (Chapter 2). Next, as most of the 
empirical studies were inspired by insights and assumptions of SDT, this section also aims to reflect on SDT as a guiding framework for workplace mentoring. Several suggestions for future research on mentoring using a SDT approach are presented.

First, in several of our studies, mentoring was conceptualized as a process that could take place in multiple simultaneous developmental relationships. This multiple relationships approach (i.e., developmental network approach) could be extended by our methods and analyses. For example, social network analysis (Borgatti, Mehra, Brass, \& Labianca, 2009) would allow to examine how employees' participation in a formal developmental network (e.g., assigned coaches, supervisors) differs from their simultaneous participation in informal developmental networks (e.g., self-identified developers from inside and outside the organization). In their analyses, mentoring scholars could more closely examine how developers' need-supportive behaviors differ across their simultaneous developmental relationships and how this is evaluated by both the mentor and the protégé.

Next, especially with regard to what was proposed as 'a life cycle approach of mentoring relationships' in our review, a lot of work needs to be done. We look forward to future research using longitudinal approaches to examine how mentoring relationships change over time. Particularly, it was argued in the review that mentoring relationships are influenced by previous mentoring experiences through mentoring schemas (Chapter 5). However, this concept was not included in our measurements. Studies using a repertory grid technique in combination with in-depth interviews (Huang et al., 2008) could more closely examine which specific mentoring schemas protégés and mentors hold and how this influences their mentoring expectations, behaviors, and experiences.

As explained in the previous chapters, SDT is actually not one theory, but is an approach which combines several theories (Vansteenkiste et al., 2010). The empirical studies in this dissertation are based on premises derived from three of these theories: basic needs theory, organismic integration theory, and relationships motivation theory. First, basic needs theory (Chapter 3, Chapter 5 ) is concerned with the relationships between the basic psychological needs and psychological health and well-being. The theory argues that well-being and 
functioning are optimal when needs for autonomy, competence, and relatedness are fulfilled in social contexts. Second, organismic integration theory (Chapter 4) examines properties, determinants, and consequences of various forms of extrinsic motivation. The theory proposes that human motivation falls along a continuum, ranging from non-internalized (controlled) to internalized (autonomous) motivations. The theory is concerned with how social contexts influence internalization: an active process in which individuals attempt to assimilate and reform controlled regulations so they can be autonomous while enacting them (Deci \& Ryan, 2000). The more internalized the extrinsic motivation the more intrinsically motivated the person will be when enacting the behaviors. Last, relationships motivation theory (Deci \& Ryan, 2014) has recently been introduced to the set of SDT's mini theories. This theory is concerned with high-quality relationships, and proposes that highquality relationships require that people experience satisfaction of all three basic psychological needs (Chapter 5).

These mini-theories of SDT have been developed through empirical studies in a wide range of fields. In these domains, comparable findings have been consistently obtained, which shows both the wide scope of the theory and its validity (Vallerand, Pelletier, \& Koestner, 2008). SDT also has issues to come up with conceptual explanation and theory development concerning some of its essential elements (Vallerand et al., 2008). Below, attention is paid to such issues that seem particularly relevant in the context of this dissertation.

First, future work on SDT should address the issue of how the three basic needs are exactly related. SDT states that all three needs are important in experiencing optimal well-being and a study of Sheldon \& Niemiec (2006) shows that the balance in the satisfaction of the three needs, in addition to the total amount, is important for psychological health. However, SDT also claims that people who experience satisfaction of one of the three needs will experience satisfaction on the other needs too (Deci \& Ryan, 2014). Many studies on SDT are concerned with the particular importance of the need for autonomy (e.g., Deci et al., 2006; Reeve, 2006; Ryan et al., 2011). In contrast, the need for relatedness has been less studied in past SDT research (Vallerand et al., 2008). As this dissertation shows, satisfaction of the need for relatedness is important for employees in their developmental context, and future research 
on SDT in the work context should more closely focus on this need and how it is related to the other two needs.

Second, there is only limited understanding of how the thwarting of one or more needs impacts motivations (Deci \& Ryan, 2008; Vallerand et al., 2008) and how individuals cope with such need-deprivations. Interestingly, the participants in our studies mentioned negative examples of developers, even though our main focus was on positive mentoring relationships. These negative examples served as role models in that they were examples of how someone would not want to behave, and were closely aligned to the thwarting or deprivation of protégés' basic needs. Future research may more closely examine how the thwarting of one or more basic needs impacts members' relationship satisfaction and functioning. In the same vein, very little research on SDT has used an experimental design (Vallerand et al., 2008). As a result, most SDT studies are not suitable to prove cause-and-effect relationships between need satisfaction, motivation, and outcomes such as well-being and performance. Future studies should focus more clearly on the impact of different types of motivation and outcomes of psychological well-being and work performance.

Notwithstanding such critical reflections on SDT, several areas in mentoring literature could be further explored with SDT. With regard to basic psychological needs theory and relationships motivation theory, a next important step would be to examine the effects of basic need-fulfillment on members' relationship satisfaction and work motivation. This dissertation showed the relevance of the fulfillment of protégés' basic needs for autonomy, competence, and relatedness. However, our studies were not aimed at examining the exact relationship and the explanatory power of basic needfulfillment in how mentoring relationships are evaluated by their members and how this impacts other individual work outcomes. Future studies may for example use between-subjects (i.e., individual difference) and within-subjects (i.e., across time) designs to examine how satisfaction of each of the three basic needs within mentoring relationships is related to outcomes such as personal well-being, relationship quality, and work motivation.

Next, research is needed that explores if and how mentors' basic needs for autonomy, competence, and relatedness are fulfilled by their engagement in 
mentoring relationships. Two pathways for mentors' need-fulfillment processes may be most likely. On the one hand, the engagement in mentoring relationships may be a form of cognitive and relational job crafting (Wrzesniewski \& Dutton, 2001) for mentors, as mentors may change the form of activities they engage in while performing their jobs (e.g., coaching activities) and change with whom they interact while performing their jobs (e.g., mentoring a junior colleague from another department). Both ways of job crafting may lead to a greater sense of autonomy, as they allow mentors to maintain control over their work. As Chapter 4 showed, mentoring activities also allow mentors to create a positive self-image, and next to that, most mentors explained that their affiliative or relational motivations also played a role in their informal mentoring behaviors. Thus, mentors' needs for autonomy, competence, and relatedness may be fulfilled in these ways by their mentoring relationships. On the other hand, studies on friendships show that not only receiving but also giving autonomy support relates to need satisfaction (Deci et al., 2006). Mentors who give autonomy support to their protégés may thus also experience need satisfaction in that way.

With regard to organismic integration theory, a next step would be to examine how the quality of mentors' motivations impact members' relationship satisfaction. According to SDT, the quality of the motivation (e.g., if the motivation is autonomous rather than controlled in nature) would lead to desirable outcomes rather than the amount of motivation (Vansteenkiste, Sierens, Soenens, Luyckx, \& Lens, 2009). Based on this, one would argue that mentors holding controlled forms of motivations to engage in mentoring relationships (e.g., because it is beneficial for their own reputation in the organization), would perform their mentoring role not as optimal as mentors holding autonomous forms of motivations to engage in mentoring relationships (e.g., because they enjoy the conversations with their protégé). Next, also protégés' motivations could be investigated as there is no clear understanding of why protégés engage in their mentoring relationships and how this possibly influences their mentoring experiences. Some protégés may use their mentoring relationship in more instrumental (extrinsic) ways and others in more communal (intrinsic) ways. To date, mentoring literature provides no insight into how this affects members' relationship satisfaction and motivation. 


\subsection{Implications for Practice}

This dissertation offers theoretical and research-based insights into motivational processes in developmental relationships. This results in key recommendations for several parties: mentors and protégés, managers, and organizations.

First, it is important that both mentors and protégés actively pay attention to the fulfillment of basic needs for autonomy, competence, and relatedness in their mentoring relationships. For developers such as mentors and coaches it is necessary to understand the importance of the satisfaction of protégés' needs for autonomy, competence, and relatedness. This can help them to optimally shape their relationships with their protégés. The core of their interpersonal style should be that they try to understand their protégés' perspectives and needs (Baard, Deci, \& Ryan, 2004) and accordingly provide them with choice (autonomy), give them confirmation (competence), and show genuine interest (relatedness). For protégés, an awareness of their own expectations and wishes with regard to the fulfillment of basic needs will be beneficial. This may help them to express their needs to their mentors and to find ways in which the mentor can help them in fulfilling these needs. Preferably, protégés come to an understanding of their basic needs in dialogue with their mentor, to build a shared meaning of the role of basic needs in their specific relationship.

Second, most managers will, to some degree, mentor their subordinates (Pan et al., 2011). Given their responsibility for employees' work-related development, they are in a unique position to coach and counsel their employees, and in that way, to promote their employees' career advancement. So, also for managers, it is important to pay attention to the role of the satisfaction of basic needs in their work relationships and to promote employees' basic need-fulfillment. One way of doing this, is by showing managerial behaviors that support basic needs for autonomy, competence, and relatedness (Baard, 2002). For example, by optimizing subordinates' control over their work and allowing self-selection for tasks (autonomy), helping employees to determine reasonable ambitions and providing them with optimal challenges (competence), and by sharing information whenever feasible and showing interest to gain trust (relatedness).

Third, organizations can learn from the studies in this dissertation in their design of formal mentoring programs. This dissertation has mainly focused on 
informal mentoring relationships, which are inherently unmanageable and uncontrollable. However, many of the findings may also be important in the context of formal mentoring programs. The results may help design developmental environments in organizations that optimize employees' development, performance, and well-being. For example, for mentoring partners in formal mentoring programs, it is important that they become aware of their own expectations and experiences with regard to autonomy, competence, and relatedness and the expectations and experiences of their mentoring partner. By making this a subject for discussion, it is more likely to get agreement on a workable relational contract regarding these basic needs. This dissertation provides also insight into possible mentor motives. This can help organizations working with formal mentoring programs in their sampling procedures of possible mentors. However, as a final recommendation, (HR) managers should be aware that mentoring practices may bring perceptions of exclusion and organizational injustice to a workgroup, as the results of our study on outsiders' perceptions imply that workgroup members experience both positive and negative consequences of mentoring. Managers may emphasize the positive consequences of mentoring practices, however, it is also important to clearly communicate about followed procedures regarding mentoring practices, regarding given rewards to mentors and protégé as a result of their participation in mentoring programs, and reasons for doing this.

\subsection{Concluding Thoughts}

The studies reported in this dissertation aimed to inform researchers studying workplace mentoring relationships. This dissertation started with an extensive literature review, which serves as a future research agenda to inspire scholars working in the field of mentoring. Several underdeveloped research areas were identified in this review. The empirical studies in this dissertation contributed to these research areas. SDT was found to serve as a relevant framework for unveiling underlying mechanisms of mentoring relationships and to get more insight into the role of need-fulfilment processes in these relationships. Essential in SDT is the role of how other people affect individuals' needs and motivations. In line with this, this dissertation shows how mentors play an important role in satisfying protégés' needs and how protégés evaluate these need-supportive functions. This dissertation also shows the motives mentors may have for providing developmental support to their protégés. Last, this dissertation showed how outsiders of informal mentoring relationships 
perceive these relationships in their direct work context. The studies presented in this dissertation show us the importance of informal relationships and processes in organizations and how they may satisfy employees' needs for autonomy, competence, and relatedness. 
References 
Adams, J. S. (1965). Inequity in social exchange. Advances in Experimental Psychology, 2, 267-299.

Allen, T. D. (2003). Mentoring others: A dispositional and motivational approach. Journal of Vocational Behavior, 62(1), 134-154. doi: 10.1016/s0001-8791(02)00046-5

Allen, T. D. (2004). Protégé selection by mentors: Contributing individual and organizational factors. Journal of Vocational Behavior, 65(3), 469-483. doi: 10.1016/j.jvb.2003.07.003

Allen, T. D., Day, R., \& Lentz, E. (2005). The role of interpersonal comfort in mentoring relationships. Journal of Career Development, 31(3), 155169. doi: 10.1177/089484530503100301

Allen, T. D., \& Eby, L. T. (2004). Factors related to mentor reports of mentoring functions provided: Gender and relational characteristics. Sex Roles, 50, 129-139.

Allen, T. D., \& Eby, L. T. (2007a). Blackwell handbook of mentoring: A multiple perspectives approach. London, England: Blackwell.

Allen, T. D., \& Eby, L. T. (2007b). Common bonds: An integrative view of mentoring relationships. In T. D. Allen \& L. T. Eby (Eds.), The Blackwell handbook of mentoring: A multiple perspectives approaches (pp. 398419). Oxford, England: Blackwell.

Allen, T. D., Eby, L. T., \& Lentz, E. (2006a). The relationship between formal mentoring program characteristics and perceived program effectiveness. Personnel Psychology, 59, 125-153.

Allen, T. D., Eby, L. T., O' Brien, K. E., \& Lentz, E. (2008). The state of mentoring research: A qualitative review of current research methods and future research implications. Journal of Vocational Behavior, 73(3), 343-357. doi: 10.1016/j.jvb.2007.08.004

Allen, T. D., Eby, L. T., Poteet, M. L., Lentz, E., \& Lima, L. (2004). Career benefits associated with mentoring for proteges: A meta-analysis. Journal of Applied Psychology, 89(1), 127-136. doi: 10.1037/0021-9010.89.1.127

Allen, T. D., \& Finkelstein, L. M. (2003). Beyond mentoring: Alternative sources and functions of developmental support. The Career Development Quarterly, 51, 346-355.

Allen, T. D., Lentz, E., \& Day, R. (2006b). Career success outcomes associated with mentoring others: A comparison of mentors and nonmentors. Journal of Career Development, 32(3), 272-285. doi: $10.1177 / 0894845305282942$ 
Allen, T. D., \& Poteet, M. L. (1999). Developing effective mentoring relationships: Strategies from the mentor's viewpoint. The Career Development Quarterly, 48, 59-73.

Allen, T. D., Poteet, M. L., \& Burroughs, S. M. (1997a). The mentor's perspective: A qualitative inquiry and future research agenda. Journal of Vocational Behavior, 51, 70-89.

Allen, T. D., Poteet, M. L., \& Russell, J. E. A. (2000). Protégé selection by mentors: What makes the difference? Journal of Organizational Behavior, 21, 271-282.

Allen, T. D., Poteet, M. L., Russell, J. E. A., \& Dobbins, G. H. (1997b). A field study of factors related to supervisors' willingness to mentor others. Journal of Vocational Behavior, 50, 1-22.

Anderson, S. E., \& Williams, L. J. (1996). Interpersonal, job, and individual factors related to helping processes at work. Journal of Applied Psychology, 81(3), 282-296.

Arriaga, X. B., \& Rusbult, C. E. (1998). Standing in my partner's shoes: Partner perspective taking and reactions to accommodative dilemmas. Personality and Social Psychology Bulletin, 24(9), 927-948.

Aryee, S., Chay, Y. W., \& Chew, J. (1996). The motivation to mentor among managerial employees: An interactionist approach. Group \& Organization Management, 21(3), 261-277.

Association of Dutch Universities. (2010). Competence instrument for the Dutch universities Retrieved from Association of Dutch Universities website:

http://www.vsnu.nl/files/documenten/CAO/Competence\%20Instrum ent\%20Dutch\%20Universities\%20april\%202011.pdf

Atkinson, J. W., Heyns, R. W., \& Veroff, J. (1954). The effect of experimental arousal of the affiliation motive on thematic apperception. Journal of Abnormal and Social Psychology, 49, 404-410.

Baard, P. P. (2002). Intrinsic need satisfaction in organizations: A motivational basis of success in for-profit and not-for-profit settings. In E. L. Deci \& R. M. Ryan (Eds.), Handbook of self-determination theory. Rochester, NY: University of Rochester Press.

Baard, P. P., Deci, E. L., \& Ryan, R. M. (2004). Intrinsic need satisfaction: A motivational basis of performance and well-being in two work settings. Journal of Applied Social Psychology, 34(10), 2045-2068. 
Bagnoli, A. (2009). Beyond the standard interview: The use of graphic elicitation and arts-based methods. Qualitative Research, 9(5), 547-570. doi: $10.1177 / 1468794109343625$

Baldwin, M. W. (1992). Relational schemas and the processing of social information. Psychological Bulletin, 112, 461-484.

Baranik, L. E., Roling, E. A., \& Eby, L. T. (2010). Why does mentoring work? The role of perceived organizational support. Journal of Vocational Behavior, 76(3), 366-373. doi: 10.1016/j.jvb.2009.07.004

Batson, C. D., Early, S., \& Salvarani, G. (1997). Perspective taking: Imagining how another feels versus imagining how you would feel. Personality and Social Psychology Bulletin, 23(7), 751-758.

Baugh, S. G., \& Fagenson-Eland, E. A. (2007). Formal mentoring programs: A "poor cousin" to informal relationships? Thousand Oaks, CA: Sage.

Baumeister, R. F., \& Leary, M. R. (1995). The need to belong: Desire for interpersonal attachments as a fundamental human motivation. Psychological Bulletin, 117, 497-529.

Baxter, L. A., \& Bullis, C. (1986). Turning points in developing romantic relationships. Human Communication Research, 12, 469-493.

Bearman, S., Blake-Beard, S., Hunt, L., \& Crosby, F. J. (2007). New directions in mentoring In T. D. Allen \& L. T. Eby (Eds.), Blackwell handbook of mentoring: A multiple perspectives approach (pp. 275 - 295). New York, NY: Blackwell.

Berger, P. L., \& Luckmann, T. (1966). The social construction of reality: A treatise in the sociology of knowledge. Garden City, NY: Doubleday.

Berscheid, E. (1999). The greening of relationship science. American Psychologist, 54(4), 260-266.

Bies, R. J., \& Moag, J. S. (1986). Interactional justice: Communication criteria of fairness. Research on Negotiations in Organizations, 1, 43-55.

Blais, M. R., Sabourin, S., Boucher, C., \& Vallerand, R. J. (1990). Toward a motivational model of couple happiness. Journal of Personality and Social Psychology, 59, 1021-1031.

Blake-Beard, S. D., O'Neill, R. M., \& McGowan, E. (2007). Blind dates? The importance of matching in successful formal mentoring relationships. In B. R. Ragins \& K. E. Kram (Eds.), The handbook of mentoring at work: Theory, research, and practice (pp. 617-632). Thousand Oaks, CA: Sage Blau, P. (1964). Exchange and power in social life. New York, NY: Wiley. 
Blickle, G., Schneider, P. B., Meurs, J. A., \& Perrewé, P. L. (2010). Antecedents and consequences of perceived barriers to obtaining mentoring: $\mathrm{A}$ longitudinal investigation. Journal of Applied Social Psychology, 40(8), 1897-1920.

Blickle, G., Witzki, A., \& Schneider, P. B. (2009). Self-initiated mentoring and career success: A predictive field study. Journal of Vocational Behavior, 74(1), 94-101. doi: 10.1016/j.jvb.2008.10.008

Blustein, D. L. (2011). A relational theory of working. Journal of Vocational Behavior, 79(1), 1-17. doi: 10.1016/j.jvb.2010.10.004

Blustein, D. L., Schultheiss, D. E. P., \& Flum, H. (2004). Toward a relational perspective of the psychology of careers and working: A social constructionist analysis. Journal of Vocational Behavior, 64(3), 423-440. doi: 10.1016/j.jvb.2003.12.008

Boeije, H. (2002). A purposeful approach to the constant comparative method in the analysis of qualitative interviews. Quality \& Quantity, 36, 391409.

Borgatti, S. P., Mehra, A., Brass, D. J., \& Labianca, G. (2009). Network analysis in the social sciences Science 323(5916), 892-895.

Bouquillon, E., Sosik, J., \& Lee, D. (2005). 'It's only a phase': Examining trust, identification and mentoring functions received across the mentoring phases. Mentoring \& Tutoring: Partnership in Learning, 13(2), 239-258. doi: $10.1080 / 13611260500105808$

Bozeman, B., \& Feeney, M. K. (2007). Toward a useful theory of mentoring: A conceptual analysis and critique. Administration \& Society, 39(6), 719739. doi: $10.1177 / 0095399707304119$

Bozeman, B., \& Feeney, M. K. (2008). Mentor matching: A "Goodness of Fit" model. Administration \& Society, 40(5), 465-482. doi:

$10.1177 / 0095399708320184$

Bozionelos, N. (2004). Mentoring provided: Relation to mentor's career success, personality, and mentoring received. Journal of Vocational Behavior, 64(1), 24-46. doi: 10.1016/s0001-8791(03)00033-2

Bradley, C. L. (1997). Generativity-stagnation: Development of a status model. Developmental Review, 17, 262-290.

Brannick, T., \& Coghlan, D. (2007). In defense of being "native": The case for insider academic research. Organizational Research Methods 10(1), 5974. 
Brummans, B. H. J. M., Cooren, F., Robichaud, D., \& Taylor, J. R. (2014).

Approaches to the communicative constitution of organizations. In L. L. Putnam \& D. K. Mumby (Eds.), The Sage handbook of organizational communication (3rd ed.). Thousand Oaks, CA: Sage

Bryant, S. E. (2005). The impact of peer mentoring on organizational knowledge creation and sharing: An empirical study in a software firm. Group \& Organization Management, 30(3), 319-338. doi:

$10.1177 / 1059601103258439$

Burk, H. G., \& Eby, L. T. (2010). What keeps people in mentoring relationships when bad things happen? A field study from the protégé's perspective. Journal of Vocational Behavior, 77(3), 437-446. doi: 10.1016/j.jvb.2010.05.011

Burke, R. J., \& McKeen, C. A. (1997). Benefits of mentoring relationships among managerial and professional women: A cautionary tale. Journal of Vocational Behavior, 51, 43-57.

Burrell, G., \& Morgan, G. (1979). Sociological paradigms and organisational analysis: Elements of the sociology of corporate life. London, England: Heinemann Educational.

Burt, R. S., \& Knez, M. (1996). Trust and third-party gossip. In R. M. Kramer \& T. R. Tyler (Eds.), Trust in organizations: Frontiers of theory and research. Thousand Oaks, CA: Sage.

Byrne, D. (1971). The attraction paradigm. New York, NY: Academic Press.

Cameron, K., Dutton, J. E., \& Quinn, R. (2003). Positive Organizational Scholarship. San Fransisco, CA: Berrett-Koehler.

Cameron, K. S., \& Spreitzer, G. M. (2011). Introduction: What is positive about positive organizational scholarship? In K. S. Cameron \& G. M. Spreitzer (Eds.), The Oxford handbook of positive organizationl scholarship New York, NY: Oxford University Press.

Carbonneau, N., Vallerand, R. J., \& Lafreniere, M. A. K. (2012). Toward a tripartite model of intrinsic motivation. Journal of Personality 80(5), 1147-1178. doi: 10.1111/j.1467-6494.2011.00757.x

Chandler, D. E., Kram, K. E., \& Yip, J. (2011). An ecological systems perspective on mentoring at work: A review and future prospects. The Academy of Management Annals, 5(1), 519-570. doi: 10.1080/19416520.2011.576087

Chao, G. T. (1997). Mentoring phases and outcomes. Journal of Vocational Behavior, 51(15-28), 15-28. 
Chao, G. T. (2009). Formal mentoring: Lessons learned from past practice. Professional Psychology: Research and Practice, 40(3), 314-320. doi: $10.1037 / \mathrm{a} 0012658$

Chao, G. T., Walz, P. M., \& Gardner, P. D. (1992). Formal and informal mentorships: A comparison on mentoring functions and contrast with nonmentored counterparts. Personnel Psychology, 45, 619-636.

Chia, R. (1995). From modern to postmodern organizational analysis. Organization Studies, 16, 579-604.

Chiaburu, D. S., \& Harrison, D. A. (2008). Do peers make the place? Conceptual synthesis and meta-analysis of coworker effects on perceptions, attitudes, OCBs, and performance. Journal of Applied Psychology, 93(5), 1082-1103. doi: 10.1037/0021-9010.93.5.1082

Christensen, L. T., \& Cornelissen, J. (2011). Bridging corporate and organizational communication: Review, development and a look to the future. Management Communication Quarterly, 25(3), 383-414. doi: $10.1177 / 0893318910390194$

Clark, M. S., \& Mills, J. (1993). The difference between communal and exchange relationships: What it is and what is not. Personality and Social Psychology Bulletin, 19, 684-691.

Cohen-Charash, Y., \& Spector, P. E. (2001). The role of justice in organizations: A meta-analysis. Organizational Behavior and Human Decision Processes, 86(2), 278-321. doi: 10.1006/obhd.2001.2958

Cooren, F., Kuhn, T., Cornelissen, J. P., \& Clark, T. (2011). Communication, organizing and organization: An overview and introduction to the special issue. Organization Studies, 32(9), 1149-1170. doi: 10.1177/0170840611410836

Cotton, R. D., Shen, Y., \& Livne-Tarandach, R. (2011). On becoming extraordinary: The content and structure of developmental networks of major league baseball hall of famers. Academy of Management Journal, 54(1), 15-46.

Cropanzano, R., \& Mitchell, M. S. (2005). Social exchange theory: An interdisciplinary review. Journal of Management, 31(6), 874-900. doi: $10.1177 / 0149206305279602$

Cummings, J. N., \& Higgins, M. C. (2006). Relational instability at the network core: Support dynamics in developmental networks. Social Networks, 28(1), 38-55. doi: 10.1016/j.socnet.2005.04.003 
Cunliffe, A. L. (2008). Orientations to social constructionism: Relationally responsive social constructionism and its implications for knowledge and learning. Management Learning, 39(2), 123-139.

Cunliffe, A. L., \& Eriksen, M. (2011). Relational leadership. Human Relations, 64(11), 1425-1449.

Custers, A. F. J., Westerhof, G. J., Kuin, Y., Gerritsen, D. L., \& Riksen-Walraven, J. M. (2012). Relatedness, autonomy, and competence in the caring relationship: The perspective of nursing home residents. Journal of Aging Studies, 26(3), 319-326. doi: 10.1016/j.jaging.2012.02.005

De Naeghel, J., Van Keer, H., Vansteenkiste, M., \& Rosseel, Y. (2012). The relation between elementary students' recreational and academic reading motivation, reading frequency, engagement, and comprehension: A self-determination theory perspective. Journal of Educational Psychology, 104(4), 1006-1021. doi: 10.1037/a0027800

Deci, E. L., Connell, J. P., \& Ryan, R. M. (1989). Self-determination in a work organization. Journal of Applied Psychology, 74, 580-590.

Deci, E. L., Eghrari, H., Patrick, B. C., \& Leone, D. R. (1997). Facilitating internalization: The self-determination theory perspective. Journal of Personality 62, 119-142.

Deci, E. L., La Guardia, J. G., Moller, A. C., Scheiner, M. J., \& Ryan, R. M. (2006). On the benefits of giving as well as receiving autonomy support: Mutuality in close friendships. Personality and Social Psychology Bulletin, 32(3), 313-327. doi: 10.1177/0146167205282148

Deci, E. L., \& Ryan, R. M. (1985). Intrinsic motivation and self-determination in human behavior. New York, NY: Plenum Press.

Deci, E. L., \& Ryan, R. M. (2000). The "what" and "why" of goal pursuits: Human needs and the self-determination of behavior. Psychological Inquiry, 11, 227-268.

Deci, E. L., \& Ryan, R. M. (2008). Facilitating optimal motivation and psychological well-being across life's domains. Canadian Psychology, 49, 14-23.

Deci, E. L., \& Ryan, R. M. (2012). Motivation, personality, and development within embedded social contexts: An overview of self-determination theory. In R. M. Ryan (Ed.), Oxford handbook of human motivation (pp. 85-107). Oxford, England: Oxford University Press.

Deci, E. L., \& Ryan, R. M. (2014). Autonomy and need satisfaction in close relationships: Relationships motivation theory. In N. Weinstein (Ed.), 
Human motivation and interpersonal relationships: Theory, research, and applications (pp. 53-73). Dordrecht: Springer

Deci, E. L., Ryan, R. M., Gagné, M., Leone, D. R., Usunov, J., \& Kornazheva, B. P. (2001). Need satisfaction, motivation, and well-being in the work organizations of a former Eastern Bloc country: A cross-cultural study of self-determination. Personality and Social Psychology Bulletin, 27(8), 930-942.

DeRue, D. S., \& Ashford, S. J. (2010). Who will lead and who will follow? A social process of leadership identity construction in organizations. Academy of Management Review, 35(4), 627-647.

Dickson, J., Kirkpatrick-Husk, K., Kendall, D., Longabaugh, J., Patel, A., \& Scielzo, S. (2013). Untangling protégé self-reports of mentoring functions: Further meta-analytic understanding. Journal of Career Development, 41(4), 263-281. doi: 10.1177/0894845313498302

Dobrow, S. R., Chandler, D. E., Murphy, W. M., \& Kram, K. E. (2011). A review of developmental networks: Incorporating a mutuality perspective. Journal of Management, 210-242. doi: 10.1177/0149206311415858

Dobrow, S. R., \& Higgins, M. C. (2005). Developmental networks and professional identity: A longitudinal study. Career Development International, 10(6/7), 1362-0436.

Donaldson, S. I., Ensher, E. A., \& Grant-Vallone, E. J. (2000). Longitudinal examination of mentoring relationships on organizational commitment and citizenship behavior. Journal of Career Development, 26, 233-247.

Dovidio, J. F., Piliavin, J. A., Schroeder, D. A., \& Penner, L. A. (2006). The social psychology of prosocial behavior. Mahwah, NJ: Lawrence Erlbaum Associates.

Durbin, S., \& Tomlinson, J. (2014). Female part-time managers: Careers, mentors and role models. Gender, Work \& Organization, 21(4), 308320.

Eby, L. T. (1997). Alternative forms of mentoring in changing organizational environments: A conceptual extension of the mentoring literature. Journal of Vocational Behavior, 51, 125-144.

Eby, L. T. (2007). Understanding relational problems in mentoring. In B. R. Ragins \& K. E. Kram (Eds.), The handbook of mentoring at work: Theory, research, and practice (pp. 323-372). Thousand Oaks, CA: Sage 
Eby, L. T., \& Allen, T. D. (2008). Moving toward interdisciplinary dialogue in mentoring scholarship: An introduction to the special issue. Journal of Vocational Behavior 72(2), 159-167. doi: 10.1016/j.jvb.2008.02.005

Eby, L. T., Allen, T. D., Evans, S. C., Ng, T., \& DuBois, D. L. (2008a). Does mentoring matter? A multidisciplinary meta-analysis comparing mentored and non-mentored individuals. Journal of Vocational Behavior, 72(2), 254-267. doi: 10.1016/j.jvb.2007.04.005

Eby, L. T., Allen, T. D., Hoffman, B. J., Baranik, L. E., Sauer, J. B., Baldwin, S., . . Evans, S. C. (2013). An interdisciplinary meta-analysis of the potential antecedents, correlates, and consequences of protege perceptions of mentoring. Psychological Bulletin, 139(2), 441-476. doi: 10.1037/a0029279

Eby, L. T., Butts, M. M., Durley, J., \& Ragins, B. R. (2010). Are bad experiences stronger than good ones in mentoring relationships? Evidence from the protégé and mentor perspective. Journal of Vocational Behavior, 77(1), 81-92. doi: DOI: 10.1016/j.jvb.2010.02.010

Eby, L. T., Durley, J. R., Evans, S. C., \& Ragins, B. R. (2008b). Mentors' perceptions of negative mentoring experiences: Scale development and nomological validation. Journal of Applied Psychology, 93(2), 358-373. doi: 10.1037/0021-9010.93.2.358

Eby, L. T., \& McManus, S. E. (2004). The protégé's role in negative mentoring experiences. Journal of Vocational Behavior, 65(2), 255-275. doi: 10.1016/j.jvb.2003.07.001

Eby, L. T., McManus, S. E., Simon, S. A., \& Russell, J. E. A. (2000). The protege's perspective regarding negative mentoring experiences: The development of a taxonomy. Journal of Vocational Behavior, 57(1), 121. doi: $10.1006 /$ jvbe.1999.1726

Eby, L. T., Rhodes, J. E., \& Allen, T. D. (2007). Definition and evolution of mentoring. In T. D. Allen \& L. T. Eby (Eds.), Blackwell handbook of mentoring: A multidisciplinary approach (pp. 7-20). Oxford, England: Blackwell.

Emerson, R. M. (1976). Social exchange theory. Annual Review of Sociology, 2, 335-362.

Evans, S. B. T. (1984). Heuristic and analytical processes in reasoning. British Journal of Psychology, 75, 451-468. 
Fagenson, E. A. (1988). The power of a mentor: Protégés and nonprotégés' perceptions of their own power in organizations. Group \& Organization Studies, 13(2), 182-194.

Fagenson, E. A. (1989). The mentor advantage: Perceived career/job experiences of proteges versus non-proteges. Journal of Organizational Behavior, 10(4), 309-320.

Fagenson, E. A. (1992). Mentoring -- who needs it? A comparison of protégés and nonproteges need for power, achievement, affiliation, and autonomy. Journal of Vocational Behavior, 41, 48-60.

Feldman, D. C. (1999). Toxic mentors or toxic protégés? A critical reexamination of dysfunctional mentoring. Human Resource Management Review, 9, 247-278.

Felmee, D. H. (2001). No couple is an island: A social network perspective on dyadic stability. Social Forces, 79(4), 1259-1287.

Ferrin, D. L., Dirks, K. T., \& Shah, P. P. (2006). Direct and indirect effects of thirdparty relationships on interpersonal trust. Journal of Applied Psychology 91(4), 870-883. doi: 10.1037/0021-9010.91.4.870

Flanagan, J. C. (1954). The critical incident technique. Psychological Bulletin, 51(4), 327-358.

Fletcher, J. K. (1996). A relational approach to developing the protean worker. In D. T. Hall (Ed.), The career is dead-Long live the career: A relational approach to careers (pp. 105-131). San Francisco, CA: Jossey-Bass.

Fletcher, J. K., \& Ragins, B. R. (2007). Stone center relational cultural theory: A window on relational mentoring In B. R. Ragins \& K. E. Kram (Eds.), The handbook of mentoring at work: Theory, research, and practice (pp. 373399). Thousands Oaks, CA: Sage.

Flum, H. (2001). Relational dimensions in career development. Journal of Vocational Behavior, 59(1), 1-16. doi: 10.1006/jvbe.2000.1786

Gagné, M., \& Deci, E. L. (2005). Self-determination theory and work motivation. Journal of Organizational Behavior, 26, 331-362.

Gagné, M., Forest, J., Vansteenkiste, M., Crevier-Braud, L., van den Broeck, A., Aspeli, A. K., ... Westbye, C. (2015). The multidimensional work motivation scale: Validation evidence in seven languages and nine countries. European Journal of Work and Organizational Psychology, 24(2), 178-196. doi: 10.1080/1359432x.2013.877892

Gaine, G. S., \& La Guardia, J. G. (2009). The unique contributions of motivations to maintain a relationship and motivations toward relational activities 
to relationship well-being. Motivation and Emotion, 33(2), 184-202. doi: 10.1007/s11031-009-9120-x

George, J. M., \& Jones, G. R. (2000). The role of time in theory and theory building. Journal of Management, 26(4), 657-684.

Ghosh, R. (2014). Antecedents of mentoring support: A meta-analysis of individual, relational, and structural or organizational factors. Journal of Vocational Behavior, 84(3), 367-384. doi: 10.1016/j.jvb.2014.02.009

Ghosh, R., \& Reio, T. G. (2013). Career benefits associated with mentoring for mentors: A meta-analysis. Journal of Vocational Behavior, 83(1), 106116. doi: 10.1016/j.jvb.2013.03.011

Glaser, B. G., \& Strauss, A. L. (1967). The discovery of grounded theory: Strategies for qualitative research. Chicago, IL: Aldine Publishing Company.

Godshalk, V. M., \& Sosik, J. J. (2000). Does mentor-protege agreement on mentor leadership behavior influence the quality of a mentoring relationship? Group \& Organization Management, 25(3), 291-317. doi:

$10.1177 / 1059601100253005$

Godshalk, V. M., \& Sosik, J. J. (2003). Aiming for career success: The role of learning goal orientation in mentoring relationships. Journal of Vocational Behavior, 63(3), 417-437. doi: 10.1016/s00018791(02)00038-6

Greenberg, J. (1990). Organizational justice: Yesterday, today, and tomorrow. Journal of Management, 16, 399-432.

Guest, G., Bunce, A., \& Johnson, L. (2006). How many interviews are enough? An experiment with data saturation and variability. Field Methods, 18(1), 59-82. doi: 10.1177/1525822x05279903

Haggard, D. L., Dougherty, T. W., Turban, D. B., \& Wilbanks, J. E. (2011). Who is a mentor? A review of evolving definitions and implications for research. Journal of Management, 37(1), 280-304. doi: $10.1177 / 0149206310386227$

Hall, D. T. (1996a). The career is dead: Long live the career. San Francisco, CA: Jossey-Bass.

Hall, D. T. (1996b). Protean careers of the 21st century. Academy of Management Executive, 10(4), 8-16.

Hall, D. T., \& Chandler, D. E. (2007). Career cycles and mentoring. In K. E. Kram \& B. R. Ragins (Eds.), The handbook of mentoring at work: Theory, research, and practice (pp. 471-498). Thousand Oaks, CA: Sage. 
Hartmann, N. N., Rutherford, B. N., Feinberg, R., \& Anderson, J. G. (2014). Antecedents of mentoring: Do multi-faceted job satisfaction and affective organizational commitment matter? Journal of Business Research, 67(9), 2039-2044. doi: 10.1016/j.jbusres.2013.10.006

Hayamizu, T. (1997). Between intrinsic and extrinsic motivation: Examination of reasons for academic study based on the theory of internalization. Japanese Psychological Research, 39(2), 98-108.

Hernes, T., \& Weik, E. (2007). Organization as process: Drawing a line between endogenous and exogenous views. Scandinavian Journal of Management, 23(3), 251-264.

Higgins, M. C. (2000). The more the merrier? Multiple developmental relationships and work satisfaction. Journal of Management Development, 19(4), 277-296.

Higgins, M. C. (2001). Changing careers: The effects of social context. Journal of Organizational Behavior, 22, 595-618.

Higgins, M. C., Dobrow, S. R., \& Roloff, K. S. (2010). Optimism and the boundaryless career: The role of developmental relationships. Journal of Organizational Behavior, 31(5), 749-769. doi: 10.1002/job.693

Higgins, M. C., \& Kram, K. E. (2001). Reconceptualizing mentoring at work: A developmental network perspective. Academy of Management Review, 26(2), 264-288.

Higgins, M. C., \& Thomas, D. A. (2001). Constellations and careers: Toward understanding the effects of multiple developmental relationship. Journal of Organizational Behavior, 22, 237-247.

Hogg, M. A., \& Reid, S. A. (2006). Social identity, self-categorization, and the communication of group norms. Communication Theory, 16(1), 7-30. doi: 10.1111/j.1468-2885.2006.00003.x

Hogg, M. A., \& Terry, D. J. (2000). Social identity and self-categorization processes in organizational contexts. Academy of Management Review, 25(1), 121-140.

Hooper, D. T., \& Martin, R. (2008). Beyond personal leader-member exchange (LMX) quality: The effects of perceived LMX variability on employee reactions. The Leadership Quarterly, 19(1), 20-30. doi: 10.1016/j.leaqua.2007.12.002

Horvath, M., Wasko, L. E., \& Bradley, J. L. (2008). The effect of formal mentoring program characteristics on organizational attraction. Human Resource Development Quarterly, 19(4), 323-349. doi: 10.1002/hrdq.1244 
Hu, C., Baranik, L. E., \& Wu, T. (2014). Antidotes to dissimilar mentor-protégé dyads. Journal of Vocational Behavior, 85(2), 219-227. doi: 10.1016/j.jvb.2014.07.002

Hu, C., Thomas, K. M., \& Lance, C. E. (2008). Intentions to initiate mentoring relationships: Understanding the impact of race, proactivity, feelings of deprivation, and relationship roles. The Journal of Social Psychology, 148(6), 727-744.

Huang, X., Wright, R. P., Chiu, W. C. K., \& Wang, C. (2008). Relational schemas as sources of evaluation and misevaluation of leader-member exchanges: Some initial evidence. The Leadership Quarterly, 19(3), 266-282. doi: 10.1016/j.leaqua.2008.03.003

Ibarra, H. (1999). Provisional selves: Experimenting with image and identity in professional adaptation. Administrative Science Quarterly, 44(4), 764791.

Ilardi, B. C., Leone, D., Kasser, T., \& Ryan, R. M. (1993). Employee and supervisor ratings of motivation: Main effects and discrepancies associated with job satisfaction and adjustment in a factory setting. Journal of Applied Social Psychology, 23(21), 1789-1805. doi: 10.1111/j.15591816.1993.tb01066.x

Janssen, S., van Vuuren, M., \& de Jong, M. D. T. (2013). Identifying support functions in developmental relationships: A self-determination perspective. Journal of Vocational Behavior, 82(1), 20-29.

Janssen, S., van Vuuren, M., \& de Jong, M. D. T. (2014). Motives to mentor: Selffocused, protégé-focused, relationship-focused, organization-focused, and unfocused motives. Journal of Vocational Behavior, 85(3), 266-275. doi: 10.1016/j.jvb.2014.08.002

Janssen, S., van Vuuren, M., \& de Jong, M. D. T. (in press). Informal mentoring at work: A review and suggestions for future research. International Journal of Management Reviews.

Jones, R., \& Corner, J. (2012). Seeing the forest and the trees: A complex adaptive systems lens for mentoring. Human Relations, 65(3), 391-411. doi: $10.1177 / 0018726711430556$

Jordan, J., Kaplan, A., Miller, J. B., Stiver, I., \& Surrey, J. (1991). Women's growthin-connection. New York, NY: Guilford Press.

Kao, K., Rogers, A., Spitzmueller, C., Lin, M., \& Lin, C. (2014). Who should serve as my mentor? The effects of mentor's gender and supervisory status 
on resilience in mentoring relationships. Journal of Vocational Behavior, 85(2), 191-203. doi: 10.1016/j.jvb.2014.07.004

Kelly, G. (1955). The psychology of personal constructs New York: Norton. Kirchmeyer, C. (1995). Demographic similarity to the work group: A longitudinal study of managers at the early career stage. Journal of Organizational Behavior, 16(1), 67-83.

Kirchmeyer, C. (2005). The effects of mentoring on academic careers over time: Testing performance and political perspectives. Human Relations, 58(5), 637-660. doi: 10.1177/0018726705055966

Knee, C. R., Patrick, H., Vietor, N. A., Nanayakkara, A., \& Neighbors, C. (2002). Self-determination as growth motivation in romantic relationships. Personality and Social Psychology Bulletin, 28(5), 609-619. doi: $10.1177 / 0146167202288005$

Kram, K. E. (1983). Phases of the mentoring relationship. The Academy of Management Journal, 26(4), 608-625.

Kram, K. E. (1985). Mentoring at work: Developmental relationships in organizational life. Glenview, IL: Scott Foresman.

Kram, K. E., \& Isabella, L. (1985). Mentoring alternatives: The role of peer relationships in career development. Academy of Management Journal, 28(1), 110-132.

Kram, K. E., \& Ragins, B. R. (2007). The landscape of mentoring in the 21st century. In B. R. Ragins \& K. E. Kram (Eds.), The handbook of mentoring at work: Theory, research, and practice Thousand Oaks, CA: Sage.

Kruglanski, A. W., \& Gigerenzer, G. (2011). Intuitive and deliberate judgments are based on common principles. Psychological Review 118(1), 97-109. doi: $10.1037 / \mathrm{a} 0020762$

La Guardia, J. G., \& Patrick, H. (2008). Self-determination theory as a fundamental theory of close relationships. Canadian Psychology, 49(3), 201-209. doi: 10.1037/a0012760

La Guardia, J. G., Ryan, R. M., Couchman, C. E., \& Deci, E. L. (2000). Withinperson variation in security of attachment: A self-determination theory perspective on attachment, need fulfillment, and well-being. Journal of Personality and Social Psychology, 79(3), 367-384. doi: 10.1037//00223514.79 .3367

Langley, A., \& Tsoukas, H. (2010). Introducing perspectives on process organization studies In T. Hernes \& S. Maitlis (Eds.), Process, 
sensemaking, and organizing: Perspectives on process organization studies (pp. 1-26). Oxford, England: Oxford University Press.

Lankau, M. J., Riordan, C. M., \& Thomas, C. H. (2005). The effects of similarity and liking in formal relationships between mentors and protégés. Journal of Vocational Behavior, 67(2), 252-265. doi: 10.1016/j.jvb.2004.08.012

Laurenceau, J. P., Barrett, L. F., \& Pietromonaco, P. R. (1998). Intimacy as an interpersonal process: The importance of self-disclosure, partner disclosure, and perceived partner responsiveness in interpersonal exchanges. Journal of Personality and Social Psychology, 74(5), 12381251.

Leary, M. R., Twenge, J. M., \& Quinlivan, E. (2006). Interpersonal rejection as a determinant of anger and aggression. Personality and Social Psychology Bulletin, 10(2), 111-132.

Lindlof, T. R., \& Taylor, B. C. (2002). Qualitative communication research methods Thousands Oaks, CA: Sage

Maguire, M. C. (1999). Treating the dyad as the unit of analysis: A primer on three analytic approaches. Journal of Marriage and Family, 61(1), 213223.

Markland, D., \& Tobin, V. J. (2010). Need support and behavioural regulations for exercise among exercise referral scheme clients: The mediating role of psychological need satisfaction. Psychology of Sport and Exercise, 11(2), 91-99. doi: 10.1016/j.psychsport.2009.07.001

McAdams, D. P., \& Constantian, C. A. (1983). Intimacy and affiliation motives in daily living: An experience sampling analysis. Journal of Personality and Social Psychology, 45(4), 851-861.

McAdams, D. P., \& de St. Aubin, E. (1992). A theory of generativity and its assessment through self-report, behavioral acts, and narrative themes in autobiography. Journal of Personality and Social Psychology, 62(6), 1003-1015.

McKeen, C., \& Bujaki, M. (2007). Gender and mentoring: Issues, effects, and opportunities. In B. R. Ragins \& K. E. Kram (Eds.), The handbook of mentoring at work: Theory, research, and practice. Thousand Oaks, CA: Sage.

Mezias, J. M., \& Scandura, T. A. (2005). A needs-driven approach to expatriate adjustment and career development: A multiple mentoring perspective. Journal of International Business Studies, 36, 519-538. 
Miller, J. B. (1976). Toward a new psychology of women. Boston, MA: Beacon Press.

Mills, J., Clark, M. S., Ford, T. E., \& Johnson, M. (2004). Measurement of communal strength. Personal Relationships, 11, 213-230.

Missirian, A. K. (1982). The corporate connection: Why executive women need mentors to reach the top. Englewood Cliffs, NJ: Prentice-Hall.

Molden, D. C., \& Maner, J. K. (2013). How and when exclusion motivates social reconnection. In C. N. DeWall (Ed.), The Oxford Handbook of Social Exclusion (pp. 121-132). Oxford, England: Oxford University Press.

Morrison, E. W. (2011). Employee voice behavior: Integration and directions for future research. The Academy of Management Annals, 5(1), 373-412. doi: 10.1080/19416520.2011.574506

Mummendey, A., \& Wenzel, M. (1999). Social discrimination and tolerance in intergroup relations: Reactions to intergroup difference. Personality and Social Psychology Review, 3(2), 158-174.

Murphy, W. M., \& Kram, K. E. (2010). Understanding non-work relationships in developmental networks. Career Development International, 15, 637663.

Noe, R. A. (1988). An investigation of the determinants of succesful assigned mentoring relationships. Personnel Psychology, 41, 457-479.

Noe, R. A., Greenberger, D. B., \& Wang, S. (2002). Mentoring: What we know and where we might go. Research in Personnel and Human Resource Management, 21, 129-173.

Olian, J. D., Carroll, S. J., \& Giannantonio, C. M. (1993). Mentor reactions to proteges: An experiment with managers. Journal of Vocational Behavior, 43, 266-278.

Olian, J. D., Carroll, S. J., Giannantonio, C. M., \& Feren, D. B. (1988). What do proteges look for in a mentor? Results of three experimental studies. Journal of Vocational Behavior, 33, 15 - 37.

Pan, W., Sun, L.-Y., \& Chow, I. H. S. (2011). The impact of supervisory mentoring on personal learning and career outcomes: The dual moderating effect of self-efficacy. Journal of Vocational Behavior, 78(2), 264-273. doi: 10.1016/j.jvb.2010.05.001

Patrick, H., Knee, C. R., Canevello, A., \& Lonsbary, C. (2007). The role of need fulfillment in relationship functioning and well-being: A selfdetermination theory perspective. Journal of Personality and Social Psychology, 92(3), 434-457. doi: 10.1037/0022-3514.92.3.434 
Patton, M. Q. (1990). Qualitative evaluation and research methods (2nd ed.). Thousand Oaks, CA: Sage.

Patton, M. Q. (1999). Enhancing the quality and credibility of qualitative analysis. HSR: Health Services Research, 34(5), 1189-1208.

Payne, S. C., \& Huffman, A. H. (2005). A longitudinal examination of the influence of mentoring on organizational commitment and turnover. Academy of Management Journal, 48(1), 158-168.

Phillips, L. L. (1977). Mentors and protégés: A study of the career development of women managers and executives in business and industry. Unpublished doctoral dissertation. University of California. Los Angeles.

Planalp, S. (1985). Relational schemata: A test of alternative forms of relational knowledge as guides to communication. Human Communication Research, 12, 3-29.

Planalp, S. (1987). Interplay between relational knowledge and events. In R. Burnett, P. McGhee \& D. Clarke (Eds.), Accounting for relationships: Explanation, representation, and knowledge (pp. 175-191). New York, NY: Methuen.

Pollock, R. (1995). A test of conceptual models depicting the developmental course of informal mentor-protégé relationships in the work place. Journal of Vocational Behavior, 46, 144-162.

Postmes, T., \& Branscombe, N. R. (2010). Rediscovering social identity. New York, NY: Pscyhology Press

Pratt, M. (2012). Rethinking identity construction processes in organizations: Three questions to consider. In M. Schultz, S. Maguire, A. Langley \& H. Tsoukas (Eds.), Constructing identity in and around organizations (pp. 21-49). Oxford, England: Oxford University Press.

Raabe, B., \& Beehr, T. A. (2003). Formal mentoring versus supervisor and coworker relationships: Differences in perceptions and impact. Journal of Organizational Behavior, 24(3), 271-293. doi: 10.1002/job.193

Ragins, B. R. (2012). Relational mentoring: A positive approach to mentoring at work. In K. S. Cameron \& G. M. Spreitzer (Eds.), The Oxford handbook of positive organizational scholarship. New York, NY: Oxford University Press.

Ragins, B. R., \& Cotton, J. L. (1993). Gender and willingness to mentor in organizations. Journal of Management, 19(1), 97-111. 
Ragins, B. R., \& Cotton, J. L. (1999). Mentor functions and outcomes: A comparison of men and women in formal and informal mentoring relationships. Journal of Applied Psychology, 4, 529-550.

Ragins, B. R., \& Kram, K. E. (2007a). The roots and meaning of mentoring. In B. R. Ragins \& K. E. Kram (Eds.), The handbook of mentoring at work: Theory, research, and practice (pp. 3-15). Thousands Oaks, CA: Sage

Ragins, B. R., \& Kram, K. E. (Eds.). (2007b). The handbook of mentoring at work: Theory, research, and practice. Thousand Oaks, CA: Sage

Ragins, B. R., \& McFarlin, D. B. (1990). Perceptions of mentor roles in crossgender mentoring relationships. Journal of Vocational Behavior, 37(3), 321-339.

Ragins, B. R., \& Scandura, T. A. (1994). Gender differences in expected outcomes of mentoring relationships. Academy of Management Journal, 37, 957972.

Ragins, B. R., \& Scandura, T. A. (1997). The way we were: Gender and the termination of mentoring relationships. Journal of Applied Psychology, 82, 945-953.

Ragins, B. R., \& Scandura, T. A. (1999). Burden or blessing? Expected costs and benefits of being a mentor. Journal of Organizational Behavior, 20(4), 493-509.

Ragins, B. R., \& Verbos, A. K. (2007). Positive relationships in action: Relational mentoring and mentoring schemas in the workplace. In J. E. Dutton \& B. R. Ragins (Eds.), Positive relationships at work: Building a theoretical and research foundation (pp. 91-116). Mahwah, NJ: Lawrence Erlbaum.

Ramaswami, A., Huang, J. C., \& Dreher, G. F. (2014). Mentoring across cultures: The role of gender and marital status in Taiwan and the U.S. Journal of Business Research, 67, 2542-2549.

Reeve, J. (2006). Teachers as facilitators: What autonomy-supportive teachers do and why their students benefit. The Elementary School Journal, 106(3), 225-237.

Reis, H. T., \& Wheeler, L. (1991). Studying social interaction with the Rochester Interaction Record. Advances in Experimental Social Psychology, 24, 269-318.

Rescher, N. (1996). Process metaphysics: An introduction to process philosophy. New York, NY: SUNY.

Rohatinsky, N. (2014). Mentorship in healthcare organizations: Managers' perspectives. Management Education, 13(1), 11-20. 
Russell, J. E. A., \& Adams, D. M. (1997). The changing nature of mentoring in organizations: An introduction to the special issue on mentoring in organizations. Journal of Vocational Behavior, 51, 1-14.

Ryan, R. M. (1982). Control and information in the intrapersonal sphere: An extension of cognitive evaluation theory. Journal of Personality and Social Psychology, 43, 450-461.

Ryan, R. M., \& Deci, E. L. (2000a). Intrinsic and extrinsic motivations: Classic definitions and new directions. Contemporary Educational Psychology, 25(1), 54-67. doi: 10.1006/ceps.1999.1020

Ryan, R. M., \& Deci, E. L. (2000b). Self-determination theory and the facilitation of intrinsic motivation, social development, and wellbeing. American Psychologist, 55, 68-78.

Ryan, R. M., Lynch, M. F., Vansteenkiste, M., \& Deci, E. L. (2011). Motivation and autonomy in counseling, psychotherapy, and behavior change: A look at theory and practice. The Counseling Psychologist, 39, 193-260.

Ryan, R. M., Patrick, H., Deci, E. L., \& Williams, G. C. (2008). Facilitating health behaviour change and its maintainance: Intervenctions based on selfdetermination theory. The European Health Psychologist, 10, 2-5.

Ryan, R. M., Sheldon, K. M., Kasser, T., \& Deci, E. L. (1996). All goals are not created equal: An organismic perspective on the nature of goals and their regulation. In P. M. Gollwitzer \& J. A. Bargh (Eds.), The psychology of action: Linking cognition and motivation to behavior (pp. 7-26). New York, NY: Guilford Press.

Scandura, T. A. (1992). Mentorship and career mobility: An empirical investigation. Journal of Organizational Behavior, 13(2), 169-174.

Scandura, T. A. (1997). Mentoring and organizational justice: An empirical investigation. Journal of Vocational Behavior, 51, 58-69.

Scandura, T. A., \& Ragins, B. R. (1993). The effects of sex and gender role orientation on mentorship in male-dominated occupations. Journal of Vocational Behavior, 43, 251-265.

Scandura, T. A., \& Williams, E. A. (2001). An investigation of the moderating effects of gender on the relationships between mentorship initiation and protégé perceptions of mentoring functions. Journal of Vocational Behavior, 59(3), 342-363. doi: 10.1006/jvbe.2001.1809

Sheldon, K. M., \& Niemiec, C. P. (2006). It's not just the amount that counts: Balanced need satisfaction also affects well-being. Journal of 
Personality and Social Psychology, 91(2), 331-341. doi: 10.1037/00223514.91.2.331

Sheldon, K. M., Ryan, R. M., Deci, E. L., \& Kasser, T. (2004). The independent effects of goal contents and motives on well-being: It's both what you pursue and why you pursue it. Personality and Social Psychology Bulletin, 30(4), 475-486. doi: 10.1177/0146167203261883

Sheldon, K. M., Ryan, R. M., \& Reis, H. T. (1996). What makes for a good day? Competence and autonomy in the day and in the person. Personality and Social Psychology Bulletin, 22, 1270-1279.

Sheldon, K. M., Turban, D. B., Brown, K. G., Barrick, M. R., \& Judge, T. A. (2003). Applying self-determination theory to organizational research. Research in Personnel and Human Resource Management, 22, 357-393.

Singh, R., Ragins, B. R., \& Tharenou, P. (2009). Who gets a mentor? A longitudinal assessment of the rising star hypothesis. Journal of Vocational Behavior, 74(1), 11-17. doi: 10.1016/j.jvb.2008.09.009

Sminia, H. (2009). Process research in strategy formation: Theory, methodology and relevance. International Journal of Management Reviews, 11(1), 97125.

Stone, D. N., Deci, E. L., \& Ryan, R. M. (2009). Beyond talk: Creating autonomous motivation through self-determination theory. Journal of General Management, 34(3), 75-91.

Sun, L., Pan, W., \& Chow, I. H. S. (2014). The role of supervisor political skill in mentoring: Dual motivational perspectives. Journal of Organizational Behavior, 35(2), 213-233. doi: 10.1002/job.1865

Tsoukas, H., \& Chia, R. (2002). On organizational becoming: Rethinking organizational change. Organization Science, 13, 567-582.

Uhl-Bien, M. (2006). Relational leadership theory: Exploring the social processes of leadership and organizing. The Leadership Quarterly, 17(6), 654-676. doi: 10.1016/j.leaqua.2006.10.007

Uhl-Bien, M., Graen, G. B., \& Scandura, T. A. (2000). Implications of leadermember exchange (LMX) for strategic human resource management systems: Relationships as social capital for competitive advantage. Research in Personnel and Human Resource Management, 18, 137-185.

Underhill, C. M. (2006). The effectiveness of mentoring programs in corporate settings: A meta-analytical review of the literature. Journal of Vocational Behavior, 68(2), 292-307. doi: 10.1016/j.jvb.2005.05.003 
Vallerand, R. J. (1997). Toward a hierarchical model of intrinsic and extrinsic motivation. New York, NY: Academic Press.

Vallerand, R. J., Pelletier, L. G., \& Koestner, R. (2008). Reflections on selfdetermination theory. Canadian Psychology, 49(3), 257-262. doi: 10.1037/a0012804

Van de Schoot, R., Yerkes, M. A., Mouw, J. M., \& Sonneveld, H. (2013). What took them so long? Explaining PhD delays among doctoral candidates. PLoS One, 8(7). doi: 10.1371/journal.pone.0068839

Van de Ven, A. H., \& Poole, M. S. (2005). Alternative approaches for studying organizational change Organization Studies, 26, 1377-1404.

Van den Broeck, A., Vansteenkiste, M., \& De Witte, H. (2008). Self-determination theory: A theoretical and empirical overview in occupational health psychology. In J. Houdmont \& S. Leka (Eds.), Occupational health psychology: European perspectives on research, education, and practice. Nottingham, England: Nottingham University Press.

Van Emmerik, I. J. H. (2004). The more you can get, the better: Mentoring constellations and intrinsic career success. Career Development International, 9(6), 578-594.

Van Emmerik, I. J. H., Baugh, S. G., \& Euwema, M. C. (2005). Who wants to be a mentor? An examination of attitudinal, instrumental, and social motivational components. Career Development International, 10, 310 324.

Vansteenkiste, M., Niemiec, C. P., \& Soenens, B. (2010). The development of the five mini-theories of self-determination theory: An historical overview, emerging trends, and future directions. Advances in Motivation and Achievement 16, 105-165. doi: 10.1108/s0749-

7423(2010)000016a007

Vansteenkiste, M., Sierens, E., Soenens, B., Luyckx, K., \& Lens, W. (2009). Motivational profiles from a self-determination perspective: The quality of motivation matters. Journal of Educational Psychology, 101(3), 671-688. doi: 10.1037/a0015083

Vansteenkiste, M., Simons, J., Lens, W., Sheldon, K. M., \& Deci, E. L. (2004). Motivating learning, performance, and persistence: The synergistic role of intrinsic goals and autonomy-support. Journal of Personality and Social Psychology, 87, 246-260.

Verbrugge, L. M. (1979). Multiplexity in adult friendships. Social Forces, 57(4), 1286-1309. 
Vidyarthi, P. R., Liden, R. C., Anand, S., Erdogan, B., \& Ghosh, S. (2010). Where do I stand? Examining the effects of leader-member exchange social comparison on employee work behaviors. Journal of Applied Psychology, 95(5), 849-861. doi: 10.1037/a0020033

Wanberg, C. R., Kammeyer-Mueller, J. K., \& Marchese, M. (2006). Mentor and protégé predictors and outcomes of mentoring in a formal mentoring program. Journal of Vocational Behavior, 69(3), 410-423. doi: 10.1016/j.jvb.2006.05.010

Wanberg, C. R., Welsh, E. T., \& Hezlett, S. A. (2003). Mentoring research: A review and dynamic process model. Research in Personnel and Human Resource Management, 22, 39-124.

Wang, S., Noe, R. A., Wang, Z., \& Greenberger, D. B. (2009). What affects willingness to mentor in the future? An investigation of attachment styles and mentoring experiences. Journal of Vocational Behavior, 74(3), 245-256. doi: 10.1016/j.jvb.2008.12.002

Waters, L. (2004). Protege-mentor agreement about the provision of psychosocial support: The mentoring relationship, personality, and workload. Journal of Vocational Behavior, 65(3), 519-532. doi: 10.1016/j.jvb.2003.10.004

Weick, K. E. (1995). Sensemaking in organizations. Thousands Oaks, CA: Sage.

Weick, K. E. (2001). Making sense of the organization. Oxford, England: Blackwell.

Weick, K. E., Sutcliffe, K. M., \& Obstfeld, D. (2005). Organizing and the process of sensemaking. Organization Science, 16(4), 409-421. doi: 10.1287/orsc.1050.0133

Weik, E. (2011). In deep waters: Process theory between Scylla and Charybdis. Organization, 18(5), 655-672.

Welch, C., \& Paavilainen-Mäntymäki, E. (2014). Putting process (back) in: Research on internationalization process of the firm. International Journal of Management Reviews, 16(1), 2-23.

Whetten, D. A. (1989). What constitutes a theoretical contribution? Academy of Management Review, 14(4), 490-495.

Williams, G. C., \& Deci, E. L. (1996). Internalization of biopsychosocial values by medical students: A test of self-determination theory. Journal of Personality and Social Psychology, 70, 767-779. 
Wrzesniewski, A., \& Dutton, J. E. (2001). Crafting a job: Revisioning employees as active crafters of their work. Academy of Management Review, 26(2), 179-201.

Young, A. M., Cady, S., \& Foxon, M. J. (2006). Demystifying gender differences in mentoring: Theoretical perspectives and challenges for future research on gender and mentoring. Human Resource Development Review, 5(2), 148-175. doi: $10.1177 / 1534484306287140$

Young, A. M., \& Perrewé, P. L. (2000). The exchange relationship between mentors and protégés: The development of a framework. Human Resource Development Review, 10(2), 177-209. 
Samenvatting

(summary in Dutch) 
Om inzetbaar te blijven in steeds veranderende werkomgevingen, is het voor iedere werknemer noodzakelijk zich continu te blijven ontwikkelen. Deze ontwikkeling vindt altijd plaats in een sociale omgeving van collega's, vrienden en familie. Dergelijke relaties die bijdragen aan iemands ontwikkeling worden ook wel developmental relationships genoemd. Deze relaties zijn voor een belangrijk deel bepalend voor de wijze waarop medewerkers functioneren en groeien. Een specifiek voorbeeld van een dergelijke relatie is de mentoringrelatie: een relatie tussen een persoon met meer ervaring en kennis (de mentor) en een persoon met minder ervaring en kennis (de protegé), die primair tot doel heeft de protegé te helpen ontwikkelen in zijn of haar carrière. In sommige organisaties zijn deze relaties geformaliseerd in mentoringprogramma's, waarin mentoren en protegés aan elkaar gekoppeld worden door de organisatie. Bijna iedereen kent echter ook wel voorbeelden van informele mentoringrelaties. Deze relaties ontstaan spontaan, zonder beïnvloeding van een derde partij. Een voorbeeld hiervan is een mentoringrelatie die kan ontstaan tussen een nieuwkomer in een organisatie en een meer ervaren medewerker, doordat zij bijvoorbeeld tegenover elkaar zitten in de kantoortuin of regelmatig overleggen, en waarbij de mentor steeds belangrijker wordt voor de carrièreontwikkeling van de protegé.

Het onderzoek in dit proefschrift richt zich op deze informele mentoringrelaties. Verschillende studies laten zien dat het hebben van een mentoringrelatie leidt tot positieve uitkomsten zoals snellere promotie, een hogere werktevredenheid en een hogere betrokkenheid bij de organisatie (Allen et al., 2004; Payne \& Huffman, 2005). Mede door de kwantitatieve designs die domineren in de huidige mentoringliteratuur is de kennis over mentoringervaringen en -processen echter beperkt. Op welke specifieke manieren helpen mentoren hun protegés? Wat vinden protegés belangrijk in de steun die zij van mentoren krijgen? Welke belangen en motieven hebben mentoren om iemand te helpen? En hoe interpreteren collega's een dergelijke mentoringrelatie eigenlijk? Dit proefschrift benadert deze vragen met kwalitatief onderzoek, door middel van interviews.

Belangrijk in de beantwoording van deze vragen is de self-determination theory (Deci \& Ryan, 1985). Deze theorie gaat ervan uit dat mensen drie basisbehoeften hebben: een behoefte aan autonomie, competentie en verbondenheid. De behoefte aan autonomie wordt vervuld wanneer iemand eigen keuzes kan maken. Wanneer iemand invloed heeft op zijn of haar 
omgeving en het gevoel heeft dat hij of zij de benodigde capaciteiten heeft om doelen te bereiken, wordt de behoefte aan competentie vervuld. Tot slot is het hebben van positieve relaties en je geaccepteerd en gewaardeerd voelen door anderen belangrijk voor de vervulling van de behoefte aan verbondenheid. Wanneer deze drie basisbehoeften bevredigd worden door de sociale context, kan iemand zich optimaal ontwikkelen. Ook de intrinsieke motivatie van een persoon wordt beïnvloed door de bevrediging van deze behoeften. Alleen wanneer alle drie de basisbehoeften vervuld worden, kan iemand intrinsiek gemotiveerd zijn om een bepaalde taak uit te voeren, volgens de selfdetermination theory. Hoe deze drie basisbehoeften vervuld worden in de context van mentoringrelaties, is een belangrijke vraag geweest bij de totstandkoming van dit proefschrift.

Dit proefschrift begon met een review van het beschikbare onderzoek naar informele mentoringrelaties op de werkvloer. Het doel van deze review was om tekortkomingen in de kennis over mentoringrelaties te identificeren. Gebaseerd op de inzichten uit deze review is een aantal empirische studies uitgevoerd. Daarin zijn zowel protegés, mentoren, gekoppelde paren van protegés en mentoren, en personen uit de directe omgeving van dit soort relaties ondervraagd. De studies laten zien dat de vervulling van de basisbehoeften aan autonomie, competentie en verbondenheid van protegés een belangrijke rol speelt in het succes van mentoringrelaties, maar ook dat het afstemmen van de vervulling van deze behoeften op de protegé een complex proces tussen mentor en protegé is. Ook laat dit proefschrift zien welke motieven mentoren kunnen hebben om iemand te helpen, en hoe de directe werkomgeving van mentor en protegé reageert op een mentoringrelatie. Dit proefschrift levert daarmee een bijdrage aan een beter begrip van de manier waarop mentoren, protegés, en hun collega's mentoringrelaties beleven.

\section{Hoofdstuk 2: Literatuurreview}

In dit hoofdstuk wordt een literatuurreview gerapporteerd dat een overzicht geeft van belangrijke ontwikkelingen in het mentoringonderzoek. Deze review werd vormgegeven vanuit twee basisgedachten over interpersoonlijke relaties. Ten eerste de gedachte dat relaties nooit in een vacuüm bestaan, maar altijd beïnvloed worden door andere relaties. Ten tweede de gedachte dat mensen nooit alleen instrumentele motieven hebben om relaties met anderen aan te gaan. Ieder mens heeft ook relationele motieven, zoals de behoefte om een 
goede positieve verstandhouding met anderen te hebben, zonder daar iets concreets voor terug te willen krijgen (Baumeister \& Leary, 1995). Deze gedachte komt overeen met de basisbehoefte aan verbondenheid zoals geformuleerd in de self-determination theory.

Vanuit deze twee basisgedachten werden vier aspecten van mentoringrelaties geïdentificeerd die nader onderzoek verdienen. Ten eerste dient mentoringonderzoek meer aandacht te besteden aan de context van mentoringrelaties, door bijvoorbeeld na te gaan wat de invloed van andere developers - buiten de mentor - op iemands ontwikkeling is. Ook is tot dusverre nauwelijks aandacht besteed aan de manier waarop mentoringrelaties en de context waarin deze zich bevinden (een organisatie, opgebouwd uit werkrelaties) elkaar beïnvloeden. Ten tweede zouden onderzoekers er goed aan doen om tijdsaspecten in hun studies op te nemen, aangezien mentoring altijd over een langere periode plaatsvindt. Zo kan de invloed van specifieke gebeurtenissen op het verloop van de relatie onderzocht worden. Mentoring schema theory (Ragins, 2012) geeft een aanzet tot het bestuderen van de invloed van eerdere mentoringervaringen op de impliciete verwachtingen die een persoon van een mentoringrelatie heeft en het verloop van de mentoringrelatie. Ten derde wordt in de literatuurreview betoogd dat mentoringonderzoek meer aandacht zou moeten besteden aan de onderliggende mechanismen die ervoor zorgen dat mentoringrelaties effectief zijn voor protegés en mentoren. In het literatuuroverzicht worden hiervoor twee theorieën geïntroduceerd: self-determination theory (Deci \& Ryan, 1985) en relational leadership theory (Uhl-Bien, 2006). Het onderzoek in dit proefschrift probeert een bijdrage te leveren aan het begrijpen van onderliggende processen door basisconcepten van de self-determination theory te gebruiken binnen mentoringrelaties. Tot slot zouden onderzoekers relationele motieven van zowel protegés als mentoren dienen te onderzoeken. Kennis over dergelijke wederkerige processen binnen mentoring relaties is beperkt. Tot nu toe richt het meeste onderzoek zich alleen op de protegé, en in veel mindere mate op de mentor. Onderzoek waarin echt naar de relatie tussen beiden wordt gekeken, en waarbij dus zowel de mentor als de protegé worden onderzocht, is zeer schaars. De empirische studies leveren een eerste bijdrage aan meer inzicht in deze onderzoeksgebieden. 


\section{Hoofdstuk 3: Onderzoek onder protegés}

In het eerste empirische hoofdstuk van dit proefschrift wordt een studie gerapporteerd waarin protegés uit verschillende leeftijdscategorieën is gevraagd om te vertellen over hun loopbaan en de ontwikkeling die zij daarin hadden doorgemaakt. Aan de deelnemers werd tevens gevraagd hoe anderen hen tot dan toe geholpen hadden in deze ontwikkeling. Vervolgens werd in de analyse van deze interviews bekeken of deze vormen van steun, hulp en feedback te categoriseren waren aan de hand van de drie basisbehoeften van de self-determination theory: autonomie, competentie en verbondenheid. Voor iedere basisbehoefte werden diverse subcategorieën onderscheiden, die goed laten zien op welke specifieke manieren protegés steun ervaren van hun mentoren en andere developers (in dit geval: andere collega's). Zo beschreven protegés hoe mentoren hun vrijheid gaven en hen aanmoedigden initiatieven te nemen (autonomie), hoe mentoren een rolmodel waren vanwege hun competenties en hoe mentoren protegés bevestigden in hun competenties (competentie), en hoe mentoren altijd oprechte interesse in hen toonden (verbondenheid). Dit hoofdstuk laat daarmee zien dat de self-determination theory als een goede basis kan dienen van de processen binnen mentoringrelaties.

\section{Hoofdstuk 4: Onderzoek onder mentoren}

In het tweede empirische hoofdstuk wordt het accent verlegd naar de mentor. Het onderzoek dat in dit hoofdstuk gerapporteerd wordt, laat zien welke motieven mentoren hebben om een protegé te helpen in zijn of haar carrierontwikkeling. Anders dan bij eerdere onderzoeken op dit gebied werd in de interviews niet alleen gevraagd naar de algemene motivatie om anderen te mentoren, maar ook naar de specifieke motivatie om een bepaalde persoon te mentoren. Vervolgens werden deze interviews ten eerste geanalyseerd aan de hand van de self-determination theory om zo motieven gerelateerd aan de mentor zelf te identificeren. Waar veel motivatietheorieën alleen onderscheid maken tussen intrinsieke en extrinsieke motivatie, specificeert deze theorie vier vormen van extrinsieke motivatie. Dit onderzoek laat daardoor een uitgebreider scala aan specifieke motieven zien. Deze motieven variëren van het mentoren omdat het als deel van de functie wordt gezien (extrinsiek) tot mentoren omdat de mentor daar direct plezier aan beleeft (intrinsiek). Daarnaast werden in de analyse vier andere categorieën geïdentificeerd. Ten 
eerste een categorie met motieven die gericht waren op de protegé, waarin mentoren bijvoorbeeld aangaven de protegé te helpen omdat ze hem of haar die ontwikkeling gunden. Ten tweede een categorie met motieven die gericht waren op de relatie tussen mentor en protegé, waarin een mentor de protegé helpt omdat er bijvoorbeeld al een goede werkrelatie of vriendschappelijke relatie tussen hen beiden is. Ook werd een categorie geïdentificeerd waarin de motieven gericht waren op de organisatie. Mentoren gaven bijvoorbeeld aan dat ze de protegé helpen omdat het werkteam en uiteindelijk de gehele organisatie daarvan profiteert. Tot slot werd een categorie geïdentificeerd met niet-specifieke motieven. Hierin beschreven mentoren dat hun mentoringgedrag ongepland was, en eerder een resultaat van meerdere toevalligheden dan van een bewust proces. Dit hoofdstuk laat zien dat het zinvol is om de bereidheid van mentoren om protegés te helpen te zien als een proces waarin zowel instrumentele als relationele motieven een rol spelen.

\section{Hoofdstuk 5: Onderzoek naar dyades}

In het derde empirische hoofdstuk wordt een dyadische studie gerapporteerd waarvoor gekoppelde paren van oud-promovendi en hun (co-)promotoren zijn geïnterviewd. In deze studie is onderzocht hoe mentoren en protegés tot een impliciete overeenstemming komen over de manieren waarop de behoeften van promovendi aan autonomie, competentie en verbondenheid worden vervuld. Vanuit relational mentoring kan worden geredeneerd dat een mentoringrelatie optimaal is wanneer mentor en protegé gelijke verwachtingen en ideeën hebben over wat beiden zouden moeten doen in de relatie, wat de relatie hun brengt, en hoe de relatie functioneert. Deze verwachtingen en ideeën worden relational schemas genoemd. In de praktijk blijkt de afstemming van deze schema's echter een complex proces te zijn, waarbij incongruente schema's eerder regel dan uitzondering lijken. In de interviews kwam bijvoorbeeld naar voren dat promovendi en hun mentoren dikwijls verschillende opvattingen hebben over wie de leiding in het onderzoek dient te nemen (autonomie). Daarnaast hebben promovendi erg hoge verwachtingen van de competenties van hun begeleider en hebben de begeleiders op hun beurt veelal slechts vage ideeën over wat de promovendus zou moeten kunnen (competentie). Tot slot worstelen zowel begeleider als promovendus met het vinden van een juiste balans tussen het opbouwen van een professionele danwel persoonlijke relatie (verbondenheid). 


\section{Hoofdstuk 6: Onderzoek naar de omgeving van mentorrelaties}

Het laatste empirische hoofdstuk beschrijft een kwalitatieve studie die zich richt op de collega's van informele mentoren en protegés. Aan medewerkers die een informele mentoringrelatie in hun directe werkomgeving hebben, werd gevraagd om ervaringen met mentoringprocessen te beschrijven. Deze studie laat zien dat medewerkers zowel positieve als negatieve ervaringen met en gedachtes over informele mentoringrelaties hebben. Voor de protegé, mentor en organisatie zien zij zowel positieve als negatieve kanten. Zo hebben medewerkers het idee dat een mentoringrelatie nuttig kan zijn voor protegés omdat zij zo vertrouwd raken met en ervaring opdoen in de werkomgeving. Deelnemers vertelden echter ook dat mentoring negatief kan zijn voor de protegé, de mentor en de organisatie. Zo kan mentoring tot meer werkdruk voor de mentor leiden, aangezien informele mentoring altijd naast de reguliere werkzaamheden moet plaatsvinden. Wanneer de deelnemers consequenties voor henzelf beschreven, waren zij overwegend negatief. Informele mentoringrelaties zorgen voor gevoelens van jaloezie, onrechtvaardigheid en buitensluiting bij collega's. Ook gaven deelnemers aan dat het samenwerken met mentor en protegé hun werkmotivatie kan verlagen en dat zij weinig vertrouwen hebben in de mentor en protegé, omdat ze ervan uitgaan dat zij alles met elkaar delen. Hoewel mentoring in voorgaande hoofdstukken dus als positieve relatie werd benaderd, zijn hier - vanuit het perspectief van collega's - wel kanttekeningen bij te plaatsen.

\section{Algemene conclusie}

De studies in dit proefschrift verrijken onze kennis van mentoringrelaties in organisaties. Aan de hand van een uitgebreide literatuurreview werden verschillende onderzoeksgebieden geïdentificeerd die verder ontwikkeld konden worden. De empirische studies in dit proefschrift hebben daar een eerste bijdrage aan geleverd. Self-determination theory blijkt een relevant raamwerk om onderliggende mechanismen van mentoringrelaties zichtbaar te maken. Dit proefschrift laat zien hoe de drie basisbehoeften (autonomie, competentie en verbondenheid) vervuld worden in de context van mentoringrelaties. Op deze manier laat dit proefschrift zien hoe mentoren een belangrijke rol spelen in het vervullen van deze behoeften van protegés en hoe protegés dit ervaren. Dit proefschrift laat ook zien welke motieven mentoren hebben om protegés te helpen in hun professionele ontwikkeling. Tot slot geeft 
dit proefschrift inzicht in percepties van buitenstaanders op mentoringprocessen in hun directe werkomgeving. Elk van deze studies laat ons het belang van informele relaties en mentoringprocessen in organisaties zien. Bovendien geven de studies aanwijzingen hoe de behoeften van medewerkers aan autonomie, competentie en verbondenheid vervuld kunnen worden. 
Bibliography 


\section{Scientific publications}

Janssen, S., Van Dalfsen, K.A., Van Hoof, J.J., \& Van Vuuren, M. (2012). Balancing uniqueness and similarity: A content analysis of textual characteristics in Dutch corporate stories. Public Relations Review, 38(1), 32-39.

Janssen, S., Van Vuuren, M., \& De Jong, M. D. T. (2013). Identifying support functions in developmental relationships: A self-determination perspective. Journal of Vocational Behavior, 82, 20-29.

Janssen, S., Van Vuuren, M., \& De Jong, M. D. T. (2014). Motives to mentor: Selffocused, protégé-focused, relationship-focused, organization-focused and unfocused motives. Journal of Vocational Behavior, 85, 266-275.

Janssen, S., Van Vuuren, M., \& De Jong, M. D. T. (in press). Informal mentoring at work: A review and suggestions for future research. International Journal of Management Reviews.

\section{Conferences}

Janssen, S., Van Dalfsen, K. A., Van Hoof, J. J., \& Van Vuuren, M. (2011). Corporate stories: Elk bedrijf zijn unieke verhaal? Een inhoudsanalyse naar verhaalkenmerken van corporate stories. Paper presented at the annual meeting of the Netherlands-Flanders Communication Association, Enschede, the Netherlands.

Janssen, S., De Jong, M. D. T., Renes, S., \& Konijn, S. (2011). De waarde van kernwaarden: Twee studies naar kennis, houding en gedrag van medewerkers ten opzichte van kernwaarden. Paper presented at the annual meeting of the Netherlands-Flanders Communication Association, Enschede, the Netherlands.

Janssen, S., Van Vuuren, M., \& De Jong, M. D.T. (2012) Who is your mentor? Applying self-determination theory to developmental relationships at work. Paper presented at the annual meeting of the International Communication Association, Phoenix, AZ.

Timmer, J. F. M., Janssen, S., Beldad., A., \& De Jong, M. D.T. (2012). Corporate social responsibility communication through corporate stories: The challenge of reducing skepticism. Paper presented at the annual meeting of the International Communication Association, Phoenix, AZ.

Janssen, S., Mensink, M., \& Van Vuuren (2013). Great expectations: The role of mentoring schemas in protégés' and mentors' sensemaking of formal 
mentoring relationships. Paper presented at the annual meeting of the Netherlands-Flanders Communication Association, Rotterdam, the Netherlands.

Janssen, S., van Vuuren, M., \& de Jong, M. D.T. de (2014). Mentor motives: insights from self-determination theory and relational mentoring. Paper presented at the European Conference on Positive Psychology, Amsterdam, the Netherlands.

Janssen, S., Alberts, M. \& van Vuuren, M. (2014). The role of developmental networks in career starters' meaning of work. Paper presented at the annual meeting of the International Communication Association, Seattle, WA.

Einhoff, S., Janssen, S., \& van Hoof, J. (2014). How to design corporate texts? Effects of metaphor use on remembrance, attitude toward the message, and attitude toward the organization in traditional statements and corporate stories. Poster presented at the annual meeting of the Netherlands-Flanders Communication Association, Wageningen, the Netherlands.

Janssen, S., Tahitu, J., \& Van Vuuren, M. (2015). Informele mentoring relaties op de werkvloer: Percepties en ervaringen van buitenstaanders. Poster presented at the annual meeting of the Netherlands-Flanders Communication Association, Antwerp, Belgium.

Janssen, S., Van Vuuren, M., \& De Jong, M. D. T. (2015). Supporting employees' sustainable labour participation through mentoring relationships: Insights from self-determination theory. In: Van Vuuren, C. V., Motivating sustainable labour participation by building on selfdetermination theory. Symposium conducted at the meeting of European Work and Organizational Psychology, Oslo, Norway. 
